The University of Chicago Science Series

\title{
INDIVIDUALITY IN ORGANISMS
}

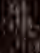

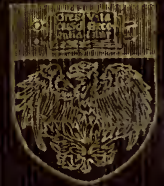

CHARLES MANNING CHILD 


Digitized by the Internet Archive in 2008 with funding from Microsoft Corporation 


\title{
THE UNIVERSITY OF CHICAGO SCIENCE SERIES
}

\author{
Editorial Committee \\ ELIAKIM HASTINGS MOORE, Chairman \\ JOHN MERLE COULTER \\ ROBERT ANDREWS MILLIKAN
}



INDIVIDUALITY IN ORGANISMS 
The University of Chicago Press

Chicago, Illinois

Agentis

THE CAMBRIDGE UNIVERSITY PRESS

LONDON AND EDINBURGH

THE MARUZEN-KABUSHIKI-KAISHA

TOKYO, OSAKA, KYOTO

KARL W. HIERSEMANN

LEIPZIG

THE BAKER \& TAYLOR COMPANY NEW YORK 
c

\section{INDIVIDUALITY IN ORGANISMS}

By

CHARLES MANNING CHILD

Of the Department of Zoölogy

The University of Chicago

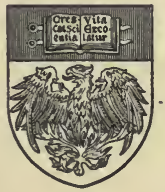

THE UNIVERSITY OF CHICAGO PRESS CHICAGO, ILLINOIS 


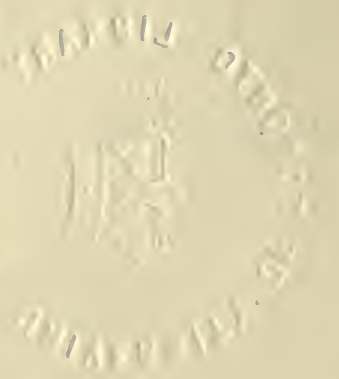

Copyright Igis By

The University of Chicago

\section{All Rights Reserved}

Published November I9I5 


\section{CONTENTS}

CHAPTER

PAGE

I. The Problem _. . . . . . I

The Characteristics of the Organic Individual; Unity and Order in the Life of the Individual; Reproduction and Individuation; Metabolism and Protoplasm; Terminology.

II. Theories of Organic Individuality . . . .

Theoretical Review and Critique; A Dynamic Conception of the Organic Individual.

III. Metabolic Gradients in Organisms . . . . . 50

Susceptibility Gradients in Animals and Plants; Further Physiological Evidence for the Existence of Metabolic Gradients; Embryological Evidence for the Existence of Axial Metabolic Gradients; Developmental Gradients in Agamic and Experimental Reproduction; Conclusion.

IV. Physiological Dominance in the Process of IndiVIDUATION

The Experimental Material; The Independence of the Apical Region; Dominance and Subordination in Experimental Reproduction; The Reconstitution of an Individual from an Isolated Piece; Some Modifying and Limiting Factors in Animal Reconstitution; Conclusion.

V. The Range of Dominance, Physiological Isolation, AND Experimental Reproduction . . . . .

Experimental Control of Spatial Relations of Parts and of the Range of Dominance; Experimental Obliteration and Determination of Axial Gradients and Dominance; The Extension of Dominance during Development; Experimental Physiological Isolation and Reproduction in Plants; The Localization of Experimental Reproduction in Relation to Different Axes; Conclusion.

VI. Discussion, Conclusions, and Suggestions .

The Nature of Dominance; The Nature of Inhibition; Origin of Metabolic Gradients and of Dominance; Morphological Differentiation in Relation to Metabolic Rate; The Fundamental Reaction System; Agamic Reproduction in Relation to Physiological Isolation; Gametic Reproduction; Heredity, Evolution, and Other Problems from the Dynamic Standpoint. 



\section{PREFACE}

The present book is an attempt to state, and to present some of the evidence in favor of, a conception of the nature of organic individuality which has gradually developed in the mind of the writer during the course of some fifteen years' investigation of the simpler processes of reproduction and development in the lower animals. In these forms organic individuality appears in relatively simple terms, and it is here if anywhere that we must look for the key to the problem of individuality in the higher animals and man.

With the great variety of facts at hand and the limited space available, it has often been difficult to decide what particular points of the evidence to include in the consideration and what to omit. To those familiar with biological facts it will doubtless be evident that many data from various lines of investigation have been either barely mentioned or entirely omitted.

The attempt has been made to show in some degree the wide range of applicability of this conception of individuality to various biological fields, and it is perhaps permissible to express the hope that, not only the physiologist and botanist, but also the neurologist, the psychologist, and the sociologist may find something of interest in it. Chaps. $\mathrm{i}$ and ii are necessarily somewhat abstract and condensed and may seem to some readers to demand too extensive a background of biological knowledge. A re-reading of these chapters after reading chaps. iii-vi will assist in decreasing this difficulty.

In the book Senescence and Rejuvenescence, recently published, the writer was chiefly concerned with the 
periodic changes of the age cycle in the organic individual as one aspect of the life cycle. The present book deals primarily with the problem of the nature of the unity and order in the organism, the constancy of character and course of development, the maintenance of individuality in a changing environment, and the processes of physiological isolation, disintegration, and integration or individuation in reproduction. The two books, concerned as they are with these intimately associated aspects of the life cycle, are in many respects complementary and together constitute a presentation of the more important results and conclusions from the writer's investigations and a consideration of certain biological problems from the point of view attained.

For permission to reproduce or to make drawings based upon figures which have appeared in other books acknowledgments are due to publishers as follows: to the University of Chicago Press, for Figs. I6, I7, 25-27, 47, 48 in part, reproduced from Senescence and Rejuvenescence; to Wilhelm Engelmann, for Fig. 13, drawn after von Graff's Fig. 8, Tafel XVIII, in Monographie der Turbellarien, I, Rhabdocoelida; to Henry Holt \& Co., for Figs. I4 and I5, reproduced from Lillie, Development of the Chick; to Gustav Fischer, for Fig. 86, reproduced from Hildebrand, Die Gattung Cyclamen; to B. G. Teubner, for Fig. 92, drawn after Fig. 84 in Goebel, Einleitung in die experimentelle Morphologie der Pflanzen. For certain figures drawn from botanical preparations and for other figures not original, acknowledgments are made in the legends. The writer is also deeply indebted to Dr. C. J. Herrick and to Dr. W. J. G. Land, both of the University of Chicago, for reading the manuscript and for suggestions and criticisms.

C. M. Child

October, rgr 5 


\section{CHAPTER I}

\section{THE PROBLEM}

The organic world appears in the form of more or less clearly defined and limited and more or less complex entities which for lack of a better name we call individuals. The individual is not necessarily a single whole organism; it may be a part of a cell, a single cell, or a many-celled organ or complex part of the organism; or, as in most plants and some of the lower animals, a number of organisms possessing certain organs or parts in common, and therefore remaining in organic continuity with each other, may together constitute an individual. In at least most organic individuals a more or less orderly series of changes in structure and behavior which comprise the life-history occur, and in the course of these changes the individuals may give rise to new individuals by some sort of reproductive process.

In order to define the problem of the organic individual, it is necessary to inquire whether any fundamental identity or similarity is discoverable in all individuals and whether the changes which they undergo are subject to any general laws which we can at present apprehend.

THE CHARACTERISTICS OF THE ORGANIC INDIVIDUAL

The term "individual," meaning in its etymological sense something undivided or which cannot be divided, is open to various objections. Division of individuals to form new individuals is a characteristic feature of 
living forms, and many individuals are made up of other individuals and these in turn of others. Divisibility is as characteristic of the organic individual as indivisibility. Nevertheless individuality is a very real thing in the organic world. There may often be difficulty in determining the presence or absence of individuality or the limits in space or time of particular individuals, but such difficulties do not in the least shake our faith in the existence of the individual. Whatever the anatomist and the histologist tell us concerning the constitution of the human body, of hundreds of organs and millions of cells, it is perfectly evident that each human being is an individual, because his behavior proves it. And the same is true for the single cell with its nucleus, cytoplasm, centrosomes, plastids of various kinds, "mitochondria," chromosomes, chromomeres, etc. We call the cell an individual because of its behavior.

What then are the fundamental characteristics of this behavior? In what does the individuality consist? In the first place, the organic individual is alive and therefore consists essentially of the complex of substances termed in general protoplasm; secondly, it is more or less definitely limited in size; thirdly, it possesses a more or less definite morphology, a visible form and structure, which is associated in some way with dynamic and primarily chemical activity; fourthly, a greater or less degree of order, co-ordination, correlation, or harmony, as it is variously called, is perceptible in the character of its form and structure and in the dynamic activities of its constituent parts. In short, the organic individual appears to be a unity of some sort, its individuality consists primarily in this unity, and the process 
of individuation is the process of integration of a mere aggregation into such a unity, for this unity is not simply the unity of a chance aggregation, but one of a very particular kind and highly constant character for each kind of individual. In all except the simplest individuals it determines a remarkable degree of uniformity and constancy, both in the spatial relations of parts and the order of their appearance in time, and also in co-ordination or harmony of functional relation of these parts after their development.

If this conception is correct, the fundamental problem of the organic individual is the problem of the nature of this unity. The first step in consideration of this problem is to inquire whether this unity is real or apparent. Conceivably it may be only an apparent or passive unity resulting from a pre-established harmony of some kind between the constituent parts, a unity. like that of a house constructed from girders, stone, and other materials, each part of which is measured and cut beforehand according to a definite plan. The real unity here is in the plan, not in its material realization. This conception of the individual leads necessarily to the assumption of a creative entity of some sort which controls and orders the physico-chemical organism as man controls and orders the materials of the house which he builds. This dualistic or "vitalistic" conception of the organic individual, carried to its logical conclusion, denies the possibility of solution of the problem of organic individuality by scientific methods. Some of its special forms will be briefly considered in another chapter.

On the other hand, the unity of the organic individual may be an active unity resulting from interactions 
between its parts, but such a unity may again conceivably be the result of a pre-established harmony in construction like that of a steam engine, or it may be a unity which itself determines, constructs, and harmonizes as a flowing stream sculptures its channel and develops a characteristic morphological structure and dynamic activity in mutual relation to each other. ${ }^{x}$ According to this last purely mechanistic conception the problem of individuality is accessible to scientific investigation and may be solved by scientific methods.

While it is impossible to exclude absolutely the dualistic alternative as long as a complete mechanistic solution of the problem has not been reached, the advance of scientific knowledge has resulted in demonstrating the mechanistic character of one feature after another of the organism and in narrowing the field within which vitalistic assumptions are still possible. We know that actual energetic relations do exist between the different parts of the individual. These relations, which are often called physiological correlation, are of various sorts: mechanical, such as pressure or tension between parts; transportative, consisting in the transportation or exchange of substances between different parts; transmissive or conductive, consisting of changes, impulses, or excitations transmitted or conducted from molecule to molecule or from particle to particle. Physiological correlation of these different kinds unquestionably plays a very important part in the unity of the individual, and the only possible method of procedure to determine whether the unity consists essen-

${ }^{1}$ Child, "The Regulatory Processes in Organisms," Jour. of Morphol., XXII, I9II. 
tially in such correlation is the scientific method, that of experimental analysis and synthesis of data. Only in this way is there any possibility of determining whether or not the mechanistic conception is adequate. My own experiments, together with the experimental and observational data already at hand, point the way toward a conception of organic unity which is somewhat different from current views, but still entirely mechanistic, and which, as I believe, makes possible further advance toward a solution of the problem.

UNITY AND ORDER IN THE LIFE OF THE INDIVIDUAL

Life in general consists of the life-histories of individuals. Individuals arise from other individuals, undergo a more or less definite and orderly series of changes known as development, usually reproduce new individuals in a more or less orderly way, and either undergo complete physiological disintegration into new individuals in the process of reproduction or else finally lose their unity by the cessation of their activity in death.

The definitiveness and constancy, the degree of order in the behavior of the individual as regards the morphological and physiological relations of its parts in space and the sequence of the changes during its life, must be considered as, to some extent at least, a criterion of the degree of unity or individuality which it possesses. In the simplest individuals order is scarcely apparent; it is sometimes difficult to determine whether a particular aggregation of protoplasmic substance is an individual in the biological sense or merely an aggregation. Again, in some cases a given order is local or temporary and is 
soon succeeded by another. Each pseudopodium of an amoeba, for example, is to some extent an individuation of a part of the amoeba protoplasm, but it soon disappears or gives way to another individuation, and so on. Between such simple and evanescent individuals as this, at the one extreme, and the human body with its amazingly complex structural and functional order and its relative permanency at the other, there are of course many intermediate conditions. In general, organic evolution appears from this point of view to consist in an increasing complexity and stability of order; in other words, the degree of individuation, the unity of the individual, increases in the course of evolution. The series of changes which constitute development becomes more and more definite, constant, and complex in appearance, and the product of these changes, the fully. formed individual, shows an increasing complexity and stability of structure and an increasing variety and degree of interrelation of parts. In fact, a progressive morphological and physiological complication seems to occur both in individual development and in evolution. Between the unicellular organism and the adult human being the difference appears to be almost infinite, but the human individual is at the beginning a single cell with much less complex visible structure than many unicellular forms.

The process of visible structural complication which occurs in both development and evolution is commonly known as differentiation. Different regions of the cell, different cells or cell groups, become different from each other and from the original undifferentiated or so-called embryonic condition. These differences are in general 
brought about by the formation and accumulation in or about the cell of substances not present in the undifferentiated cell. Differentiation is of course merely a visible indication of differences of some sort in physiological activity in different parts, although physiological differences may exist without visible differentiation. The physiological differences appear to consist at least in large part of specialization in activity, that is, the various fundamental activities of life which are all present to some degree in the unspecialized cell or part become more or less definitely distributed and localized among different parts, a process often called division of labor. Such specialization of parts is a characteristic feature of life in all except the simplest individuals, and even there it is probably present to some extent.

Physiological specialization and the differentiation which may result from it occur in an orderly way, and in fact constitute the fundamental evidence for the orderly character of the individual. The orderly course of specialization and differentiation proceeds very much as if there were underlying it a plan or scheme characteristic for each kind of individual which is worked out in a regular constant order, as the construction of a building according to a plan follows a regular course. The orderly localization of parts and the orderly sequence in their appearance with reference to certain directions in the developing individual indicate the existence of some sort of ordering capacity underlying and preceding the stages where the order becomes structurally visible. It is evident that this underlying order, plan, or whatever it may be that determines the developmental and physiological order in the individual 
is the foundation of individual unity and order, but in attempts to solve the problem of the individual this fact has not always been clearly recognized.

This underlying capacity for unity and order finds its primary expression in what is commonly called the polarity and symmetry of the individual. These terms polarity and symmetry refer to the fact that in the appearance and maintenance of the structural and functional order in the individual certain geometrical relations, characteristic for each individual, are distinguishable. These relations are commonly expressed in terms of axes or planes. To say that an individual possesses a polar axis or a plane of symmetry is merely a convenient way of stating the fact that it is possible to conceive as drawn through the individual a line or a plane with reference to which order is perceptible. Such a geometrical conception is an abstraction from the fact that order is actually perceptible to a greater or less degree in all directions. It is merely a selection of those ideal lines or planes to which the order is most directly, simply, or permanently related, and these then serve as a system of co-ordinates, so to speak, to which the order is conveniently referred.

The geometrical relations of order differ in different individuals. In some cases the order is referable to a system of lines passing through a common center and is designated as radial or radiate. In other cases the order is referable to one or a certain number of axes and is therefore an axiate order, and it is often convenient to refer to planes instead of axes of symmetry. In the living individuals as they exist in nature various combinations of these relations occur. In the starfish, for 
example, a high degree of order is apparent in relation to an axis drawn through the center of the body vertical to the plane in which the arms extend. Centering about this axis is an order referable to radii centering in this axis, and again the order in each arm is referable to a plane passed through the radius of each arm and the central axis of the body. In a bilaterally symmetrical individual, such as man and many animals, the order can be referred to three axes-longitudinal, transverse, and dorso-ventral - at right angles to each other, or perhaps better to a longitudinal axis, and two planes, transverse and ventro-dorsal, passed at right angles to each other through this longitudinal axis.

These axes and planes drawn through the individual as a whole represent merely the general plan of orderly arrangement. Geometrical relations are also distinguishable in the order of various parts and organs, and these relations do not necessarily coincide in direction with the geometrical scheme of the whole individual but differ from it in all conceivable ways. Evidently the geometrical relations of order in the organic individual, particularly where the structure is complex, are by no means as simple as the general scheme might seem to indicate.

The reason for making a distinction between polarity and symmetry lies in the fact that in most axiate individuals one axis, the polar axis, is distinguishable as the chief or major axis of the body. In the direction of this axis the specialization and differentiation are most marked and the order in this direction is usually more conspicuous or more stable and commonly appears earlier than that in other directions. This axis is also 
very often the chief direction of growth, so that the body becomes elongated in this direction and the polar axis becomes the longitudinal axis. In short, the so-called polarity of the individual represents the direction of the chief or major order, while the axes of symmetry represent the directions of minor orders.

The two terminal regions of the polar axis exhibit in general distinct and characteristic differences in behavior and structure. In most plants, in sessile animals, and in radially symmetrical forms generally, these two regions are commonly called the apical and basal regions, while in bilaterally symmetrical motile animals they are usually known as anterior and posterior. The apical or anterior region is primarily the region of greatest dynamic or metabolic activity in the individual: in the plants it becomes the growing tip, the region of most active primary growth, while in the animals it becomes the most highly specialized and differentiated region of the body, and in those forms which possess a central nervous system, including all except the simplest animals, the chief part of the central nervous system, the cephalic ganglion or brain and the chief sense organs usually arise in this region; in other words it becomes the head and in motile forms usually precedes in locomotion.

The basal or posterior end, on the other hand, is primarily the least active region, although in many forms it may become secondarily a region of growth or specialized activity because of certain changes during the life of the individual which will be considered later. In sessile forms it is usually the region of attachment and may develop special organs of attachment, while in motile forms its activity is more or less under the control 
of the apical or anterior region. In fact it is impossible to escape the conclusion that certain general features common to most or all axiate individuals are similarly related to the polar apico-basal or antero-posterior axis, as it is variously called. As regards other axes, the differences in relation between them and the differences in behavior and structure in different individuals complicate the matter, but I shall show that there are good grounds for believing that an organic or physiological axis is fundamentally the same in all cases, whether it is an axis of polarity or symmetry of a whole organism or of a part. These geometrical relations serve primarily to express in a general way the fact that spatial order of certain kinds exists in the organic individual, but the orderly sequence of events in time is also referable to a greater or less degree to the geometrical scheme of the individual or part. In development the specialization and differentiation make their appearance and undergo their progressive changes in a more or less definite sequence with respect to the chief axes. In many cases the original geometrical plan of the individual undergoes modification or gives place to a different plan. Such changes are sometimes brought about by conditions within the individual and sometimes occur in response to changes in external conditions. In general, however, it may be said that in any given kind of individual the plan is always the same or undergoes the same changes and is always worked out in essentially the same way during development, provided external conditions are the same. Under altered external conditions departures from the plan may occur, and individuals result which differ more or less widely from the 
usual form or structure. As a matter of fact, no two individuals are exactly alike, and there is abundant reason to believe that this is so because no two individuals are or have been subjected to exactly the same conditions.

From whatever standpoint we view the facts we must always return to the conclusion that the unity and order so characteristic of the life of the organic individual are in some way or other an expression of a fundamental ordering and determining capacity of some sort which makes the individual what it is.

\section{REPRODUCTION AND INDIVIDUATION}

Reproduction, the formation of new individuals from parts of those already existing, occurs in all living forms, and the question of the origin of the new individual and of the process by which the part becomes a new whole individual is perhaps the most interesting aspect of the whole problem of individuality. In the agamic or asexual forms of reproduction, which give rise to new complete organisms in the plants and lower animals, we see the existing individual dividing into two or more, sometimes in a very regular and definite manner, sometimes apparently falling apart, as it were, into fragments or single cells; or it gives rise, sometimes in a particular region, sometimes in regions manifestly determined by chance factors, to one or more small outgrowths, buds, which increase in size and become new individuals, and these in some cases remain organically connected with the parent, in others become completely separated and independent. In many cases the character of these reproductive processes varies with the 
physiological condition of the individual and often also with external conditions. In some organisms, for example, many kinds of reproductive processes occur, their character varying with internal and environmental conditions.

Very generally it is possible to distinguish more or less clearly an orderly character in these reproductive processes; some of them are in fact orderly to a high degree. But they differ so widely in different organisms that attempts to discover common fundamental factors underlying the various forms of the process have not been very successful.

In addition to those reproductive processes which give rise to whole new organisms there are also those which result in reduplication of more or less complex parts. The repetition of radially arranged parts, such, for example, as tentacles in a sea-anemone, arms in a starfish, a whorl of leaves or the parts of a flower in a plant, and on the other hand the succession of parts along an axis, leaves or branches along the stem of a plant, or the segments in the body of the earthworm, are all reproductive processes and involve processes of individuation. All such reproductive processes must be included in any attempt at a theory of reproduction.

And finally there remains the process of sexual or gametic reproduction in which the union of two cells, the gametes or their nuclei, is followed by a series of developmental changes. In most cases of gametic reproduction the two gametes are sexually differentiated as parts of two different individuals or in different organs of the same individual before they come together. Moreover, they are themselves individuals, and their 
union results in a new individuation. In the higher animals this form of reproduction is, with very rare exceptions, the only process which gives rise to organisms.

Apparently gametic and agamic reproduction are very different processes, but we must at least raise the question whether they are similar in any way, or, if they are different, what the difference may signify.

It is in those parts of pre-existing individuals which become new whole individuals that the process of individuation goes on before our very eyes, and it is there that we have the opportunity to determine something of its nature. It is by no means necessary for us to wait for the occurrence of reproduction in nature. In many of the simpler organisms we can bring about the occurrence of reproduction at will, simply by cutting out pieces of the body and so isolating them from their physiological relations with other parts. Such pieces may become new organisms or parts of organisms more or less like those from which they were taken. These experimental reproductions constitute, as I shall show, invaluable material for the study of the organic individual and of the process of individuation, although their value for this purpose has not heretofore been generally recognized.

\section{METABOLISM AND PROTOPLASM}

The living organism consists of a substance, or more properly a complex mixture of substances, in which the series of chemical reactions known as metabolism occurs. The fundamental constituents of protoplasm occur in what is known as the colloid condition, i.e., they do not form a true molecular solution, but exist as sus- 
pended particles larger than molecules in the fluid medium, which in the case of protoplasm is water. Living protoplasm may range in its physical condition from a semi-fluid to a stiff jelly-like substance according to the aggregate condition of its particles. This mixture of substances, protoplasm, is the visible substratum of the living form, and in it the changes which constitute life occur. Changes in its aggregate condition and in the chemical constitution of one or more of its parts form the basis of specialization and differentiation and so of structure and form, and the energy of the organism originates from certain of the chemical reactions which occur in it.

Metabolism consists in a complex series of interrelated chemical reactions in protoplasm. On the one hand, nutritive substances are transformed and built up into protoplasm or into other substances characteristic of living organisms, and, on the other hand, portions of the protoplasm and of these other substances are broken down and oxidized, setting free energy, which appears in the various activities of life. What we know of metabolism indicates that the oxidations are in general of fundamental importance in the whole reaction system. Apparently life cannot continue without them, and the other reactions are to a greater or less extent associated with and dependent upon them. In a given organism, under given external conditions the rate of oxidation is in some degree a measure of metabolic activity and of life. Objection is sometimes made to the term "metabolism" because of its vagueness. It is of course true that we do not know all the various reactions and their relations to each other and to other conditions, but we 
do know that for a given organism metabolism is in general a definite and characteristic system of reactions subject to variation with change in conditions but nevertheless maintaining in the long run a certain rate and character.

In general terms, protoplasm is the foundation of structure and form, and metabolism, of function, in the organism. The relation between structure and function has been the subject of much discussion. For some the organism possesses a certain structural organization which arises in some way or other quite independent of function and which makes function possible, just as a man-made machine possesses a certain structure which makes its function possible. Such an organism must be constructed before it can begin to function, and hypotheses of this character are chiefly concerned with the supposed method of construction. This conception of the organism ignores the fact that it is always functioning while it is alive: life is function. In no case does the organism begin to function only after its construction is completed; it always functions from the beginning; it constructs itself by functioning, and the character of its functional activity changes as its structural development progresses. Structure and function are mutually related. Function produces structure and structure modifies and determines the character of function.

Here it is possible to refer only very briefly to a conception of the relation between structure and function which I have discussed more at length elsewhere. ${ }^{x}$ According to this view protoplasm and structure represent primarily those products of metabolism which

${ }^{x}$ Child, Senescence and Rejuvenescence, 1915, pp. 26-31. 
are relatively stable under the ordinary physiological conditions and in such physical condition that they cannot escape from the organism without change. Therefore they accumulate, and their accumulation constitutes growth, and their differences in different parts constitute the morphological structure of the organism. The less. stable products appear only temporarily or not at all as structural features, for they are decomposed and eliminated. These differences in stability are of course only relative and between extremes numerous intermediate degrees occur. Moreover, a structure which is stable under certain conditions may, under altered conditions, become unstable and be broken down and replaced by other structures. In general, structural stability increases both during the development of the individual and the course of evolution. The evolutionary increase in structural stability is in fact what makes possible the structural permanency and complexity of the higher as compared with the lower organisms.

- If the organic individual is a physico-chemical entity of this kind the foundation of its unity and orderly character must be present somewhere and somehow in this metabolic-protoplasmic system. Definite relations in both space and time must exist among the reactions occurring in the protoplasm, and the problem of individuality resolves itself into the problem of the nature, origin, and maintenance of these relations. It is with the problem in this form that this book is chiefly concerned.

\section{TERMINOLOGY}

In order to avoid confusion and for the sake of convenience and brevity it is necessary to fix upon and 
define certain terms to be used. The individual which forms the starting-point of a developmental,reproductive, or life-history I shall call the primary individual. This primary individual may give rise by reproduction to secondary individuals, or, by the individuation of certain organs within itself, to partial or organ-individuals. When such secondary, partial, or organ-individuals continue to constitute parts of the unity of the primary individual it is the dominant individual and they are subordinate individuals. The segments of the earthworm body or the leaves of a plant are such subordinate individuals. When the primary and secondary individuals each constitute a more or less distinct unity though still organically connected they are co-ordinate individuals. In many trees and in some branching colonial animals various branches approach or attain the condition of co-ordinate individuals. Between strictly co-ordinate and the extremes of dominant and subordinate individuals there are of course various intermediate degrees. A common or general individuality resulting from the physiological combination of a number of more or less co-ordinate individuals, either similar or of different kinds, is a composite individual. Strictly speaking, all organisms except perhaps some of the simplest unicellular or monoplastic forms are to some extent composite individuals for different cells, and even different parts of a cell may possess a physiological unity and order of their own, but since the following chapters are chiefly concerned with the larger, more general, features of organic individuality rather than with its more minute details, the term will be used primarily for the more extreme cases in which a number 
of morphologically and physiologically well-defined and usually multicellular individuals make up a relatively persistent composite individual. Most plants and the so-called colonial animal forms are good examples. The individuals which make up a composite individual are constituent individuals. These may be either parts of a cell, different cells, or cell groups composing organs.

As regards the various axes of the axiate individual, uniformity of designation is also highly desirable. The polar, longitudinal, apico-basal, or antero-posterior axis, as it is variously called, represents the primary or major order when such an order is present in the individual. In 'cases where the axes of the individual arise de novo and are not simply carried over from preexisting individuals, this axis is apparently the first to arise and other axes arise in relation to it. It is often convenient, therefore, to call this axis the major axis of the individual and the other axes minor axes.

With reference to particular axes, we are accustomed to distinguish position and direction according to the general plan of the individual, the relation of certain axes to others, the characteristic position, behavior, or direction of movement of the organism. The following terms are commonly used for this purpose: apical and basal, distal and proximal, anterior and posterior, peripheral and central, median and lateral, dorsal and ventral, besides various others which refer to particular regions, such as cephalic and caudal, oral and aboral, etc. All these terms are useful in particular cases, but greater uniformity and simplicity are desirable for purposes of general consideration. 
As following chapters will show, there is reason for believing that what we call an axis in the organism represents the general course and direction of a gradient in rate of metabolic reactions, the rate of reaction being highest at one end, or in a certain region, and decreasing from this point in the direction in which we conceive the axis to extend. Moreover, the physiological and structural order along any axis is definitely related to this gradient. If all organic axes are fundamentally metabolic gradients we may call the region of highest rate in any axis the apical region or end, the region of lowest rate the basal region or end, while other intermediate regions may be distinguished as more or less apical or basal, and opposite directions in the axis as respectively apical and basal directions. From this point of view apical and basal regions of radially symmetrical whole organisms are merely the apical and basal regions of the major axis of such organisms and so the most conspicuous or most widely separated apical and basal regions of the body, but not fundamentally different in their dynamic significance from the corresponding regions of other axes. In the following pages it will often be convenient to use these terms, "apical" and "basal" in this general way for bilaterally as well as for radially symmetrical forms. 


\section{CHAPTER II}

\section{THEORIES OF ORGANIC INDIVIDUALITY}

Having formulated the problem, it is necessary to inquire what progress has already been made toward its solution. The first section of this chapter is a very summary consideration of this question. Since the experimental and observational data upon which my own conclusions are based are so varied and their relations to the problem in many cases so complex, the inductive method of procedure is impossible within the limits of the present book. It has seemed necessary, therefore, to state my conclusions briefly in categorical form as a working hypothesis before attempting to review and interpret the various lines of evidence. This I have attempted to do in the second section of the chapter.

\section{THEORETICAL REVIEW AND CRITIQUE}

The organic individual has very often been compared to a human society or state with orderly division of labor and correlation among its component parts. The fundamental feature of the human state, that which distinguishes it from a mere aggregation of human beings and makes it an individual, is some kind and degree of law and order, of co-ordination and control of the activities of its constituent units; in short, some degree and kind of government. If the organism is a cell-state or organ-state some degree and kind of government must exist in it, but in making such comparisons biologists have often ignored or failed to recognize 
the importance of this fundamental point. There has been much discussion of "formative substances" and their distribution and rôle, and the magic word "organization" has served as the all-sufficient answer to many questions, while the fundamental problem of unity and order involved in the origin and action of the so-called formative substances and in the nature of organization has too often been completely neglected.

Various theories of the organism, which may be called corpuscular theories, have been advanced and have met with more or less general acceptance. Among these Weismann's germ-plasm hypothesis is most familiar and has played the most important rôle in biological thought. These theories postulate in one form or another a multitude of specific material entities, each of which represents in some way some characteristic of the organism. The organism as we know it is the product of their combined and harmonious activity. Examination of these theories shows that these hypothetical entities, gemmules, determinants, physiological units, pangenes, specific accumulators, or whatever we prefer to call them, are themselves endowed, ex hypothesi, with the essential characteristics of individuals and that the organism as a whole is merely a composite of their orderly activities. Neither the problem of the individuality of the hypothetical units nor that of their orderly combination and unification in the organism receives any adequate consideration in those theories. They merely translate the problem into hypothetical terms which are beyond the reach of scientific method. The combination of these units into the individual is assumed to occur as the facts demand, and although the problem of the control 
and ordering of millions of such units through all the changes involved in the development of a complex organism, say the human being, is one which staggers human intelligence, it is practically ignored. Even some of our present-day speculations which attempt to assign actual topographic positions in the chromosomes to particular factors in heredity ignore completely the problem of the ordering and control of these factors which is involved in their assumptions. In fact, if we subject this group of theories to logical analysis we soon reach the point where it is necessary to assume the existence of something very like a superhuman intelligence as the underlying principle in all of them. They leave the essential problem unsolved, but their implications are anthropomorphic and teleological.

Dualistic or "vitalistic" theories of the individual recognize the real problem more or less clearly, but assume the existence of a non-mechanistic ordering and controlling principle. Before the development of the experimental method in biology the doctrine of vital force as something peculiar to the organism and fundamentally different from the forces acting in the inorganic world was very generally accepted, but as evidence for the validity of physico-chemical laws in the activities of living things accumulated, the hypothesis of vital force was discarded by most biologists. Within recent years, however, various attempts have been made to show the inadequacy of mechanistic conceptions of life. Driesch, at present the chief exponent of this line of thought, has postulated the existence of a controlling and ordering principle which he calls entelechy, following Aristotle. Entelechy is independent of and superior 
to physico-chemical laws, and controls and orders the physico-chemical factors in the organism to a definite end or purpose. It constructs the organism as a man constructs a machine. In many respects it resembles human intelligence, but seems to be far superior to it. Other neo-vitalistic theories are more or less similar in their general conceptions, but differ in detail.

In certain respects these theories constitute a real advance over the corpuscular theories, for they recognize and state more or less clearly, instead of ignoring, the essential problem. For the present, however, most of us find little intellectual satisfaction in the solution which they offer, and they are either frankly speculative or involve unwarranted or premature assumptions, and, like the corpuscular theories, they place the problem beyond the bounds of science.

Various attempts at solution or progress toward solution of the problem of organic individuality have been made along physico-chemical lines. The evident unity and order, the individuality of the inorganic crystal, together with the discovery of the existence of fluid crystals, have led to comparisons of the organism with the crystal and so to hypotheses which postulate an essentially crystalline character for organic unity and order. According to these hypotheses the laws underlying this unity and order are essentially those governing the aggregation and arrangement of molecules. The construction of the orderly framework of the organism is the expression of such laws, and its activities represent the chemical changes which go on in this framework. 
These hypotheses are open to various objections. The crystal consists primarily of like molecules though under certain conditions some crystals may show differences in constitution at the two poles resulting from the presence of other substances besides the primary constituent of the crystal. The organism, on the other hand, is a complex of many different kinds of molecules, some of which are undergoing breakdown and being built up anew during life, and, moreover, there is no optical or other evidence that protoplasm in general is fundamentally crystalline in structure. The unity of the crystal is a static unity, a unity of form and arrangement, and disappears or is replaced by another unity when chemical change occurs, while the unity of the organic individual is a dynamic unity dependent primarily for its existence on chemical activity and disappearing when such activity ceases. To believe that metabolism results from structure and "organization" as the activity of the man-made machine results from its structure is to ignore the fact that metabolism is the formative agent in the organism. Undoubtedly crystals or crystalloid individuals are present in at least many organisms, but their individuality is quite distinct from that of the organism.

Some biologists, while not admitting that the organism is fundamentally crystalline, assume that its constituent molecules possess unknown properties which determine its unity and order. These hypotheses are open to the same objections as the crystal hypotheses. All such hypotheses in fact proceed on the assumption that a certain more or less complex "organization" is necessary as a starting-point; the machine must 
somehow be constructed before it can run. Actually, however, the organism runs throughout its construction from the condition of amorphous protoplasm to that of a complex anatomical system.

Modern investigation of the chemistry of the organism has demonstrated that the chemical correlations, as they are commonly called, which exist between its parts are most various and complex and often highly specific in character. Certain parts produce substances which are essential to the normal activity or structure of other parts, and the statement is frequently made that every organ in the body is an organ of chemical correlation, which means merely that it produces something which plays a rôle in making other parts what they are.

On the basis of these facts the hypothesis has been advanced, and is at present widely current, that the unity and order in the organism consist primarily in such chemical correlations. These chemical correlations depend upon the production and transportation within the organism of more or less specific substances, and it is evident that parts more or less specifically different must be present in order to produce such substances. These hypotheses provide no solution of the real problem of individuality, for they all involve the assumption of an underlying order or "organization" which makes orderly chemical correlation possible. To return to the analogy between the organism and the state, exchange between human beings arises from the existence of different individuals with different needs. In order that the exchange may be orderly and specific in character some degree of unity and order must exist in the activities of the parties to the exchange. This order may result 
from the authority of one person and its transmission to others, or from that of consensus of opinion, but in either case it is not the act of exchange nor its character which determines this order but the order that determines the exchange and its character. The orderly union of human beings to form an individuality which shows the most various degrees of individuation from the family through the clan and tribe, etc., to the highly developed modern state is based primarily on authority of some kind and its transmission, not upon the material relation of the production and transportation of substances. When this union of men exists, no matter how primitive its character, the substances which it receives in exchange may play a very important part in determining the character and course of its further development. If the unity of the organic individual is in any way comparable with that of these composite social individuals, it is evident that it must originate in some ordering or controlling factor which makes possible the existence and orderly and definite arrangement of specific parts. These two types of relation-authority or dominance of some sort and its transmission to subordinate parts and the production and transportation of substancesrepresent the two kinds of relation possible between persons, organs, cells or parts of a cell, so far as direct mechanical relations of contact, pressure, or tension are not concerned. The unity of the social individual evidently depends primarily upon the transmissive rather than the transportative kind of relation. If the organic individual is in any way comparable to it we might reasonably expect to find the same thing true there. 
Various biological theories have concerned themselves primarily with that particular aspect of unity and order which appears in the geometrical relations of parts. These are commonly known as theories of polarity and symmetry, but since polarity and symmetry are fundamental features of organic individuality, these theories must be regarded as theories of the organic individual. It is unnecessary to discuss these theories particularly, for they fall into the same groups as those already considered, and are open to the same objections. They either assume the existence of some kind of structural order or "organization," physical or chemical, or some sort of pre-existent plan or pre-established harmony, or they ignore or fail to recognize the real problem and postulate migrations or distributions of formative substances, differences in tension, permeability, or other properties, as if such factors could behave in an orderly and constant way without a constant underlying order of some sort.

Some few biologists have attempted to deny the existence of individuality in the sense of a definite determining and controlling unity and order. The basis of such denials is usually the fact that organisms behave differently under different external conditions, while the more important fact that a definite unity and order exists in these different reactions is completely overlooked.

This brief consideration of the various lines of biological thought concerned with the problem of the individual is sufficient to show that the problem is by no means solved. The remainder of the present book is an attempt to make some progress toward a solution of the 
problem along somewhat different lines from those already considered. My own investigations in this field, extending over some fifteen years, together with the facts already at hand, as I see them, have forced me to the conclusion that the organic individual is fundamentally neither a structural system, whether physical or "vitalistic" in character, nor a system of chemical reactions, but rather a system of relations between a physical substratum or structure and chemical reactions. These relations, I believe, constitute the fundamental problem of life, so far as it is a biological problem, and as one aspect of it the problem of biological individuality. This is the point of view which underlies the conception of the individual presented in the following pages. Since the relations between protoplasmic substratum and chemical reactions, whatever their physical or chemical character in particular cases, are essentially dynamic, I have called it a dynamic conception.

A DYNAMIC CONCEPTION OF THE ORGANIC INDIVIDUAL

The foundation of unity and order in the organic individual is the transmission of dynamic change, "stimulus," "excitation," from one point to another in the protoplasm. In the course of such transmission the transmitted change undergoes a decrement in intensity or energy so that finally at a greater or less distance from its point of origin it becomes inappreciable or ineffective. In the simplest case such a transmitted change originates in a region of high metabolic rate, and transmission occurs to regions of lower rate. The region of high metabolic rate results in the final analysis from 
the action of factors external to the mass acted upon, whether part of a cell or a cell mass. A simple schematic consideration will serve to make these points clear. Let us assume a spherical mass of living protoplasm (Fig. I) which is morphologically and physiologically homogeneous except as regards the essential features of protoplasm or cells. Such a mass, whether consisting of a single or of many cells, possesses no axis, is undiffer-

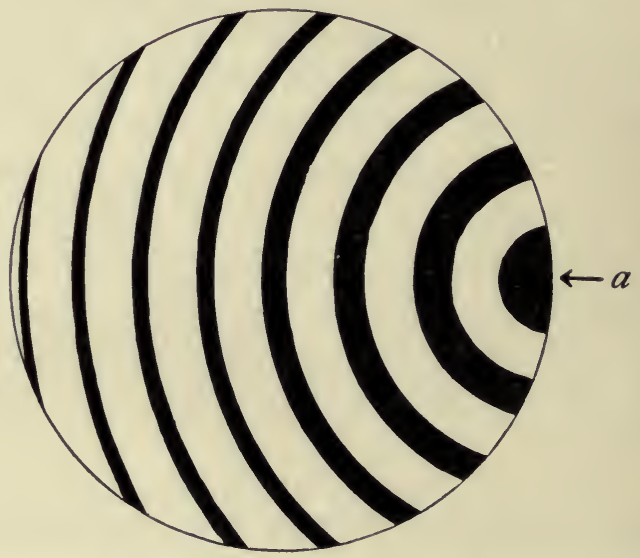

FIG. I.-Diagram illustrating the origin of a single axial gradient in protoplasm: $a$, the point of action of the external factor.

entiated, and is not a physiological individual. Now let us suppose some external factor which increases metabolic rate, a "stimulus," to act on this mass in the region $a$ of its surface. The first result of such action is an increase in the rate of metabolic or of certain metabolic reactions in the region $a$. This is followed by a spreading or irradiation of a dynamic change, either over the surface of the mass or through it from the region $a$. 
This change is fundamentally a transmission, not a transportation, for it consists in the passage of a certain energetic change and not in the bodily transportation of substance. ${ }^{\mathrm{I}}$ Such a process of transmission may be compared to the spreading of waves in a pond from the point where a stone is thrown into the water, although it probably does not always or necessarily consist of a series of rhythmical changes like the water waves.

The question of the nature of the transmitted or conducted excitation has been the subject of much investigation and discussion, and many different attempts to answer it have been made. Recent investigation indicates, however, that whatever its exact nature, it involves an increase in metabolic activity. It seems in fact to be a wave of increased chemical activity spreading from the point of origin much as a wave spreads in a pond. The question of the relation of the electrical and chemical changes observed in the transmission of excitation in protoplasm does not concern us here. The fact of transmission and the increase in metabolic activity in connection with it are the important points for the present purpose.

The transmission of excitations is one of the characteristic features of living protoplasm, and undoubtedly occurs to a greater or less extent in all protoplasm. In its simplest form it is perhaps little more than a spreading or irradiation to a greater or less distance of the change produced at the point of origin, but in its most

I It should perhaps be noted that from the standpoint of current physico-chemical theory transmission itself may be regarded as molecular, atomic, ionic, or electronic transportation. Nevertheless, the differences between such transportation and the transportation in mass of substances is sufficient to warrant the distinction made. 
highly specialized form, the nerve impulse, it probably differs more or less widely from the initial change.

The second point of importance in connection with such transmission is the existence of a decrement in intensity or energy of the change in the course of its transmission. Apparently a part of its energy is used in overcoming a resistance or inertia or in producing other changes which play no part in further transmission. The existence of this decrement, which may be called the transmission-decrement, determines that at a greater or less distance from its point of origin the transmitted change becomes inappreciable or ineffective, and transmission does not proceed farther. In Fig. I the intensity of excitation or the amount of increase in metabolic activity is indicated diagrammatically for different distances from the point of origin in $a$ by the bands of different width concentric at $a$. The limit of effectiveness of transmission depends on the intensity or energy of the original change produced at $a$ and, secondly, upon the character of the protoplasm. The higher the conductivity of the surrounding protoplasm -in other words, the less its resistance or the greater its sensitiveness to the transmitted change-the greater the distance to which the change will be transmitted before becoming ineffective, and vice versa. In the existence of this transmission-decrement the resemblance to the transmission of waves in water and to various other forms of physical transmission, such as electrical transmission, is also apparent. A decrement in velocity of transmission accompanies decrement in intensity, at least in certain forms of transmission, but is not of primary importance in the present consideration. 
If the external factor acts only momentarily at $a$, the increase in rate of reaction at $a$ is usually only momentary or of short duration, and $a$ sooner or later returns to or approaches its original condition, perhaps in some cases with a gradually disappearing rhythm of increase and decrease in rate. The transmitted change consists in this case of a wave or a series of successively decreasing waves of change.

It is probable that even the occurrence and passage of such momentary changes as these in a substratum so sensitive and so intimately associated with the reactions as protoplasm produce changes which persist for a longer or shorter time after the metabolic change has disappeared, but such changes are usually slight or inappreciable. If, however, the external factor continues to act on $a$ for a sufficiently long time, or if it acts intermittently with sufficient and not too great frequency or intensity, it produces sooner or later more or less permanent changes in the protoplasm, which are most marked in the region $a$ and decrease with the transmission-decrement. The exact nature of these changes is not certainly known, but their effect is to increase the reactive capacity, to alter the protoplasm so that in the absence of external stimuli, or with a given intensity of external stimulus, a rate or intensity of chemical reaction exists higher than the rate under similar conditions before the change. In the terms generally employed, the irritability of the protoplasm is increased.

Since this change is greatest in the region $a$, Fig. I, where the excitation is greatest, and decreases with increasing distance from this region, the result of 
continued or frequently repeated excitation is the establishment of a gradient in the condition of the protoplasm which constitutes a more or less permanent material substratum for a persistent metabolic gradient independent of the local external stimulus. In short the effect of the local action of an external factor on protoplasm may sooner or later result in the establishment of a metabolic gradient, or the material basis for such a gradient, which persists for a longer or shorter time after the external factor has ceased to act. As a matter of fact, such gradients, once established, often persist throughout the life of the individual. These gradients may be directly visible in a graded structure of the protoplasm as well as in differences in rate of reaction, or they may appear only or chiefly in the differences in rate, according to the nature of the protoplasm. There is considerable evidence to show that when once established to a certain degree they tend to persist and even to become more marked, because the rate and extent of further changes in the protoplasm at different levels of the gradient are determined by the differences in rate of reaction at these different levels. As a rapidly flowing stream quickly removes from its channel obstacles which a slowly flowing stream removes only slowly or not at all, so the changes in protoplasm which make a higher rate of reaction possible are more rapid and more extensive with a high than with a low rate of reaction.

If these considerations are correct, and there are, as will appear; many facts to support them, it is evident that a persistent metabolic gradient associated with a material gradient in the protoplasmic substratum may arise as the result of the local or differential 
action of an external factor on a morphologically and physiologically homogeneous living mass.

The formation of metabolic gradients in another way is possible, at least in single cells. If, for example, inactive substances of different weight from the active protoplasm are present in the cell, and if the position of the cell with respect to the force of gravity remains unchanged for a sufficiently long time, the inactive substances and active protoplasm may be more or less definitely localized in different parts of the cell and so a metabolic gradient may result. Again, it is conceivable that continued intake of nutrition at some particular point of the cell surface might load that portion of the cell with inactive reserve substances and so give rise to a gradient. To what extent the origin of metabolic gradients is due to such factors as this is still a question. In the frog's egg gravity undoubtedly contributes to intensify the existing gradient by bringing about a further separation of the heavier yolk granules and the lighter protoplasm, but it is not responsible for the origin of the gradient. Unquestionably the primary factor in the origin of these persistent metabolic-protoplasmic gradients is in most cases at least a reaction-gradient, and the persistent or permanent gradient in the protoplasmic substratum is secondary.

Such metabolic gradients are, I believe, the simplest expression of physiological unity and order in living protoplasm, and at the same time they are the simplest and primary form of the organic axes of so-called polarity and symmetry and the starting-point of the mysterious "organization." They are factors in determining the direction of growth and differentiation and 
so are the basis of the geometrical space relations and the sequences in time which arise during the development of the individual. They may then be called axial gradients. The region of highest rate in such a gradient is the apical, the region of lowest rate the basal region of the axis which represents the general direction and course of the gradient.

Other factors besides actual rate of metabolic reactions are doubtless concerned in the formation and establishment of these gradients in protoplasm, but these are associated either with the rate of reaction or its change, or with the character of the protoplasm in which the reaction occurs and have to do rather with particular cases than with the gradient in general. The intensity of reaction, for example, is probably such a factor. A sudden or very rapid increase in rate on excitation is probably more effective in producing transmitted changes than a gradual increase, and it is also probable that in protoplasm with a high reactionintensity excitations are transmitted to greater distances than where the reaction-intensity is low. Excitation and transmission are undoubtedly also correlated with the physiological stability and physico-chemical constitution of the protoplasm. Such factors as these may play a part in determining length, slope, or other characteristics of the gradient, but the primary factor in its production appears to be rate of reaction.

In a metabolic gradient a relation of dominance and subordination exists between the level of highest and the levels of lower metabolic rate. A brief consideration will show that this relation is a simple and necessary result of the differences in rate of reaction. 
In the first place, the apical region ( $a$, Fig. I) is the chief factor in determining the rate of reaction at other levels, for in the varying conditions of a natural environment it responds more rapidly or with a higher rate of reaction than other levels of the gradient to external exciting conditions, and it is also more sensitive and may react to conditions which produce no reaction at lower levels of the gradient. With every such increase of metabolic rate in response to external exciting factors a gradually decreasing wave of change spreads from this region of highest rate, as in the original excitation which gave rise to the gradient, though the intensity, velocity, and limit of effectiveness of the transmitted change may be much greater than in the original transmission.

This change transmitted from the apical region $a$ plays the chief part in determining the metabolic condition at other levels, because $a$ is the region of highest metabolic rate and the changes transmitted from it are more intense than those from other levels and because the establishment of the protoplasmic gradient makes conduction in this direction more effective than in any other. Consequently the region a dominates or controls other regions within a certain distance and to a greater or less degree by influencing, through the changes transmitted from it, their metabolic rate. Dominance or control of one part over another in the organism is fundamentally, I believe, a matter of difference in metabolic rate, the region of higher rate being dominant.

If, after such a gradient is established, some other region, such as $b$, Fig. 2, undergoes excitation at the same time as $a$ and by an external factor of the same intensity as that acting at $a$, the response will be 
less rapid and less intense than that of $a$, and, as indicated in Fig. 2, the transmitted change will be weaker, perhaps less rapid, and its limit of effectiveness less than that arising from $a$. The influence of the region $b$ must then be less than that of $a$ in determining the metabolic rate in other regions and $a$ remains the dominant region.

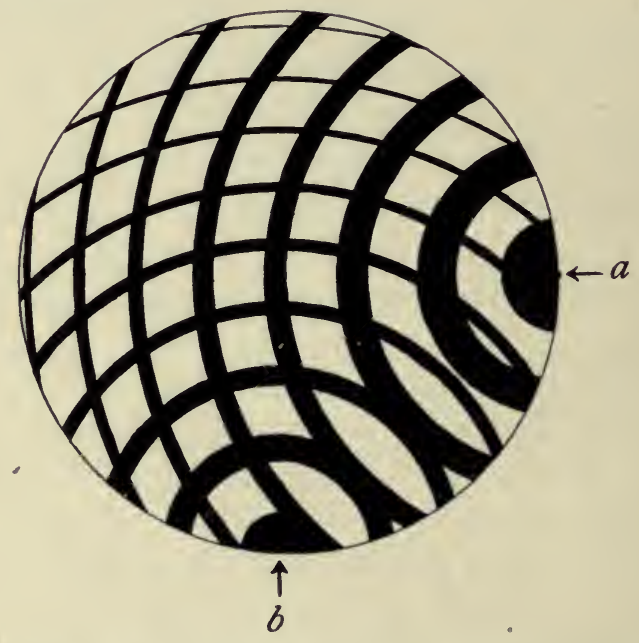

FIG. 2.-Diagram illustrating origin of major and minor gradients in a simple case: $a$, apical region of major gradient; $b$, apical region of minor gradient.

If, however, the region $b$ or any other region is sufficiently intensely or sufficiently often locally excited independently of $a$, a persistent gradient may arise with relation to $b$ without destroying that related to $a$. In such a case two dominant regions, $a$ and $b$, exist, but $a$ may still dominate $b$ to a greater or less extent unless the reactive capacity or irritability of $b$ becomes equal 
to that of $a$. Every other point in the mass, so far as it is within the limit of effectiveness of both $a$ and $b$, will be subordinate to both to a greater or less degree, and its metabolic condition will be the resultant of its position in the two gradients. Such an organism possesses not only a polar axis or gradient, but an axis or gradient of symmetry as well, and in the same way other gradients and other relations of dominance and subordination may arise. Obviously it is possible for various gradients to exist simultaneously in a living mass, and their relations may be very different in different cases, as are the relations between the different axes in organisms. Interference between different gradients in opposite or nearly opposite directions, or obliteration of one gradient by another of higher rate of reaction, undoubtedly occurs, as following chapters will show, but their relations need not be considered here.

The physiological dominance of one part over another is certainly not a constant, unchanging relation, but depends upon the metabolic rate in the dominant apical region and the conductivity of other regions. The metabolic rate in the dominant region is also not constant, but must fluctuate with changes in external conditions. With a slight rise in metabolic rate in the dominant region its influence on other regions is slight and does not extend far, but when the increase is great the degree of dominance is greater and extends to a greater distance. Certainly in the primitive individual these relations must be regarded as constantly undergoing change in degree and extent, though under the usual conditions they must also show a general average. So for each level there will be a general average of the effect of the transmitted 
change upon it, and the gradient will be further intensified by the fact that slight transmitted changes do not reach the more remote parts at all while they do affect the parts nearer the dominant region. It is this general average which determines the more conspicuous and lasting effects at different levels.

The continued existence of a metabolic gradient of this kind undoubtedly determines an increase in the conductivity of the protoplasm for the transmitted excitation. Many facts indicate that within certain limits the occurrence and repetition of transmission increase the conductivity, and in all animals except the simplest a nervous system which possesses a very high degree of conductivity develops in relation to the primary gradients. In most organisms there is therefore an extension of dominance during development, the transmitted changes become effective through a greater distance, and their limit of effectiveness, which of course determines the range of dominance, becomes farther and farther removed from the point of origin. This extension of dominance, however, is itself limited by the changes known as senescence, which become evident in a general decrease in reaction rate. These relations of parts, dependent in the final analysis on differences in metabolic rate, constitute, as I believe, the foundation of unity and order in the organic individual, the startingpoint of physiological individuation.

If this conclusion is correct, the organic individual, as a living entity possessing some degree of physiological - not merely physical - unity and order, consists in its simplest forms of one or more gradients in part of a cell, a cell, or a cell mass of specific physico-chemical consti- 
tution. The process of individuation is the process of establishment of the gradient or gradients as a more or less persistent condition, and the degree of individuation depends upon the permanency of the gradient, the metabolic rate in the dominant region, the conductivity of the protoplasm, and probably on other factors as well.

From this point of view the assumption of a mysterious, self-determined organization in the protoplasm, the cell or the cell mass as the basis of physiological individuality becomes entirely unnecessary. The origin of physiological individuality is to be found, not in living protoplasm alone, but in the relations between living protoplasm and the external world. In view of the fact that the organic individual after its formation is far from independent of its environment, it is difficult to see why we should assume that it is independent and self-determining in its origin.

It must not be supposed, however, that every new individual originates in the manner described above. When the axial gradient is once established in a cell or an organism, it may simply persist through the process of cell division or other forms of reproduction so that the unity and order of the new individual represent simply the unity and order of the parent or a part of it. In such cases the basis of individuality is inherited from the parent. In nature we find both possibilities realized: physiological individuality may arise de novo through the relation between living protoplasm and its environment, or it may be inherited from previously existing individuals. To put it more concretely, an axial gradient cannot arise in the first instance independently of conditions external to the mass of protoplasm concerned, 
but, once established, it may persist through many generations.

The question at once arises whether a quantitative gradient, such as has been described, constitutes an adequate basis for the physiological specialization and structural differentiation which arise in relation to the axes of the individual and in the higher organisms become very complex. Organs showing very definite qualitative differences in chemical constitution and metabolism and great differences in functional activity develop in the organism. Qualitative specific differences of some sort are commonly believed to be necessary as a starting-point for such complexity, hence the usual theoretical assumption of some sort of underlying organization as the basis of organic individuality. Some of the facts bearing upon this question will be considered in later chapters; here attention may be called to three points: first, it is a familiar fact of chemistry that purely quantitative differences may bring about the formation of qualitatively different products from the same reacting substances, and in a complex physico-chemical system, such as living protoplasm, the possibilities for the origin of qualitative from quantitative differences is very much greater than in the simple chemical reaction in the test tube; secondly, it is by no means clear what is quantitative and what is qualitative in organic structure and form, or in metabolism, for many structural differences which are ordinarily considered as qualitative prove on analysis to depend on quantitative differences in certain constituents of the complex; and, thirdly, morphological differences usually regarded as qualitative can unquestionably be produced 
and controlled experimentally by metabolic changes which are primarily quantitative. The morphology of the channel of a rapidly flowing stream is very different from that of a stream which flows slowly, and there can be little doubt that in the organism substances which are decomposed and transformed or eliminated with a high rate of reaction remain and accumulate in the protoplasm and may form characteristic morphological features when the rate of reaction is low.

In this connection the question must be raised whether the transmitted change is always of the same sort and produces the same effect in a protoplasm of given constitution. It is impossible at present to give a definite answer to this question, but there seems to be no positive evidence to show that the qualitative character of the effect is determined by the character of the transmitted change, although it has often been assumed that this is the case. It is very probable that the chemical or physico-chemical character of the transmitted change differs more or less widely in plants and animals, and in embryonic protoplasm as compared with the fully developed medullated nerve, but the effect in each case seems to be primarily excitatory and quantitative. It seems even possible that in passing through different tissues the character of the transmitted change may differ more or less according to the constitution of the tissues, but its effect may still remain essentially quantitative.

If it should be demonstrated that the same protoplasm may transmit different kinds of excitations, then of course different processes of morphogenesis and differentiation might be determined by the specific 
character of the transmitted changes affecting different regions. The demonstration of such relations would of course complicate our conception of the course of development, but would not necessarily alter our views concerning the fundamental principles of individuation. The problem of the nature of transmitted changes in protoplasm has been the subject of much experiment and discussion and is still by no means solved, but our knowledge concerning them is sufficient to permit us to formulate a working hypothesis of the organic individual in terms of these transmitted changes rather than in terms of transported chemical substances.

As soon as local differences in chemical constitution of the protoplasm arise, whether they result from differences in metabolic rate or from differences in character of the transmitted change, the relations commonly called chemical correlation, consisting in the production and transportation of different specific-substances, begin to play a part, and from this point on these chemical relations are factors of great importance in determining the character of the different parts, until in the adult stage of the highest forms, man and the other mammals, the complexity of chemical correlation is bewildering, as the work of recent years on hormones and internal secretions has clearly demonstrated. From the point of view developed here chemical correlation is, however, a secondary factor, for the underlying order which determines the orderly character of chemical correlation consists in the quantitative gradients which arise in the living mass.

Since a transmission-decrement in energy or in intensity of the transmitted change exists, the change 
is effective only within a certain limit of distance which we may call its range, and since physiological dominance depends upon the transmitted change it is similarly limited in range. If physiological individuation depends upon dominance of this sort associated with the metabolic gradient determined by transmitted changes, the range of dominance must determine a physiological limit of size, which the individual cannot exceed without the physiological isolation of some part from the dominance which previously determined the individuality. As already pointed out, the range of the transmitted change and so the range of dominance varies with the rate of reaction in the dominant region and with the conductivity of the protoplasm; therefore the physiological size limit of the individual must vary with the same factors.

Reproduction in its simplest asexual forms results from the physiological isolation ${ }^{x}$ of $\overline{\text { parts }}$ of the individual body in consequence of their coming to lie beyond the physiological limit of size. Such physiological isolation may result from: first, increase in size of the body of the individual by continued growth until some part of it is brought beyond the range of dominance; secondly, decrease in the range of dominance and limit of size by decrease in the rate of reaction in the dominant region; thirdly, decrease in the conductivity of the protoplasm for the transmitted changes; fourthly, the direct local action of some external factor on a subordinate part, increasing its rate of reaction to a sufficient degree to make it more or less independent of or insusceptible to the effects transmitted from the dominant

${ }^{x}$ Child, "Die physiologische Isolation von Teilen des Organismus," Vorträge und Aufsätze über Entwickehngsmechanik, H, XI, Igrr. 
region. This change I have called decrease in receptivity of the subordinate part for the transmitted change.

The effect of physiological isolation of a part is essentially the same as that of physical isolation. In the lower organisms where its physiological and morphological characteristics as a part are less stable than in the higher forms and it is able to respond to the altered conditions accompanying physiological isolation, it loses more or less completely its character as a part because the conditions which determined and maintained its specialization no longer act. Consequently it undergoes dedifferentiation to a greater or less degree and so approaches or returns to the undifferentiated or embryonic condition, and is then capable, if differences in metabolic rate in the direction of the original gradient or gradients still exist in it, or if conditions determine the origin of new gradients in it, of development into a new individual. I have shown that development and differentiation are in general accompanied by a decrease in metabolic rate which constitutes physiological senescence and that the dedifferentiation of isolated parts brings about rejuvenescence varying in degree with the degree of dedifferentiation. ${ }^{x}$ New individuals formed from physiologically or physically isolated parts of preexisting individuals may therefore be physiologically younger than the individuals from which they arose and so be capable of repeating the developmental history and process of senescence. Asexual reproduction in general results from such physiological isolation of parts and their dedifferentiation and redifferentiation into individuals. In the higher animals physiological

${ }^{x}$ Child, Senescence and Rejuvenescence, I9I5; particularly chaps. ii, iv, $\mathrm{v}$, vi, viii, $\mathrm{x}, \mathrm{xv}$. 
isolation of parts probably does not occur except occasionally in embryonic stages, for with the evolution and development of the nervous system in the individual the transmission-decrement decreases and the effective range of transmission therefore increases until in the nerves of mammals the transmission-decrement is inappreciable under natural conditions in the lengths of nerve fiber available for experiment. In these forms the physiological limit of size of the individual determined by the range of dominance is very great and is never attained by the individual because growth is limited by the progress of differentiation in the course of development. In such organisms, then, physiological isolation does not occur except occasionally in embryonic stages before the nervous system has developed or under special conditions which limit the range of dominance or decrease the receptivity of subordinate parts.

Moreover, in the higher animals the degree and stability of specialization of parts of the body is so great that in most cases they do not respond to physiological or physical isolation by reproduction, but either die or remain largely unchanged. For these reasons asexual reproduction among the higher animals is rare and is limited to early developmental stages. Sexual or gametic reproduction which results from the union of the two gametes or sex cells, which are usually specialized and differentiated as egg and sperm, is somewhat more complex than asexual reproduction, but I have already endeavored to show that there is a fundamental physiological similarity in the two processes, ${ }^{\mathrm{I}}$ and I shall consider the question briefly in a later chapter.

${ }^{x}$ Child, Senescence and Rejuvenescence, I915, chaps. vi, $\mathrm{x}$, xiii, xiv, xv. 
This, then, is in brief the dynamic conception of the organic individual which has grown out of years of experimental investigation, observation, and analysis of facts already at hand. Its distinctive feature is the interpretation of physiological unity and order in terms of differences in rate of reaction and of transmitted changes, instead of in terms of a hypothetical organization and of transportation of chemical substances. According to this conception the central nervous system in its relation to other parts is merely the final expression of relation which is the foundation and starting-point of organic individuation. This conception provides a working hypothesis based on a great variety of evidence and readily accessible to experimental and analytic investigation, and while it is manifestly far from being a complete solution of the problem of organic individuality, I believe that it throws some light on various characteristics of the organism the nature and significance of which have heretofore remained obscure.

It is perhaps necessary to point out that this dynamic individuality is not the only kind of individuality which exists in the organic world. Physical individuals of crystalline or crystalloid character, and perhaps physicochemical individuals of other sorts exist in organisms. It is not with these, however, that we are concerned, but with that sort of individuality which is distinctive of the living organism, which determines harmonious development and functional unity throughout the continuous dynamic change which constitutes life. Where this organic individuality makes its first appearance it is impossible to say. The cell or protoplast in its simplest terms usually shows some degree of such indi- 
viduation, but it is probable that some real or apparent individuations which arise temporarily or are persistent in the cell approach more nearly the inorganic than the organic kind. Nevertheless, wherever a region of high metabolic rate arises in protoplasm, there some degree of organic individuation arises, at least for the time being, provided relations already existing do not interfere with or inhibit the establishment of a metabolic gradient.

According to the dynamic conception organic individuality results in the final analysis from the relations between living protoplasm and the world external to it. If we accept this view we should expect to find morphological structure and differentiation making their first appearance in the superficial regions of the protoplasmic mass. These are in more direct relation with the external world and therefore more irritable and with the establishment of a region of high metabolic rate a metabolic gradient must arise much more rapidly in the superficial than in other regions. The facts agree well with this view, for the first indications of individuation in the organism are very generally superficial and in many of the simpler forms, such as the infusoria among animals, orderly morphological differentiation is always limited to the superficial regions. The nervous system is also superficial in origin. In the plant cells also the superficial portions of the cytoplasm generally show a higher degree of stability than other regions and are apparently chiefly concerned in whatever morphological protoplasmic differentiation occurs. If organic individuality is self-determined there is no apparent reason for its appearance as a superficial phenomenon. 


\section{CHAPTER III}

\section{METABOLIC GRADIENTS IN ORGANISMS}

If metabolic gradients are of such fundamental importance in the organic individual it should be possible to discover various proofs or indications of their existence. This chapter is a survey of some of the experimental and observational evidence for the existence of metabolic gradients.

\section{SUSCEPTIBILITY GRADIENTS IN ANIMALS AND PLANTS}

The resistance or susceptibility of living protoplasm to various poisons can be used, with certain precautions and within certain limits, as an index of its metabolic condition. This method, which may be called the susceptibility method, makes it possible, particularly in early stages of development and in small, simple animals, to compare the susceptibilities and so to obtain a general idea of the differences in metabolic activity of different regions of the body of a single organism. Many different substances may be used as reagents for determining susceptibility, such, for example, as the alcohols, ethers, and other narcotics, and acids and alkalies. Various products of metabolism, among them carbon dioxide, and certain conditions, such as lack of oxygen, serve the same purpose. But the cyanides, which are powerful poisons, are in many respects the most satisfactory reagents, and they have been used in most of my experiments. 
The relation between metabolic activity and susceptibility to these substances is primarily quantitative, the degree of susceptibility depending upon the rate or intensity of metabolism or of certain fundamental metabolic reactions. In aqueous concentrations of a given reagent which kill within a few hours, the susceptibility varies directly with the general metabolic rate; the higher the rate of metabolic activity, the sooner does death occur. In very low concentrations, however, to which the organism is able to acclimate or accustom itself to some extent, we find the relation reversed. The higher the metabolic rate, the greater the degree of acclimation and therefore the less the susceptibility and the later the occurrence of death. These two methods of comparing susceptibilities I have called the direct and the acclimation method.

The question how these various substances act upon the living organism, whether they enter directly into the chemical reactions or whether they change the physical condition of the protoplasm or certain of its constituents in such a way that the reactions cannot continue, has long been and is still the subject of discussion, but cannot be considered here. Whatever the nature of their action, there can be no doubt concerning the general relation between susceptibility to them and metabolic condition, although under certain conditions the relation may be masked or altered by certain incidental factors.

For the direct form of the method, which is the simplest and most widely applicable, the procedure consists in the immersion of the animals to be examined, either singly or in lots, in a concentration of cyanide 
or other reagent used, which has been previously determined as a concentration which will kill the animals in the course of a few hours under the given conditions of temperature, etc. In many of the lower animals death is followed at once or in a few moments by a visible disintegration and complete loss of structure and form of the part concerned, and in such cases the progress of death can be directly observed. In other cases other means of determining the death-point may be employed or the animals may be removed from the reagent at definite intervals and the progress of death, and so the susceptibility, determined by observing whether and to what extent recovery occurs in each case. When the method is used in this way regions of high metabolic rate die earlier than those of low rate.

In the indirect or acclimation form of the method we find that the degree of acclimation varies with metabolic rate. With this form of the method regions of high metabolic rate are least susceptible in the long run because they become acclimated more readily, while regions of lower metabolic rate undergo less acclimation and so are inhibited to a greater degree and may even die. The susceptibility gradients observed with these two modifications of the method are themselves opposite in direction, but are different expressions of the same metabolic gradient. ${ }^{x}$

Several species of the flatworm Planaria constituted the material for my first observations on susceptibility gradients. The results obtained were so definite and

${ }^{x}$ For more extended discussions of this method see Child, Senescence and Rejuvenescence, I9I5, chap. iii; also "Studies on the Dynamics of Morphogenesis and Inheritance in Experimental Reproduction, V," Jour. of Exp. Zoöl., XIV, I9I3. 
striking in character that the desirability of comparative study of different forms at once became evident. Up to the present time some fifty species of animals from various groups have been examined by means of the susceptibility method, either in the adult or embryonic stages or in both, in the attempt to determine to what extent regional differences or gradients in metabolic condition with respect to the axial or any other directions in the body are characteristic features of the animal organism. ${ }^{\mathrm{I}}$

In each form examined a more or less distinct and regular gradient in susceptibility has been observed in the direction of the major axis of the body and in many cases gradients in the direction of the minor axes and of the axes of various organs and parts as well. ${ }^{2}$

I The forms examined include twelve species of ciliate infusoria among the protozoa, the post-embryonic or adult stages of the freshwater hydra, and three species of hydroids among coelentrates; one ctenophore, eleven species of turbellaria, and certain larval stages of one trematode among the flatworms. Dr. L. H. Hyman, working under my direction, has examined in the same way nine species of oligochete annelids and one polychete. Susceptibility studies have been made upon the eggs and embryonic or larval stages of the following forms: starfish, sea-urchin, the polychete annelids Nereis, Chaetopterus, Arenicola, Hydroides among the invertebrates, and two species of fishes and the salamander and frog among the vertebrates.

${ }^{2}$ The data concerning susceptibility gradients, so far as they have been published, will be found in the following papers: Child, "Studies on the Dynamics of Morphogenesis and Inheritance in Experimental Reproduction, I-V, VII, VIII," Jour. of Exp. Zoöl., X, XI, XIII, XIV, XVI, XVII, I9II-I4; "Studies, etc., VI," Archiv für Entwickehngsmechanik, XXXVII, I9I3; "Certain Dynamic Factors in Experimental Reproduction and Their significance for the Problems of Reproduction and Development," Archiv für Entwickelungsmechanik, XXXV, I913; "Susceptibility Gradients in Animals," Science, XXXIX, No. 993, I9I4; "The Axial Gradient in Ciliate Infusoria," Biol. Bull., XXVI, 19r4; "Axial Gradients in the Early Development of the Starfish," Amer. Jour. of Physiol., XXXVII, I9I5. 
In organisms or parts with a radial structure gradients in susceptibility may commonly appear in the direction of the radial axis, and in those animals and developmental stages where the outer body surface consists of active living cells and is not covered by a heavy cuticle or exoskeleton a susceptibility gradient from the surface inward has been frequently observed.

In the simpler multicellular animals and in those unicellular organisms which possess definite permanent axes, the susceptibility gradients along the main body axes often persist from the beginning of development throughout life without essential change, but in many cases they undergo various changes during the course of development: they may disappear and new gradients arise with advancing differentiation and the appearance of new organs, or they may undergo reversal in direction in some or most of the tissues of the body. In all cases, however, so far as observed, such changes occur in a definite and orderly way, so that the relation between the original and the final condition is essentially constant and characteristic for a given species. In spite of the developmental alterations, it is true, as far as observations go at present, that for each of the main axes of the body a definite susceptibility gradient exists, at least during the earlier stages following the appearance of the axis, and a definite relation exists between the direction of the gradient from high to low susceptibility along a given axis and the course of development and differentiation and the functional correlation of different parts with reference to the same axis.

The following figures will serve to show something of the definiteness of the gradient along the apico-basal 
axis in single cells. Figs. $3^{-7}$ show the course of death and disintegration along the axis in Stentor coeruleus, one of the common infusoria. Fig. 3 represents the normal animal in extended condition, showing the
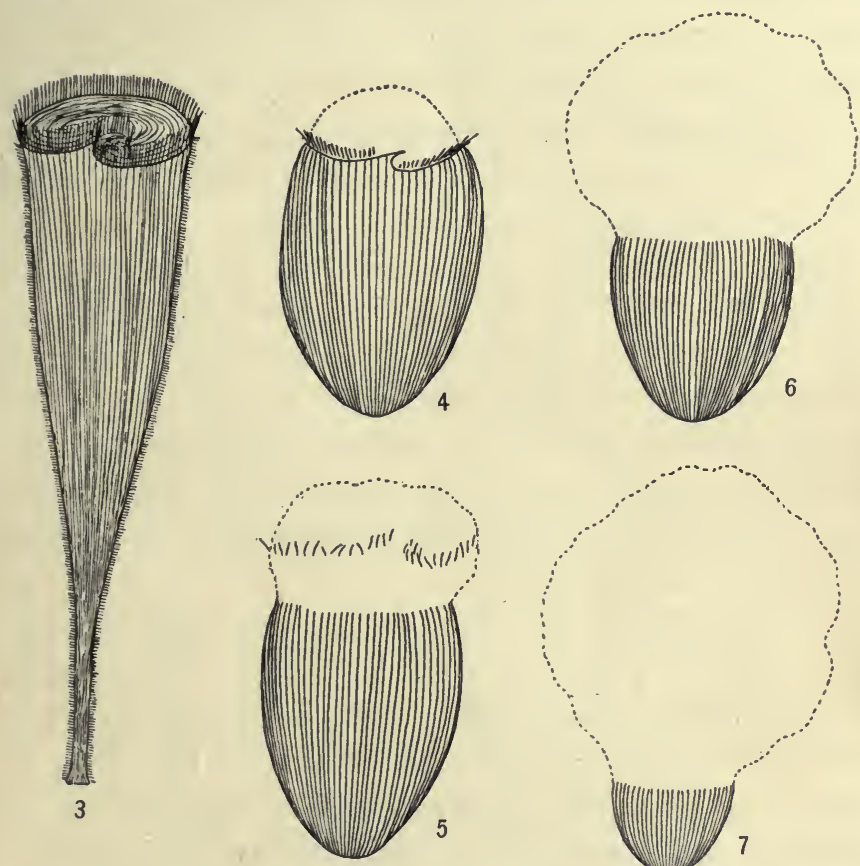

Figs. 3-7.-Axial susceptibility gradient of Stentor in cyanide: Fig. 3, intact animal; Fig. 4, beginning of disintegration; Figs. 5-7, successive stages of disintegration.

flattened peristome at the free apical end with its spiral of large cilia, the shorter cilia over other parts, the longitudinal striations or fibrillae, and the elongated basal region with organ of attachment. 
In cyanide the body undergoes some contraction, death begins at the apical end (Fig. 4) and is accompanied by the instantaneous loss of all movement and disintegration of structure in the part concerned, and the protoplasm swells and spreads out in the water, as indicated by the dotted outline in Fig. 4. Other parts remain intact and the cilia continue to vibrate. From the apical region death and disintegration proceed along the body as shown in Figs. 5-7, the line of demarkation between the dead and disintegrated and the living portions remaining distinct at all times until the progress of death ends at the basal end of the body. The rate of progress of death over the whole body may vary from a few seconds to five or ten minutes, according to concentration of cyanide used, temperature, and other conditions. Deviations from this course are very rare and are probably the result of local stimulations of one part or another of the body.

In Fig. 8 the beginning of death and disintegration in the unfertilized starfish egg is shown. The region of the egg where disintegration begins is that region where the nucleus lies nearest the surface. When the egg develops this region gives rise to the apical end of the embryo and larva. From this region disintegration proceeds through the egg along the axis determined by the eccentric position of the nucleus (Fig. 9), and this axis corresponds with the major axis of the embryo and larva. The same susceptibility gradient also appears in embryonic and early larval stages. In these cases the death gradient does not indicate the presence of more than one axis. In many forms other axes are also indicated by the course of death. In the embryo of the 
frog, for example, which is bilaterally symmetrical and in which three axes, the major or longitudinal axis and the minor transverse and dorso-ventral axes, are distinguishable in the arrangement of parts, disintegration begins first of all at the anterior end and proceeds posteriorly, and at any level of the body it begins in the median dorsal region and proceeds laterally and ventrally.

The susceptibility gradients in particular organs or parts of the body also show a relation to the axes of these parts. In the elongated tentacles of hydra and various
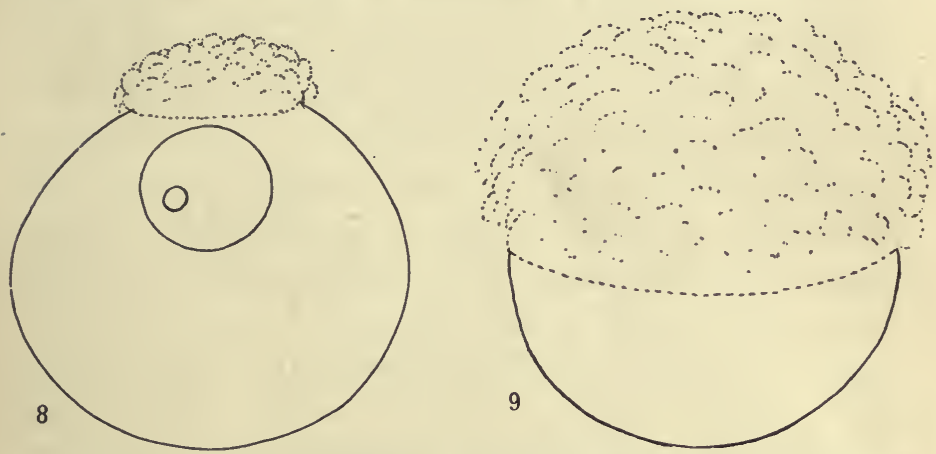

Figs. 8, 9. -Axial susceptibility gradient of starfish egg in cyanide

sea-anemones, for example, death begins at the tip and proceeds toward the base, and in nerves, so far as examined, a susceptibility gradient exists and death proceeds in the direction of conduction.

Many other examples might be cited to show the relation between the progress of death over the body and the axes with reference to which an order in the course of development, the arrangement of parts, or the behavior of the organism can be distinguished. For the present, however, it must suffice to say that the results 
of experimentation along this line have demonstrated beyond a doubt the existence of such gradients as a general feature of the constitution of the animal body.

Such susceptibility gradients may be demonstrated, not only by the course of death over the body, but by the different degrees of retardation or inhibition of growth and development at different levels under the same experimental conditions. I have described such retardation or inhibition gradients as observed in the flatworm Planaria, ${ }^{x}$ and in the development of the seaurchin I have found it possible to alter and control to a high degree the form and proportions of the larva through the differences in susceptibility along the axes to various reagents. Such gradients are also very clearly evident in many cases described by various authors of the effect of external conditions of various kinds on development. The abnormal forms produced in such experiments almost invariably indicate the existence of axial differences in susceptibility. The gradient which appears in such cases is usually the acclimation gradient, the regions of highest metabolic rate being least susceptible and so least affected, but if the external factor acts with sufficient intensity or if acclimation does not occur, the differences in susceptibility are parallel with the metabolic gradient itself. In the embryo of the frog, which has been much used for experiments of this sort, various experimental conditions may retard or inhibit developmental processes in the

I Child, "Studies on the Dynamics of Morphogenesis and Inheritance in Experimental Reproduction, IV, Certain Dynamic Factors in the Regulatory Morphogenesis of Planaria dorotocephala in Relation to the Axial Gradient," Jour. of Exp. Zoöl., XIII, I9I2. 
posterior region of the body while in the anterior region development proceeds more or less normally. In such cases the posterior regions, which possess a lower metabolic rate than anterior regions, do not acclimate to the conditions as readily as the latter and are therefore retarded or inhibited to a greater extent in their development. Such embryos produce certain characteristic forms of monsters, more or less completely normal anteriorly and increasingly abnormal in the posterior direction. Where acclimation does not play a part the anterior regions of the embryo may be most, the posterior least, affected and another type of monsters results. In many of these monstrous forms the symmetry gradients as well as the major gradient appear more or less clearly.

In fact the field of teratogeny, the experimental production of monstrous or abnormal forms, contains a large amount of evidence for the existence of susceptibility gradients, but neither the relation between susceptibility and metabolic rate nor the existence of the metabolic gradients has been recognized by the investigators in this field. There is no doubt that further experiments directly concerned with the problem of susceptibility and metabolic gradients will afford even more definite and positive results.

These gradients in susceptibility indicate the existence in the animal organism of more or less definite metabolic gradients essentially quantitative in nature. In other words, we find a definite order in the gradation of rate or intensity of general metabolic activity in directions coinciding with those in which an orderly sequence of events and arrangement of parts or an orderly behavior of the organism in other respects are 
distinguishable. Alteration or even reversal of certain gradients during development in some cases makes it necessary to distinguish between the primary gradients, existing at the beginning or in the early stages of development, and the secondary gradients, which arise by alteration of the primary.

The primary relations between the most conspicuous metabolic gradients and the chief axes of the individual is briefly as follows. The major axis is represented by a gradient in which the apical region is always primarily the region of highest, and the basal, that of the lowest, rate of reaction. Stated in different terms, the region of highest metabolic rate in this gradient always gives rise in development to the apical region or head of the animal, the region of lowest rate to the basal or posterior end. In radial gradients the region of highest rate may be either peripheral or central according to the character of the radius. In bilaterally symmetrical animals the relations differ in different cases. In at least most bilaterally symmetrical invertebrates the median ventral region is primarily the apical region of the minor body axes, and from this region gradients of decreasing rate extend laterally and dorsally. In the vertebrates, on the other hand, the median dorsal region is primarily the apical region, and gradients of decreasing rate extend laterally and centrally. The fact must be emphasized that these are the general and primary relations and that they may be altered in various, but always orderly and definite, ways during the development of the individual.

These facts indicate very clearly that the chief axes of the animal body are represented dynamically by metabolic gradients and that each organ or part arises 
in a relation to one or more of these gradients which is definite and characteristic for each kind of organism. The relation of the central nervous system to these gradients is highly significant. The apical portion of the central nervous system, the cephalic ganglion or brain, always arises in the region of highest metabolic rate in the whole body, the apical region of the major axis, and such portions of the central nervous system as appear in other parts of the body, e.g., the longitudinal ganglionic nerve cords of various invertebrates and the spinal cord of vertebrates, always arise in the regions of highest rate in the minor axial gradients. In the bilateral invertebrates this is the median ventral, in the vertebrates the median dorsal, region. In short, it may be said that where a central nervous system is present it is the organ characteristic of the apical, i.e., the dominant, region in each of the chief axial metabolic gradients. The functional dominance of the central nervous system in the later life of the animal is then simply a more highly specialized expression of the primary relation of dominance and subordination existing at the beginning of individuation between regions of high and those of lower metabolic rate.

As regards plants, I have as yet examined only some fifteen species of marine algae, but in all of these the apical region of each axis shows the highest susceptibility to the higher concentrations of cyanides and the susceptibility decreases very markedly in the basal direction. In these plants there is no such disintegration at death as in the lower animals, although in the more transparent forms the breaking up and coagulation of the protoplasm can be observed inside the cell. By first 
staining the plants with neutral red and then killing with cyanide or some other reagent the susceptibility gradient can be made visible, for as the cells die the red of the stain at first becomes deeper because of increasing acidity, then changes to yellow as the alkali of the solution enters, and finally all color disappears.

FURTHER PHYSIOLOGICAL EVIDENCE FOR THE EXISTENCE OF METABOLIC GRADIENTS

The susceptibility gradients do not constitute the only experimental evidence for the existence of metabolic gradients in the organism. Estimations of carbondioxide production by means of the Tashiro biometer, ${ }^{\mathrm{I}}$ which were made by Dr. Tashiro at my request, have confirmed the results obtained by the susceptibility method in all cases subjected to this test. The gradient in carbon-dioxide production is similar to the gradient in metabolic rate indicated by the differences in susceptibility. On the other hand, in the case of certain nerves I have been able to confirm Tashiro's recent discovery of a gradient in carbon-dioxide production in the direction of conduction of the impulse along the fiber by the demonstration of a gradient in susceptibility in the same direction, and have found a similar susceptibility gradient in certain other nerves for which carbon-dioxide production has not been determined. The gradient in the production of carbon dioxide indicates the existence of a gradient in the rate or intensity of the respiratory processes, the oxidations, the region

I Tashiro, "A New Method and Apparatus for the Estimation of Exceedingly Minute Quantities of Carbon Dioxide," Am. Jour. of Physiol., XXXII, I9r3. 
of highest carbon-dioxide production being the region of highest respiratory rate. Since the oxidations are unquestionably reactions of fundamental importance in the metabolic reaction system, the estimations of carbon-dioxide production lead to the same conclusions concerning the existence of metabolic gradients as do the results obtained by the susceptibility method.

So far as technical and other sources of error can be eliminated, the rate of oxygen consumption of different parts of the body may be used like the rate of carbondioxide production as a measure of respiratory activity. The use of this method in animal physiology has been such that the data, while of great value for various other purposes, have in most cases no bearing upon the problem of metabolic gradients. In the plants, however, the rate of both oxygen consumption and carbon-dioxide production have been found to differ in different parts in such a way as to indicate very clearly the existence in the plant-body of metabolic gradients. The growing bud, for example, respires at a higher rate than the full-grown stem or leaf.

Differences in electrical potential indicating differences of some kind in chemical or physical activity are known to occur very generally in different parts of both animal and plant organisms and even in different parts of the same organ or cell. The presence of these electrical differences gives no clue to the exact nature of the physical or chemical differences which produce them, but it is becoming more and more evident that in both animals and plants they are to a large extent associated with differences in metabolic activity. So far as this is the case, we should expect in general that 
parts with a higher respiratory rate would appear by the usual methods as electro-negative to regions of lower rate.

Some twelve years ago Mathews ${ }^{\mathrm{T}}$ observed a difference in electrical potential along the main axis of certain simple animals, the hydroids, the parts nearer the apical end being electro-negative to those nearer the basal end. In these forms the susceptibility method indicates that the metabolic rate decreases from the apical toward the basal end; that is, in the same direction as the decrease in electro-negativity. Probably a similar electrical gradient exists in nerves, although in the nerves of the higher animals the change is undoubtedly very slight within the physiological limits of length. As regards the plants also various data on the differences of electric potential suggest the existence of metabolic gradients, although the fact that the observations were made with other objects in view often leaves the evidence inconclusive as regards the matter of gradients.

In the early stages of development of the starfish I have been able to make the axial metabolic gradient directly visible to the eye by differential staining in the living animal, ${ }^{2}$ the stain in this case consisting of a colored precipitate formed within the cells by the oxidation of certain substances added to the water. The rate of formation of this precipitate in different cells differs with the amount or activity of enzymes or other conditions which influence the rate of oxidation. In those

I A. P. Mathews, "Electrical Polarity in the Hydroids," $A m$. Jour. of Physiol., VIII, I903.

2 Child, "Axial Gradients in the Early Development of the Starfish," Am. Jour. of Physiol., XXXVII, I9r5. 
cells where the rate of oxidation is highest the precipitate is formed most rapidly and vice versa. In the starfish embryos and early larvae the precipitate appears first in the cells of the apical region, and a very definite color gradient along the main axis arises in living animals, while in animals which have been killed before staining no gradient appears. This method is undoubtedly capable of wide application.

These various methods and results indicate the possibilities of demonstrating the existence of the metabolic gradients in organisms by biochemical and physiological methods. Unquestionably future investigation will give us much more accurate and extensive data than we possess at.present.

EMBRYOLOGICAL EVIDENCE FOR THE EXISTENCE OF AXIAL METABOLIC GRADIENTS

Gradients in rate of cell division, size of cells, condition or amount of protoplasm in the cells, rate of growth, and rate and sequence of differentiation are very characteristic features of both animal and plant development. Such gradients are definitely related to the axes of the individual or its parts, and are evidently expressions of axial metabolic gradients. While the existence of such gradients indicates the existence of gradients in activity of some sort, the various kinds of gradients are not all necessarily present where metabolic gradients exist. In some cases the visible gradient may be a gradient in rate of growth or in protoplasmic constitution; in still others a gradient in sequence of differentiation, etc., and sometimes metabolic gradients exist without any structural indiçations of their presence. 
At best these various kinds of gradients are merely general indications of differences in metabolic rate, and undoubtedly in many cases the visible differences along an axis represent something more than differences in metabolic rate. The important point is that visible indications of graded differences in metabolic rate occur so generally in definite relations to the chief axes of the body.

In the animal egg a gradient in the distribution of the yolk is often visible before development begins, and in such cases that part of the egg which gives rise to the apical region of the embryo contains less yolk than the basal region. Associated with this gradient in most cases we find differences in the size of cells appearing in very early embryonic stages. In the egg of the frog, which is an excellent example of this sort of egg, the yolk gradient is very distinct, and the early developmental stages show a gradient in the same direction in the rate of cell division and the size of the cells formed (Figs. IO, II). The yolk gradient and the associated gradient in cell division differ widely in different kinds of eggs: in some cases only the apical region of the egg divides at all, other parts serving as a source of nutrition which is gradually used up during development. At the other extreme are cases in which no yolk gradient is distinguishable and differences in division rate and size of cells do not become evident until later stages.

In all cases developmental gradients of some sort appear sooner or later as expressions of the metabolic axial gradients and usually become more distinct as morphological development proceeds. The so-called law of antero-posterior development is a partial recogni- 
tion of this fact. This "law" is merely a statement of the observed fact that in the development of the animal from the egg organs first become morphologically visible in that region which becomes the anterior or apical end, and from this region morphogenesis proceeds posteriorly or basally in a regular, orderly manner. In short, a gradient in morphogenesis exists along the major axis of the body, the apical end preceding. In addition to this major gradient more or less definite morphogenic gradients appear in relation not only to
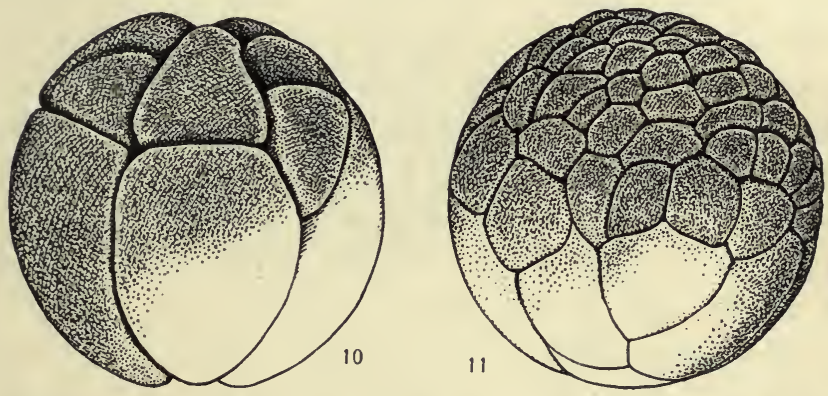

Figs. Io, Ir.-Two stages of cleavage of frog's egg, showing axial gradient in cell size resulting from gradient in rate of division.

the minor axes of the whole body, but also in relation to the axes of particular organs or parts. In fact the law of antero-posterior development is merely a statement for the major axis of the more general law of axial developmental gradients.

Embryonic stages of a flatworm among the invertebrates and the chick among the vertebrates will serve to show these developmental gradients. Fig. I2 is a diagrammatic outline of the adult stage of a small bilaterally symmetrical flatworm, showing "brain," 
pharnyx, and alimentary tract; Fig. I3 is a longitudinal section, almost in the median plane, of an embryo of the same species. The anterior end is toward the left.
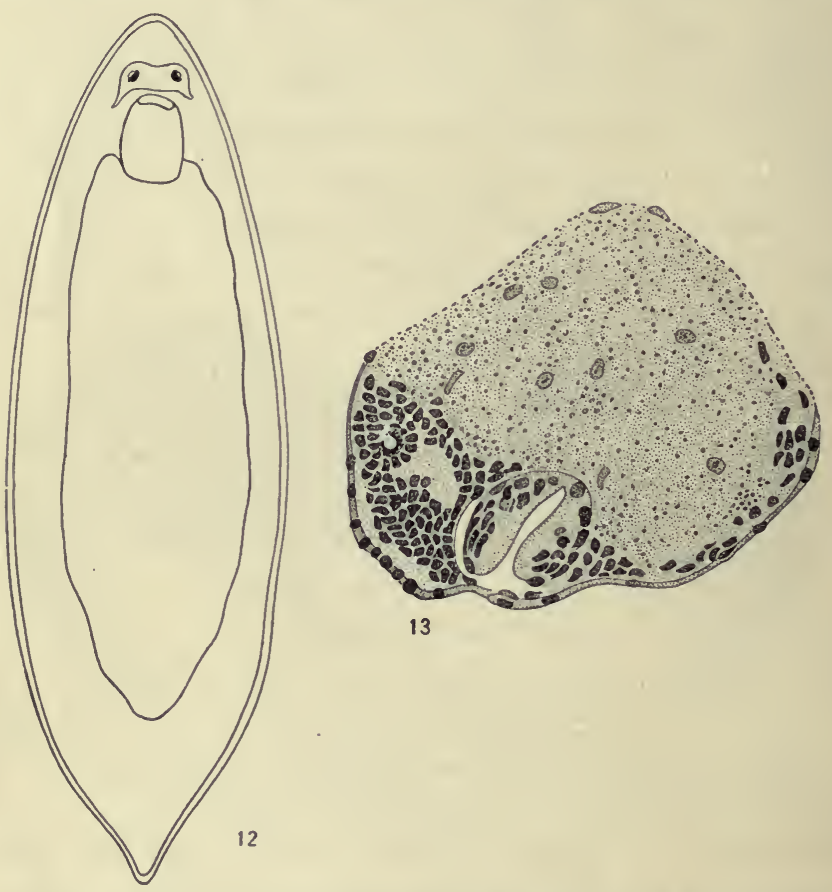

13

Figs. I2, I3.-Axial developmental gradients in flatworm, Plagiostomum girardi: Fig. I2, outline of adult worm, showing eyes, cephalic ganglia, pharynx, and alimentary tract (after von Graff); Fig. I3, longitudinal section near median plane of embryo, head at left, showing the apico-basal or longitudinal and ventro-dorsal gradients in rate of development (from Bresslau).

The organs of the anterior end, the brain and pharnyx, consist of numerous cells, and the morphological arrangement is already apparent, while the whole postpharyn- 
geal region, which in the adult is by far the larger part of the body, is very short and consists of but few cells. This major gradient is very distinct, but the ventrodorsal gradient is also evident. The section shows that multiplication of cells and structural development are proceeding chiefly in the ventral region, while the dorsal region consists of relatively few cells. Examination of transverse sections of embryos would show the transverse gradients: we should find that the development was proceeding more rapidly in the median ventral region than in the lateral regions. The transverse and the ventro-dorsal gradients are in reality different components of the same gradient. The fact is that a developmental gradient extends laterally and dorsally from the median ventral region. In such a bilaterally symmetrical animal there are then two chief developmental gradients, a major, from the anterior region posteriorly, and a minor, from the median ventral, or in some cases most of the ventral region, laterally and dorsally. In other bilaterally symmetrical invertebrates relations are in general similar. In Fig. 2 (p. 38) the relations in a simple case of this sort are diagrammatically indicated.

In the vertebrates the longitudinal gradient is similar to that in the invertebrates, but instead of a ventro-latero-dorsal gradient, as in the invertebrates, the gradient is dorso-latero-ventral in direction. Fig. I4 represents an early stage of the chick embryo in which the head is just becoming morphologically distinct, but other organs are not yet formed, while in Fig. I5, a later embryonic stage, the head region is advanced in development, and differentiation of the body is 
progressing posteriorly, the successive formation of the somites or segments being a conspicuous feature of this progress. Fig. $\mathrm{I} 6$ is a transverse section of an early
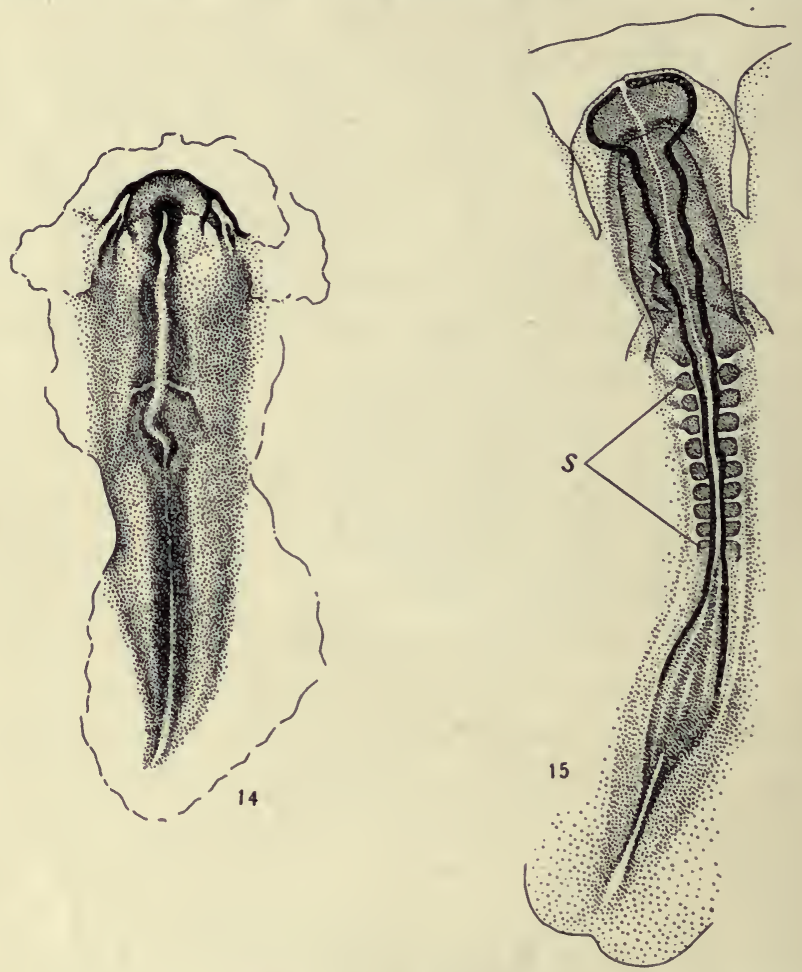

FIGS. 14, I5.-Surface views of two early stages in embryonic development of chick, showing progress of development in basal direction from the head-region (upper end) and laterally from the median region; $s$, somites (from F. R. Lillie).

stage before distinct organs have begun to form. At this time cells are separating from the outer layer of the body in what will later become the median dorsal 
region, and passing inward to form the mesoderm. Most of the region of the embryo behind the head in
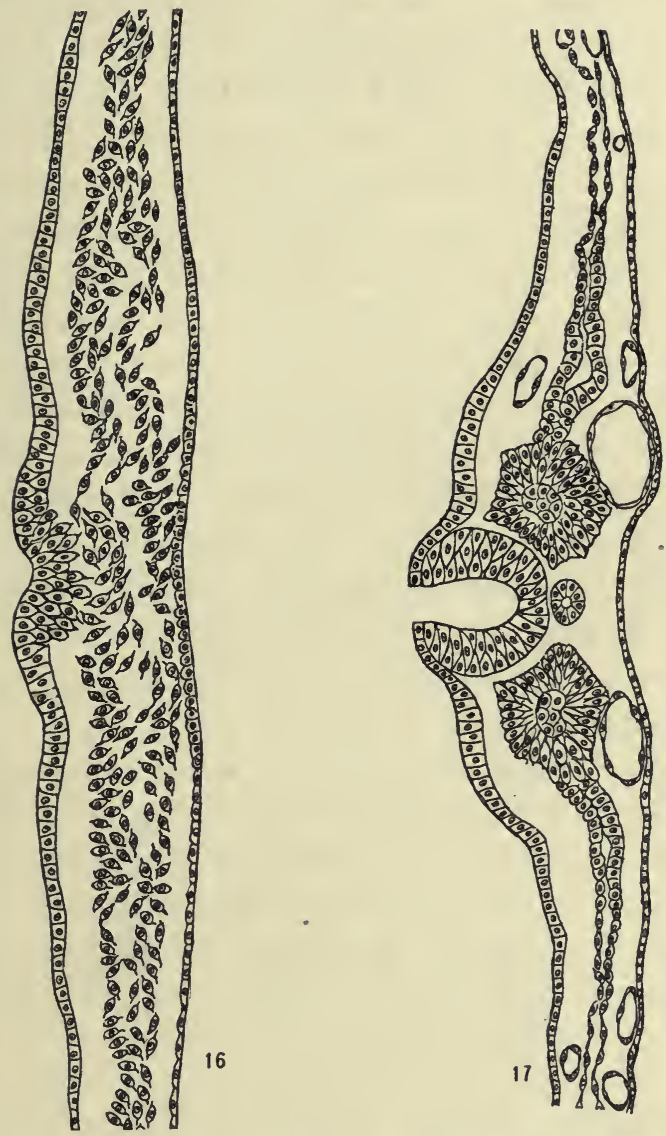

FIGS. I6, I7.-Transverse sections of chick embryo at different levels, to show developmental gradients.

Fig. I4 and the extreme posterior region of the embryo in Fig. 15 are at about this stage of development. 
Fig. I 7 is a transverse section at a stage of development corresponding to that attained at the level of the sixth somite of the embryo in Fig. I5. At this stage the embryonic nervous system is present in the form of a tube open dorsally, and differentiation has progressed both laterally and ventrally from the median dorsal region. In the other vertebrates, including the mammals, the developmental gradients are similar.

Differences in rate of growth constitute another feature of these developmental gradients, but the relation between the axial metabolic gradient and rate of growth is not simple, for the period of highest growth rate occurs at different times in different parts according to the time of their formation, and it may happen at certain stages of development that the rate of growth at the apical end of a metabolic gradient is lower than at the basal, because the region at the apical end began its growth first, has grown at a more rapid rate, and is therefore completing its growth earlier than the region at the basal end. Nevertheless, so far as it is possible to compare corresponding stages in the development of different parts, along an axial gradient, differences in rate of growth corresponding to the gradient do appear. The head-region, for example, at the stage of highest growth rate grows more rapidly than the posterior region of the body at its stage of highest rate, and similar relations exist with reference to other gradients.

In the egg of the plant as well as in that of the animal developmental gradients usually appear in early stages. In the eggs of many of the lower plants the first division is transverse, the two cells thus formed representing apical and basal regions of the plant, and in most of the 
plant groups a more or less definite relation exists between the directions of the early divisions and the major axis of the embryo. In these cases a more or less distinct gradient in division rate, cell size, and cellular constitution usually appears either at the beginning of development or in early stages. On the one hand, this gradient shows a definite relation to the position of the egg with respect to surrounding parts of the parent organism, and, on the other, the region of smallest size and most rapid division of the cells and most abundant and deeply staining protoplasm is the region of highest rate of reaction and becomes the apical region of the embryo. Fig. 18 shows this gradient in the embryo of a moss, the uppermost cell in the figure representing the apical region of the embryo.

In most of the higher plants only a portion of the egg takes part in the formation of the embryo, the remainder forming a suspensor, a stalk on which the embryo is carried. Fig. I9 shows the cellular gradient in the early developmental stage known as the proembryo of Ginkgo, a gymnosperm related to the conifers. The embryo proper arises later from the small-celled tissue in the lower part of the developing egg. Some of the cycads also show a very definite gradient of this sort. In the angiosperms, the higher seed plants, where the egg is attached to the wall of the embryo-sac, the embryo arises from its free apical end.

A characteristic feature of the plant individual in all except the simplest forms is the growing or vegetative tip. This growing tip is the region of most active nuclear division and growth and with rare exceptions forms the free end of the individual and gives rise to 
other parts of the plant body. In the complex higher plant, stems, branches, buds, roots, and various other parts possess a growing tip, at least during earlier stages, and each such part is to a certain extent an individual.

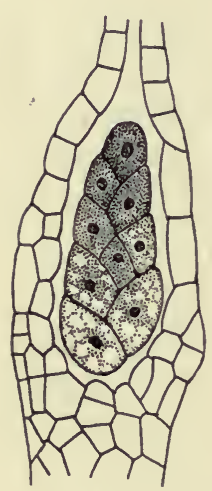

18

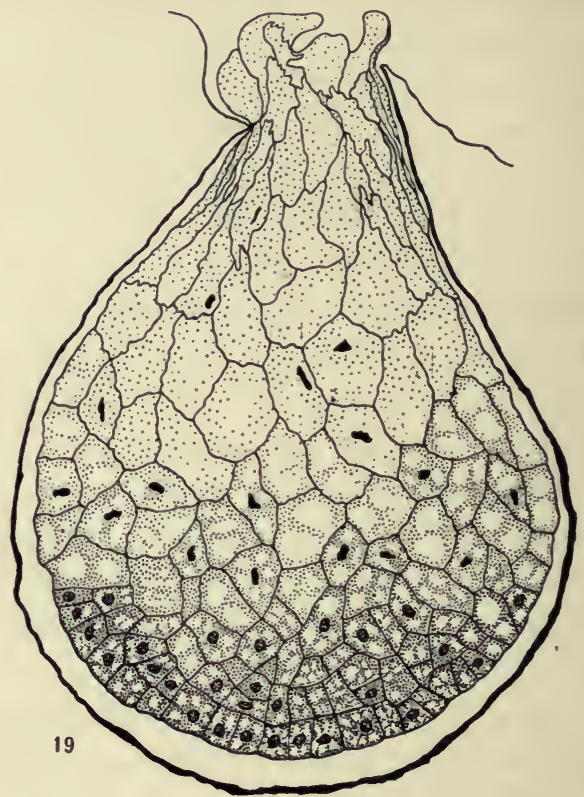

Figs. 18, I9.-Axial developmental gradients in embryonic stages of plants: Fig. I8, embryo of moss, apical cell at upper end (from preparation loaned by W. J. G. Land); Fig. 19, proembryo of gymnosperm (Ginkgo); apical region of plant arises from lower end (from Lyon).

In most of the lower plants a single cell forms the apex or center of the growing tip, and it may be larger than other cells with a gradient of decreasing size extending from it, as in the stem of the alga in Fig. 20, but during the course of plant evolution the apical cell gradually 
gives place to an apical region, consisting of several or many cells, and in the course of this change the apical cell itself becomes relatively smaller, and a gradient of increasing size extends from the apical region (Figs. I8, 36). The gradients in size in different forms depend

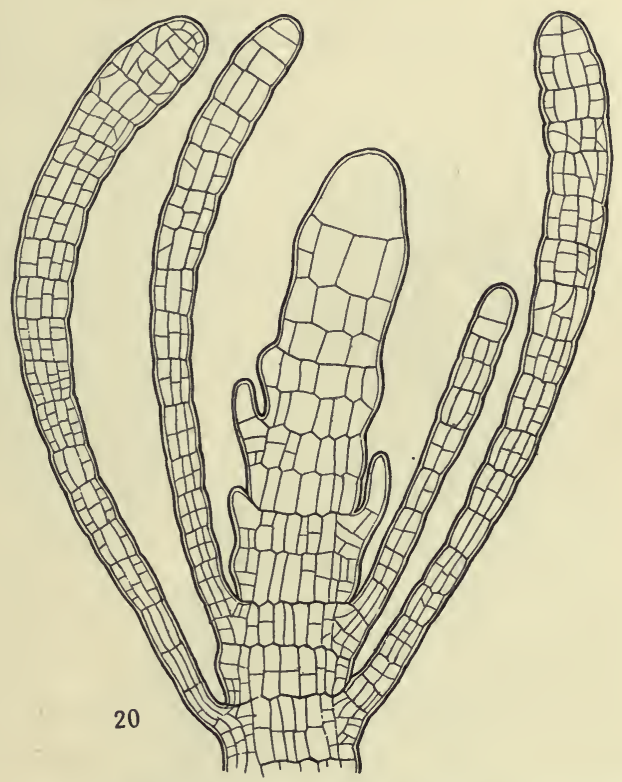

FIG. 20.-Axial gradient in cell size in alga Cladostephus (from Pringsheim).

upon the relation between frequency of division and growth in size of the apical cell, and this relation shows a characteristic range in each form. Even where the whole plant body is a single multinucleate cell, the apical regions of stem and branches are undoubtedly physiologically growing tips. In the higher plants the 
growing tip consists of several or many cells. Figs. 2 I and 22, longitudinal sections through the growing tips of a stem and a root respectively, show the gradients in cell
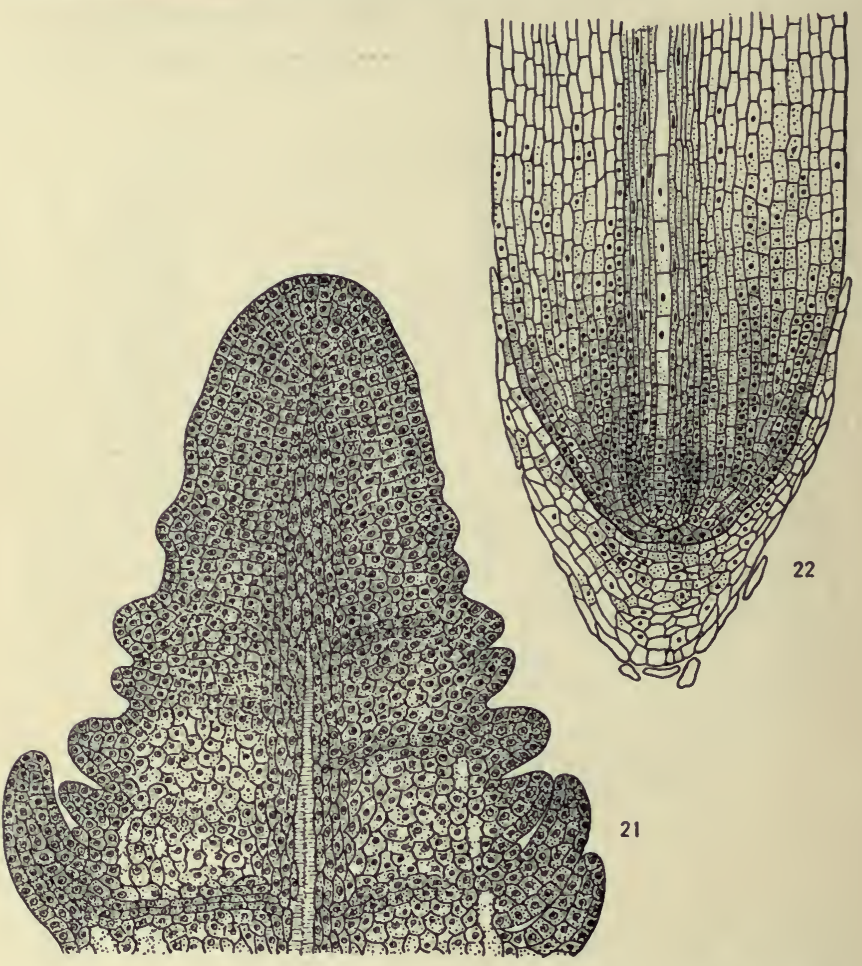

Figs. 2I, 22.-Axial developmental gradients in growing tips of seed plants: Fig. 21, stem-tip of Hippuris; Fig. 22, root-tip of Tradescantia (from preparations loaned by Department of Botany, University of Chicago).

size and protoplasmic condition which extend from the growing tips. In the stem-tip these gradients extend to a much greater distance than in the root-tip and Fig. 2 I shows only a fraction of them. 
In the development of the plant the growing tip is the first part of the individual to become distinguishable, and from it other parts arise. In the moss embryo in Fig. 18 the growing tip is already present as the uppermost cell and other cells have arisen from it in an orderly way. In the higher plants the growing tip is not usually localized until later stages. In Gingko, for example, the growing tip of the plant is not yet distinguishable at the stage of Fig. I9, although the small-celled region is the growing tip of the whole proembryo and in this the growing tip of the plant-stem later appears. In certain algae the major axial gradient in the egg is apparently determined by external factors, such as light, but in most plants this gradient is determined by the relation of the egg to the parent body, the growing tip of the plantstem arising from the apical region of this gradient.

The vegetative stages of certain liverworts and the sexual generation of various ferns show a high degree of bilateral symmetry and often consist, at least during the earlier stages of their growth, of single elongated flattened individuals (Figs. 23, 24) with a growing tip, $a$, at one end, often with a thickened longitudinal midrib and with root-like outgrowths on the ventral surface, the surface facing the substratum as the plant grows. In many cases these individuals undergo division by branching or by the formation of buds on the surface in later stages. In these plants, as in bilaterally symmetrical animals, three axes-longitudinal, transverse, and dorso-ventralare distinguishable; in other words, order is apparent in three directions. Various indications of gradients in activity appear in the same directions. As regards the major axis, the rate of cell division and growth is highest 
in the apical region and decreases basally; as the plant grows older, death may even begin at the basal end and proceed apically while the apical end is still growing actively. Evidences of a transverse gradient in activity appear in a decrease in growth toward the lateral margins and in many forms in a decrease in thickness of the body in the same direction. In the direction of the

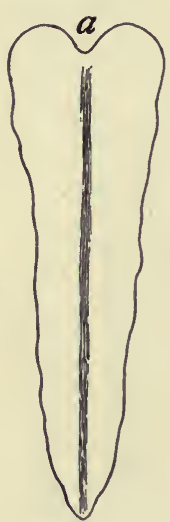

23

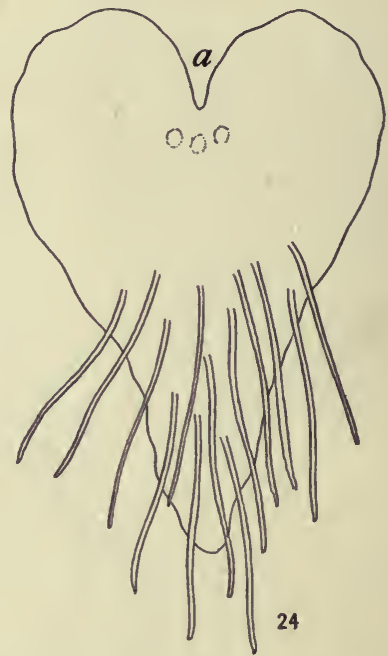

Figs. 23, 24.-Bilaterally symmetrical prothallia of liverwort, Marchantia (dorsal view), and a fern (ventral view).

dorso-ventral axis which is determined by the action of light and perhaps other external factors, the differences in metabolic activity are indicated by the outgrowth of root-like structures and the sexual organs, and in some forms of scales or leaf-like structures on the ventral surface, and also in some forms by the greater density of cellular structure in the ventral region. 
DEVELOPMENTAL GRADIENTS IN AGAMIC AND EXPERIMENTAL REPRODUCTION

Among the lower animals and most plants new individuals arise, not only by the process of gametic or sexual reproduction, but by various agamic or asexual processes, such as division, budding, etc. These processes vary greatly in different forms and even in the same individual under different conditions, but their essential feature is the formation of a new individual from a part of a pre-existing individual, a process which usually involves more or less dedifferentiation and redifferentiation in a new direction. Although these agamic reproductive processes differ more or less widely from embryonic development, the metabolic gradients characteristic of the individual either persist from the original individual or arise anew in each case, and developmental gradients of some sort appear in relation to them.

In the formation among animals of new individuals by budding, as, for example, in the hydroid, Pennaria (Figs. 25-27), the hydranth becomes distinguishable first, the stem later, and closer examination shows that apical regions of the hydranth are somewhat in advance of basal. In Figs. 26 and 27, for example, the apical tentacles are more advanced in development than the basal.

In the flatworm, Stenostomum, division occurs after the body attains a certain length, the first visible indication of the new individual being the appearance of a new head-region (Fig. 28) at a certain distance from the original head. This new head-region acquires control of parts posterior to it and finally separates as a new animal. By continued division before separation of 
each new individual thus formed chains of from eight to sixteen individuals or zooids, as they are usually called, in various stages of development may result

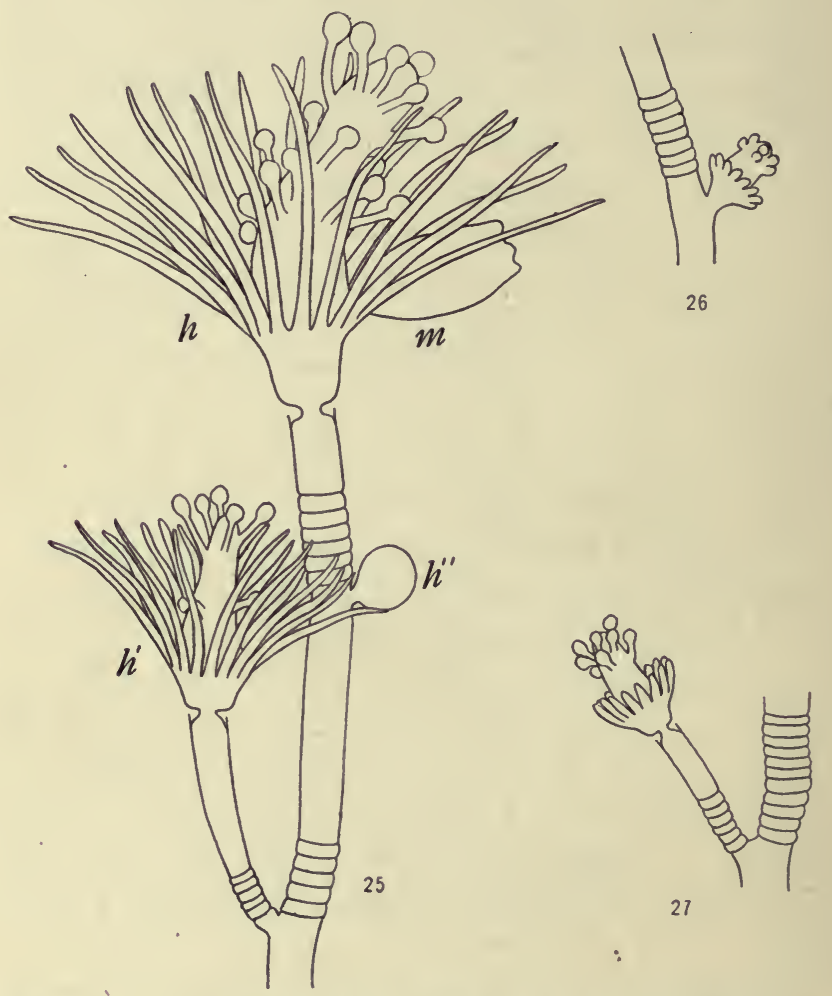

FIGS. $25^{-27 .-P e n n a r i a ~ t i a r e l l a: ~ F i g . ~} 25, h, h^{\prime}, h^{\prime \prime}$, Figs. 26 and 27 , stages of development of hydranth; $m$, medusa bud.

(Fig. 29). Many other cases of division among animals are essentially similar.

In many of the lower animals agamic reproduction can be induced experimentally by isolating pieces. In 
the flatworm Planaria (Fig. 30) a piece such as $a$ or $b$, or almost any other piece, cut from the body will develop into a whole animal of small size by the formation of a new head at one end and a new tail at the other and a transformation and redifferentiation of the internal organs of the piece into those of a whole animal as indicated in Figs. $3 \mathrm{I}^{-}-33$. In the outgrowth of the new tissue at the two cut surfaces the axial gradients appear as gradients in rate of growth. Fig. 3I shows that the outgrowth of new tissue is more rapid at the apical than at the basal end of the piece and more rapid in the median than in the lateral region of each cut surface, and Fig. 34, a side view of the piece, shows more rapid outgrowth at each end in the ventral than in the dorsal region. In this case the axial gradients in the piece persist from the parent individual, and the head arises at the apical end of the piece, the tail at the basal end. In other cases of experimental reproduction from isolated pieces the axial gradients appear either in the same or in some other way
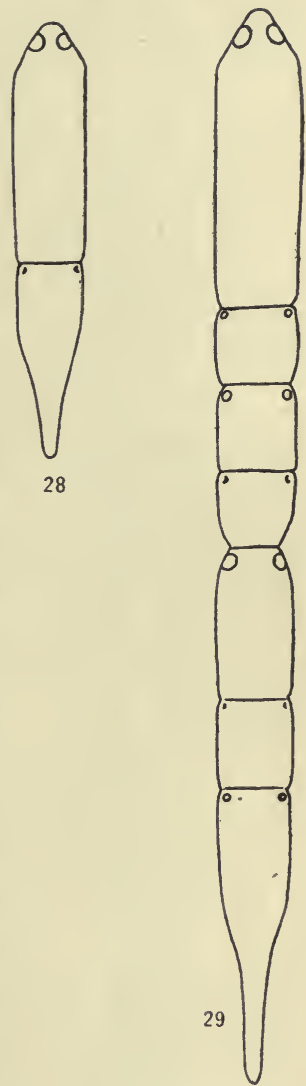

Figs. 28, 29.-Asexual reproduction in flatworm, Stenostomum: Fig. 28, stage of two zooids; Fig. 29, chain of several zooids.

according to the kind of individual and the conditions. 
In agamic reproduction in plants each new individual arises as a localized region of growth and the growing tip is the first region to become clearly defined. New
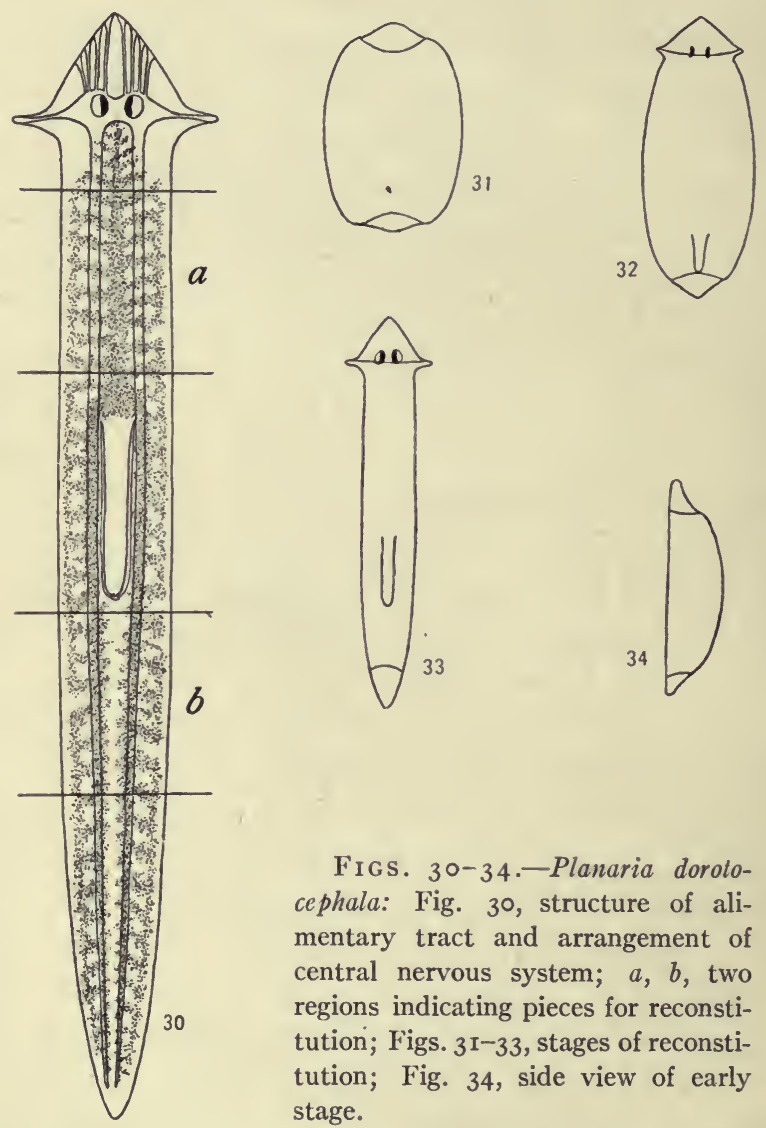

Figs. 30-34.-Planaria dorotocephala: Fig. 30, structure of alimentary tract and arrangement of central nervous system; $a, b$, two regions indicating pieces for reconstitution; Figs. 3I-33, stages of reconstitution; Fig. 34, side view of early stage.

buds, new roots, and other parts arise in this way in nature and under experimental conditions. The small outgrowths along the sides of the growing stem-tip in 
Fig. 21 (p. 76) are stages in the formation of leaves and the developmental gradients appear to some extent in them.

In many plants new "adventitious" individuals arise, either in nature or under experimental conditions, from cells already differentiated as part of an'individual. In the liverwort, Metzgeria, new individuals may arise either by division of the growing tip resulting in bifurcation of the flat body, as shown in Fig. 35, $a$, a, or after injury to, or removal of, the growing tip by a renewal of division and growth in differentiated cells. Fig. 36 shows the cellular structure of the growing tip in a well-developed individual and Fig. 37 the early stage of a new individual formed from a differentiated cell. In both figures the gradient in cell size is clearly evident.

Among the higher seed plants, as well as among lower forms, the "adventitious" formation of new individuals from differentiated cells occurs, as for example in the begonias, where buds capable of producing new plants arise under certain experimental and natural conditions from the epidermal cells of leaves. The epidermal cells which take part in the formation of such a bud lose their differentiated, vacuolated condition, become filled with protoplasm, like embryonic cells, and divide rapidly. Fig. 38 is a surface view of the formation of such a bud involving several epidermal cells, but centered chiefly in parts of four cells, and Fig. 39 is a longitudinal section through a bud formed from two cells. The double contours in Fig. 38 show the thickened cellulose walls of the original epidermal cells, the single contours within them the cells formed by their repeated division, 
and the shading indicates in a general way the disappearance of the vacuoles and the filling of the cells with

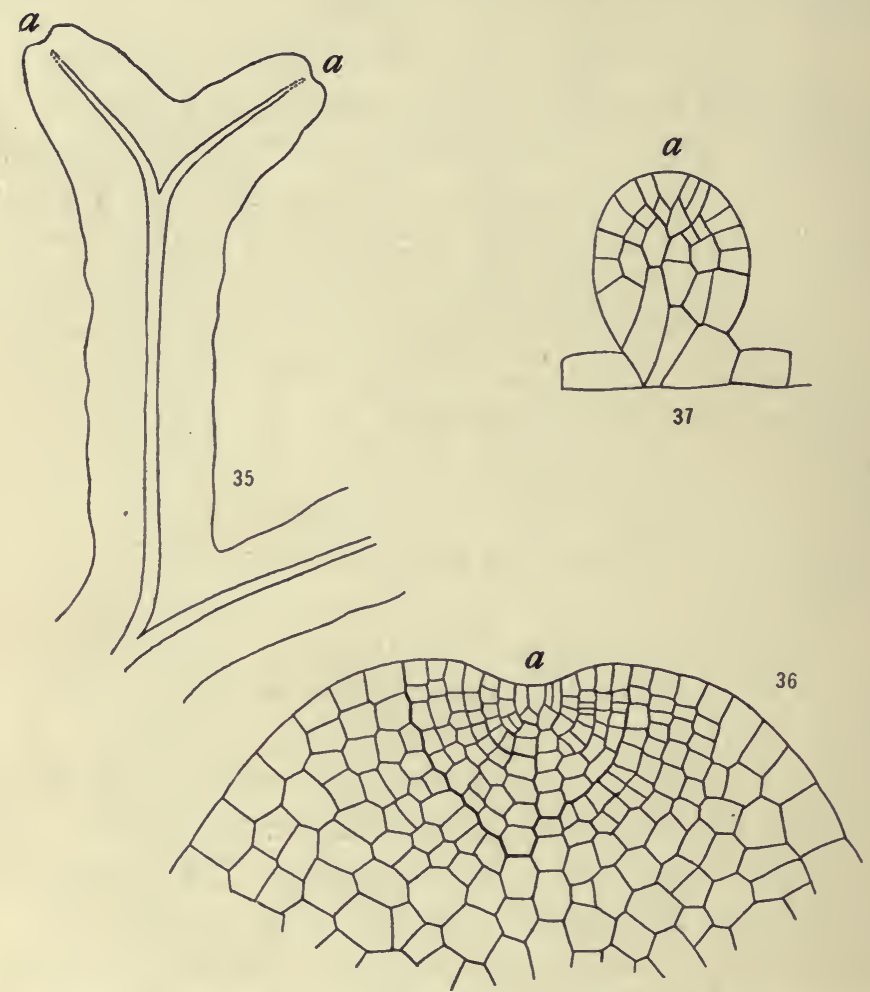

Figs. 35-37.-Metzgeria, a liverwort: Fig. 35, portion of prothallium, showing midrib and apical regions, $a, a$; Fig. 36 , cell structure of growing tip, showing apical cell, $a$, and gradient in cell size; Fig. 37, cell structure of an adventitious bud, showing apical cell, $a$, and gradient in cell size (Figs. 36, and 37 from Goebel).

protoplasm. A gradient in cell size and protoplasmic condition appears in both cases, in Fig. 38 from the center to the periphery of the region involved and in 
Fig. 39 from the upper part at the free surface of the leaf downward. These gradients are evidently the

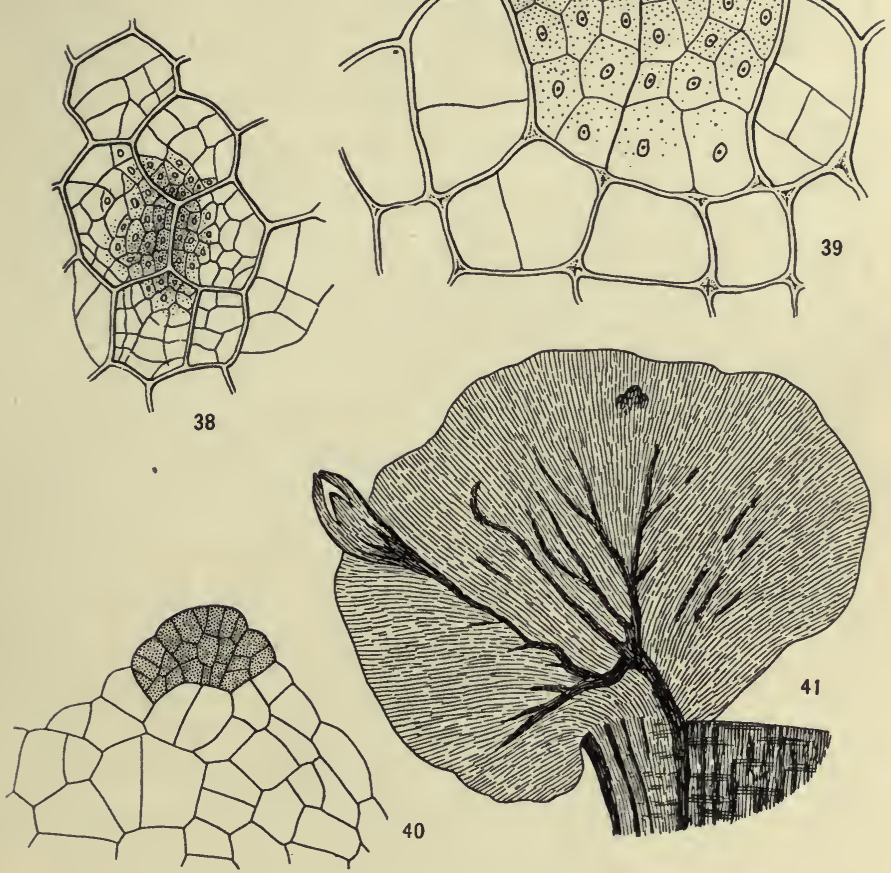

Figs. 38-4I.-Origin of adventitious buds in seed plants: Fig. 38, surface view and Fig. 39, section of bud arising from differentiated epidermal cells of leaf of Begonia (from Regel); Figs. 40, 4I, development of bud in callus (from Simon).

visible expression of gradients in metabolic activity, the smallest, most protoplasmic cells indicating the region of most intense activity, and it is from this most active 
region that the apical vegetative tip of the new plant individual develops.

In many woody plants the cut end of a stem or branch develops a mass of wound tissue, the callus, and in this callus new buds arise independently of other parts of the plant and become connected with them secondarily. In all such cases the differentiation of the vascular bundles which connect the new buds with the old parts proceeds from the buds. Fig. 40 shows an early stage of bud-formation in the poplar at the periphery of a mass of callus on the cut end of a stem, and Fig. 4r, a later stage in which vascular connection with other parts has been established. In such cases the appearance of the new bud is the first step in the formation of the new individual; it is followed by the appearance of a gradient in growth and differentiation from the bud toward other parts.

In isolated pieces of plants the formation of new growing tips or the outgrowth of resting buds occurs in certain more or less definite portions with relation to the axes. The removal of the chief growing tip of a stem results in outgrowth or altered growth of the uppermost buds or branches. When these are removed those lower down react, and so on. Evidently a gradient in the capacity to respond or in the rate of response to the altered conditions exists along the major axis, and those buds or branches which react first dominate those below them and prevent them from reacting in the same way.

In isolated pieces of the bilaterally symmetrical liverworts, such as Marchantia (Fig. 23, p. 78), the position of the new buds evidently represents the region 
of highest metabolic rate in the piece as a resultant of the three axial gradients (see Figs. 99-102, p. 167), and the formation of new individuals in these regions inhibits their formation elsewhere, although practically every cell of the plant-body is capable under proper conditions of giving rise to a new individual.

\section{CONCLUSION}

All the various lines of evidence considered agree in showing that axial gradients in the dynamic processes are characteristic features of organisms and that a definite relation exists in each individual between the direction of the gradient in any axis and the physiological and structural order which arises along that axis. In the major axis the region of highest rate in the metabolic gradient becomes the apical or anterior region of the individual, and in the minor axes also the regions of highest rate in the gradients represent particular features of the order in each case. Along any axis particular parts apparently represent particular levels in the gradients. The variety, extent, and agreement of the evidence is all the more interesting in view of the fact that such gradients have not heretofore been recognized as characteristic features of organic constitution. 


\section{CHAPTER IV}

\section{PHYSIOLOGICAL DOMINANCE IN THE PROCESS OF INDIVIDUATION}

According to the theory outlined in chap. ii, the organic individual is fundamentally a dynamic relation of dominance and subordination, associated with and resulting from the establishment of a metabolic gradient or gradients. In the present chapter some of the evidence for the existence of dominance in the process of individuation is considered.

This evidence is obtained primarily from the experimental reproductions, because only here is it possible to analyze and control the process of individuation to any considerable degree. The egg is usually a more or less highly specialized individual at the time embryonic development begins, and the earlier stages of its individuation commonly occur in such relations to the parent body that they are not readily accessible to experimental investigation. Nevertheless, the evidence indicates very clearly that the process of organic individuation is fundamentally the same in the egg and embryo and in experimental reproduction.

The evidence presented here concerns primarily the major axis, because the facts are simpler and more complete with respect to this axis. Experimental isolation of pieces with reference to the minor axes is usually complicated by the presence of the major gradient, and the order along the major axis is often such that parts necessary for continued life are absent from various 
regions of the minor axes. For these reasons the experimental investigation of dominance and subordination in relation to the minor axes is variously complicated and limited in different cases. Nevertheless, the fundamental similarity of the different directions of order in the individual is indicated by various lines of evidence, and there are no grounds for hesitation in extending to the minor axes general conclusions reached concerning the major axes.

\section{THE EXPERIMENTAL MATERIAL}

Reproduction can be induced experimentally in the plants and many of the lower animals by the isolation of pieces and in various other ways. These experimental reproductions, when properly controlled and analyzed, constitute invaluable material for study of the problem of the individual, for it is often possible to increase or decrease dominance and so to extend or decrease its range, to alter the conductivity of protoplasm, to determine the elimination of old and the establishment of new metabolic gradients, and in these and other ways to control the process of individuation to some extent, and to determine the results of such control.

Most plants and many of the lower animals give rise to new individuals by division, budding, and other agamic processes, and the new individuals thus formed often remain organically connected and give rise to a composite individual, such as a tree among plants or a hydroid colony among animals. In such reproductions definite and orderly space or distance relations are observable, which themselves suggest the existence of a limited range of dominance. The occurrence of division 


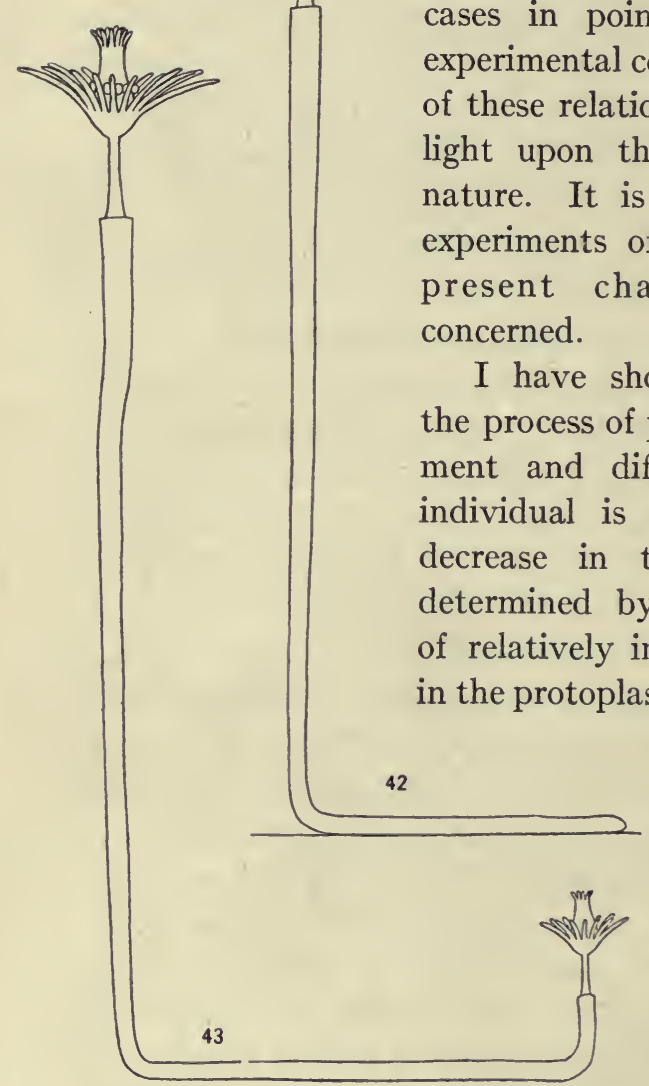

FIGS. 42, 43.-Tubularia: Fig. 42, a single individual; Fig. 43, asexual reproduction from tip of stolon. concerned. when a certain size or length is attained, or the appearance of buds at a certain distance from the chief growing tip in plants, are cases in point. In many cases experimental control and alteration of these relations throws a flood of light upon the problem of their nature. It is with material and experiments of this sort that the present chapter is largely

I have shown elsewhere that the process of progressive development and differentiation in the individual is accompanied by a decrease in the metabolic rate determined by the accumulation of relatively inactive constituents in the protoplasm. These changes, which constitute senescence, may end in death if they go far enough. On the other hand, any change which brings about the removal of such previously accumulated material makes possible an acceleration in metabolic rate, and such changes con- 
stitute rejuvenescence. The facts indicate that all reproductive processes bring about rejuvenescence to some degree, and it is certain that the new individuals which arise by division or budding from other individuals or from experimentally isolated pieces are to some extent physiologically younger than the parent individual from which they arose. ${ }^{\mathrm{I}}$ Rejuvenescence in such cases results from the loss of the differentiation as a part in that portion concerned in the reproductive process, and with the new individuation a new process of senescence begins.

Among the lower animals which have served as material for the study of regeneration or regulation two forms have been used to a large extent in my own experiments and must be briefly described here. The hydroid Tubularia in its simple unbranched form as a single individual (Fig. 42) consists of hydranth, stem, and stolon, the hydranth forming the apical end of the stem and bearing two sets of tentacles, reproductive organs between them, and a mouth at its apical end. The stem grows vertically from the surface of attachment, and the stolon adheres to the surface, forming an organ of attachment, and elongates by growth at its tip. Stem and stolon are covered by a horny cuticle, the perisarc. The apical end of the metabolic gradient of the major axis is the apical region of the hydranth, and from this region the rate decreases basally through the hydranth. In the stem the metabolic rate is lower than in the hydranth, and there is a slight decrease in rate in the basal direction, but at the growing tip of the stolon there is a short, slight gradient in the opposite direction.

${ }^{x}$ Child, Senescence and Rejuvenescence, I9I5. 
The primary form of asexual reproduction in Tubularia is represented in Fig. 43. When the stem and stolon together attain a certain length, which varies with the metabolic condition of the animal but under favorable conditions may be five to eight centimeters, the stolon turns away from the substratum and gives rise to a hydranth; then a stem forms and elongates below this hydranth, and a new stolon arises from the base of this stem. This process of reproduction itself suggests that the tip of the stolon is subordinate to the original hydranth until it attains a certain distance from it and then is able to produce a new hydranth, and experiments show that this is true. If the original stem elongates still further new hydranths may arise along the stolon and at the base of the stem, as these regions become physiologically isolated.

In Corymorpha, a form related to Tubularia, the hydranth is much larger, the stem naked except near the base and reaching a length of ten to twelve centimeters, and instead of a stolon the basal end is imbedded in sand and bears delicate root-like outgrowths as holdfasts (see Figs. 74, 78, pp. I43, I45).

Planaria dorotocephala (Fig. 30, p. 82), a flatworm and one of a number of species much used in experiment, is a much more highly differentiated, bilaterally symmetrical form, with distinct head and "brain" and two ventral nerve cords, and with definite, though rather diffuse, alimentary and excretory organs. Sexual organs appear in this form only under certain conditions. This, as well as various other species of the group, undergoes fission after it attains a certain variable size, the separation usually occurring at about the level $f f$ in Fig. 44 . 
The separated posterior portion becomes a new animal, while the anterior portion develops a new posterior end, and fission is sooner or later repeated. There is no morphological indication of a second individual or zooid in the posterior region of the body, but one or more such individuals are indicated by the metabolic gradient of the major axis and by various other physiological differences. The apical region of this gradient is the head of the animal, and from the head the metabolic rate decreases to the level where separation occurs in fission; there a sudden rise in rate occurs, and then again a downward gradient toward the posterior end. The region where the rate rises suddenly represents the apical end of the second individual and the downward gradient following is the gradient of the major axis of this zooid. In the shorter animals only one of these zooids is present, but as the length increases the basal body region may show two, three, or more of these distinct gradients. Represented graphically the metabolic gradient in such

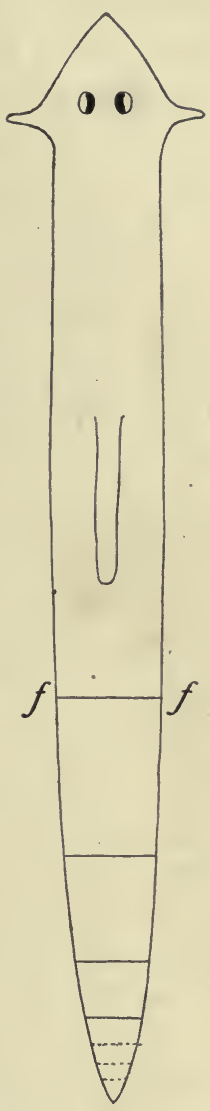

FIG. 44.-Planaria dorotocephala, outline, indicating several zooids in basal region; $f f$, usual level of fission. an animal is like the curve in Fig. 45; $a$ is the head-region, 
the long slope the body of the anterior chief zooid, which forms most of the body of the worm, $b$ represents the apical end of the second zooid, $c$ that of a third, etc. These zooids are the result of successive physiological isolations of the basal region as the animal grows in length. First a single zooid is formed at the basal end, but the range of dominance is short in this undeveloped individual, and as growth proceeds its basal region soon becomes physiologically isolated, and a second zooid arises, and so on. While a the degree of physiological isolation is not

FIG. 45.-Graphic representation of major axial gradients in a Planaria with several zooids: $a$, head of animal; $b, c$, apical regions of secondary zooids.

sufficient to permit the development of the new individual to proceed very far, some degree of rejuvenescence in the part does occur and its metabolic rate rises slightly, and with each successive isolation there is a further increase in rate, so that in each successive zooid the gradient is at a level somewhat higher than that of the preceding. 
The act of fission in this animal consists of an independent motor reaction of the posterior zooid or group. When the worm is creeping quietly, the posterior zooid or the zooid group suddenly attaches itself to the surface on which the animal is creeping, while the whole anterior individual endeavors to advance and the body in front of the attached region becomes greatly stretched (Fig. 46) and finally ruptures. The occurrence of fission can often be controlled experimentally in a way that shows the variable range of dominance very clearly. If an animal is very slightly stimulated, e.g., by a slight jarring of the aquarium, the posterior zooid will often attach itself, and fission will occur, while with stronger stimulation the animal is able to control this region and it does not become attached but advances with the rest of the body. Evidently when the animal is only moderately active the posterior region is physiologically isolated, but when it is intensely active the range of dominance of the anterior individual extends to this posterior

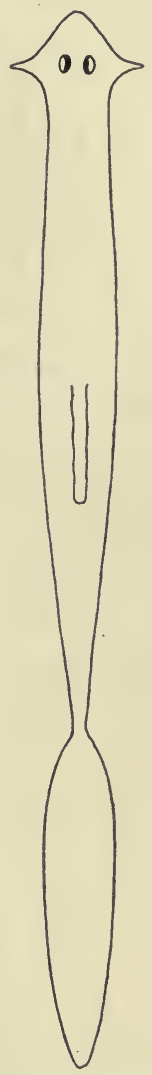

FIG. 46.-Planaria dorotocephala in the act of fission. region and determines its subordination in behavior. Similarly, in very old animals which have been prevented from undergoing fission by keeping 
them on a layer of vaseline or other surface to which they cannot attach themselves, the tissues are often so tough that rupture does not readily occur, and the anterior individual struggles more and more violently to free itself from the hindrance which is preventing its advance. In these animals such struggles often terminate in the complete subordination of the posterior zooid: it is not torn loose from its attachment, but lets go its hold and no longer reacts independently. Later, when the anterior individual has become more quiet, the same procedure may occur again. Evidently as the activity of the anterior individual increases the range of dominance increases, and, if fission does not occur at once, the posterior zooid may finally be brought under control. Moreover, one of the simplest ways of inducing fission in this species is to cut off the head of the anterior individual. Such animals creep about even in the absence of the head, but under these conditions the posterior zooid is more completely physiologically isolated and separation soon occurs if the tissues are not too tough. ${ }^{\mathrm{I}}$

Experiments to be described below will show other ways in which the existence of dominance can be demonstrated and its range varied and controlled in these and other animals and in many plants.

\section{THE INDEPENDENCE OF THE APICAL REGION}

The apical region of the organic individual is, to a large extent, independent and is capable of developing,

${ }^{8}$ For a more extended consideration of the process of fission and the various indications of the presence of the posterior zooids see Child, "Physiological Isolation of Parts and Fission in Planaria, "Archiv fuir Entwickelungsmechanik, XXX, II. Teil, I9I0; "Studies on the Dynamics of Morphogenesis, etc., III," Jour. of Exper. Zoöl., XI, Igr I; "Studies, etc., VI," Archiv für Entwickelungsmechanik, XXXV, I9г3. 
at least to an advanced stage, in the complete absence of other parts of the body. This independence is very evident in Tubularia and Planaria. Pieces one or two
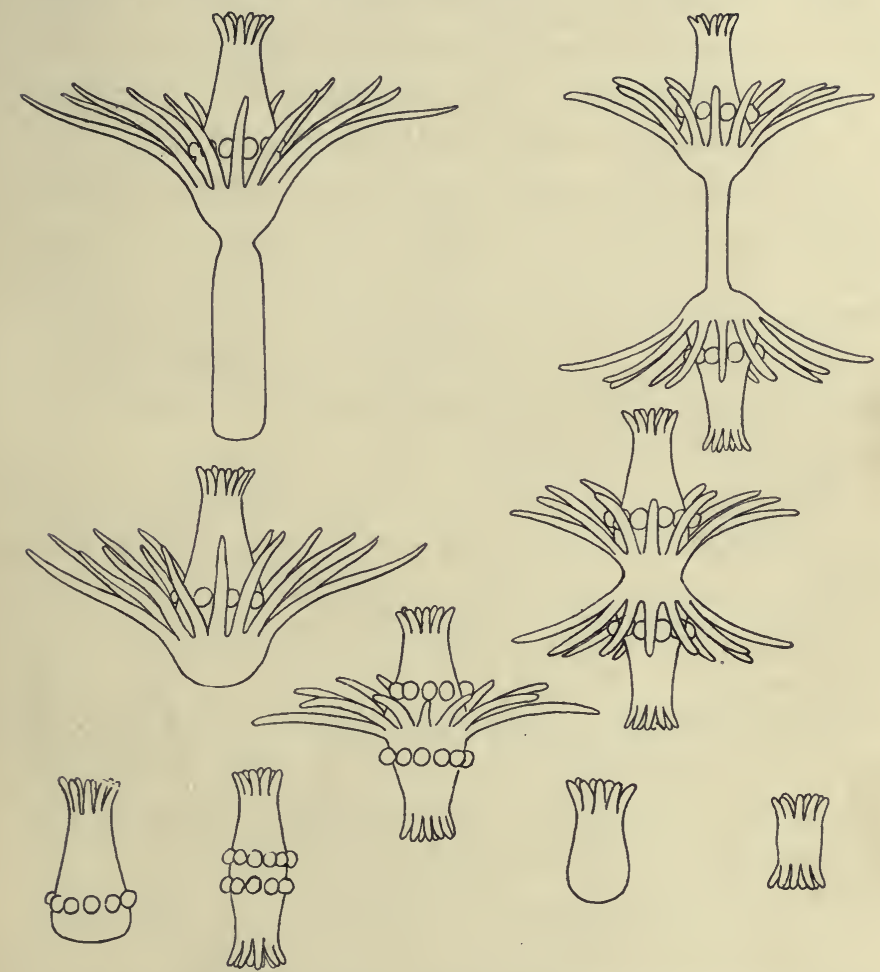

FIG. 47.-Reconstitution of single and biaxial apical structures from short pieces of stem of Tubularia, to illustrate independence of apical region.

millimeters in length cut from the stem of Tubularia usually develop into hydranths with a very short stem or partial hydranths with more or less of the basal region absent (Fig. 47). The result depends on the condition 
of the animal, the length of the piece, and the level of the stem from which it is taken. The shorter the piece from a given level of the stem the more completely is its development limited to apical parts, as Fig. 47 shows. The shortest pieces give rise to nothing but the apical ends of the hydranths, with mouths and the apical row of tentacles. In no case do such pieces produce basal parts of the hydranth without apical parts. Where anything is missing it is always the more basal region, either stem or more or less of the basal hydranth region. The results in such pieces constitute, I believe, a demonstration that the apical region of the individual arises first and other regions are determined later, as far as the length of the piece permits.

The development of hydranths or apical portions of hydranths may occur at one or both ends of such short pieces as indicated in Fig. 47. This difference arises according as the original metabolic gradient in the stem is more or less marked. In such short pieces of the stem the difference in metabolic rate at the two ends of the piece is but slight in any case. If, however, the rate at the apical end of the piece is enough higher than that at the basal end, development at the apical end proceeds more rapidly than at the basal end, the apical end is dominant, and the piece produces a single hydranth or part. But if the gradient is very slight in the piece the two ends react at the same rate, and since the presence of the wound at each end brings about an increase in metabolic rate at each end, equal or nearly equal gradients in opposite directions arise and hydranths or apical parts arise at both ends with their axes opposed. Often, even in such cases, the original gradient appears 
in the smaller size or more incomplete condition of the structure formed at the basal end of the piece. In Fig. 47 one case near the bottom of the figure is shown in which one end is a hydranth with both sets of tentacles, the other a partial hydranth with only the apical set and the reproductive organs. ${ }^{x}$

In Planaria the development of short pieces is essentially similar. Short pieces from various levels of the body may undergo complete transformation into single or double heads without the formation of other
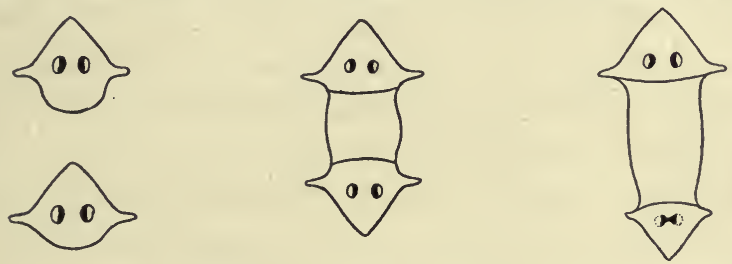

FIG. 48.-Reconstitution of single and biaxial apical structures from short pieces of Planaria, to illustrate independence of apical region.

parts of the bodyor with more or less of the anterior bodyregion (Fig. 48). When a single head arises, it is at the anterior end of the piece. The conditions determining the development of these heads are the same as those in Tubularia. As in Tubularia also, the original gradient may appear to some extent in the more rapid and more complete development, larger size, and dominance in motor activity of the head at the original anterior end of the piece, as in the case at the right of Fig. 48.

I For more extended consideration see Child, "Analysis of FormRegulation in Tubularia. V, Regulation in Short Pieces," Archiv für Entwickelungsmechanik, XXIV, I907; "Die physiologische Isolation von Teilen des Organismus," Vorträge und Aufsätze über Entwickelungsmechanik, H, XI, I9II, IoI-I9. Further references are given in these papers. 
These double apical regions and heads have been observed by many investigators in various animals and have commonly been called axial heteromorphoses, because the apical structure at the basal end of the piece was regarded as something which was out of place and abnormal. This, however, is not actually the case, for the development of these double or biaxial structures is, as I have shown, subject to exactly the same laws as the development of the usual single individual, only in these pieces the conditions are such that the original gradient is almost absent, and the increased activity at the basal end may establish a new gradient in the reverse direction, although some indication of the original gradient may remain in the smaller size or less complete development of the part at the basal end. In these short pieces, in fact, the original polarity is almost obliterated and the establishment of a new reversed polarity in relation to the basal cut end is possible. At each end the relation between the metabolic gradient and the development of an apical structure is exactly the same as in any other case of development. The apical region arises at the apical end of the gradient and the development of other parts follows as far as the gradient extends from each end, or in the case of single structures as far as the length of the piece permits. By means of the susceptibility method I have been able to demonstrate these relations between the metabolic gradients and the single or double development of such pieces.

The development of biaxial or multiple apical structures from pieces has been observed in various other animals, and, while their relations to the metabolic 
gradients have not been determined, their character and the conditions of their development indicate that whenever an apical structure arises it represents the apical region of a metabolic gradient.

In the plants also conditions are apparently similar. The apical region of a plant individual may arise independently of other parts, and if it becomes structurally connected with them later the connection develops progressively from the new apical region toward other parts and not in the opposite direction. The formation of buds on the leaves of begonia and in wound callus, described above (pp. 83-86), are cases in point, and many other similar cases might be cited. The developmental gradients in such cases indicate that the new apical structure or part represents the apical region of a metabolic gradient.

These conclusions concerning the independence of the apical region and its relation to the metabolic gradient, which are based upon experimental demonstration for certain cases and highly convincing evidence for others, are in full agreement with the facts of embryonic development. There also, so far as experimental evidence has been obtained, the apical region of the individual is the apical region of a metabolic gradient, and precedence of the apical region in development and the developmental gradients in the direction of the major axis indicate that this relation is general. I believe we are justified in concluding that in this respect development of the organic individual is always and everywhere the same. Further evidence in support of this conclusion will be presented in the following pages. 
DOMINANCE AND SUBORDINATION IN EXPERIMENTAL REPRODUCTION

The existence of a relation of dominance and subordination along the major axis is shown by the fact that, while the apical region is independent, other levels of the body can develop only in organic connection with more apical levels or with the apical region itself. In Tubularia and related forms stolons arise only in relation to stems or hydranths and stems, stem regions appear only in relation to higher levels in the gradient, etc. Stolons may grow out from stems in the absence of hydranths, and under certain conditions when the metabolic gradient is slight stolons may even arise at both ends of a piece of stem, but no case has ever been observed of the development of a stolon independently of other more apical levels.

This relation is also very evident in Planaria. ${ }^{\mathrm{T}}$ The reconstitutional development of pieces from the middle and posterior regions of the anterior individual, such as $a$ and $b$ in Fig. 49, ranges according to the physiological condition of the animal and with experimental conditions from a normal complete animal like Fig. 50 through various intermediate forms, of which the anophthalmic is shown in Fig. $5 \mathrm{r}$, to headless forms, like Figs. 52 and 53. The headless forms produce all parts of the body basal to the level which they represent, but never give rise to any part characteristic of more apical levels. The reason why they do not produce heads will appear in the following section. Thus, headless

I Child, "Studies on the Dynamics of Morphogenesis, etc., I," Jour. of Exp. Zoöl., X, I9I I; II, ibid., XI, I9II; "Experimental Control of Morphogenesis in the Regulation of Planaria," Biol. Bull., XX, I9Ir. 
forms from the level $b$ of Fig. 49 give rise to new tails and to all parts below their own level (Fig. 53), but never produce a mouth and pharynx, while headless forms from the level $a$ or any level apical to it give rise to mouth and pharynx as well as to postpharyngeal regions (Fig. 52), but never to regions representing more apical levels than themselves.

If, however, a head of any sort, even a rudimentary, anophthalmic head, like that of Fig. 5I, with no eyes and small, very incompletely developed, cephalic ganglia, arises on a piece from the level $b$, then the regions of the piece adjoining the new head give rise to the parts representing all levels between the head and the level which the piece

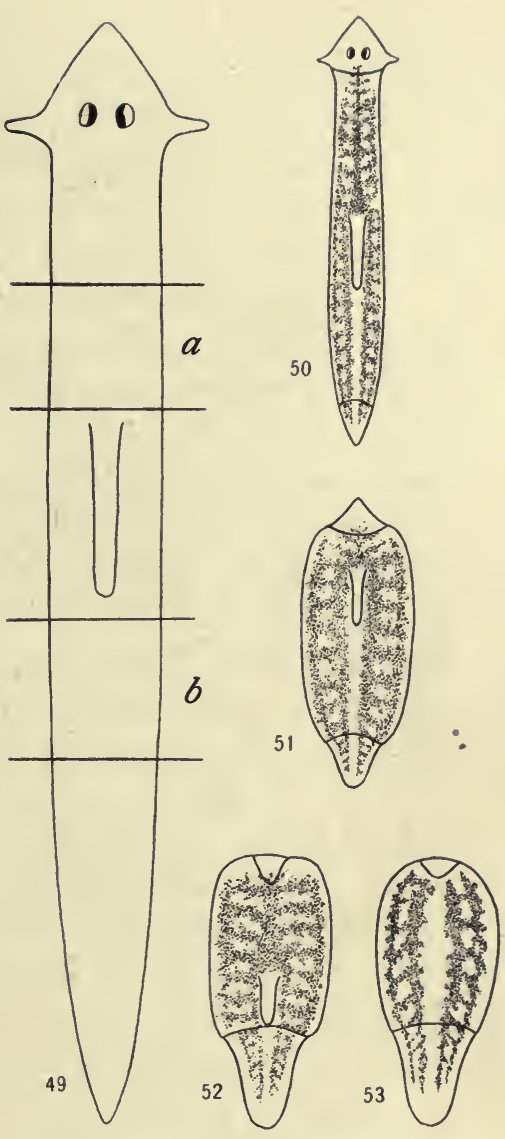

FIGS. 49-53.-Planaria dorotocephala: Fig. 49, outline indicating regions $a$ and $b$ from which pieces are taken; Figs. 50-53, different results of reconstitution, depending on presence or absence of a new head-region. $b$ occupied in the original individual. In other words, 
the development of parts apical to the original level of the piece takes place only in relation to the development of a new apical end, while the development of parts basal to the original level of the piece is determined by the piece itself, even in the absence of a head. All the facts indicate that the same relation exists in other animals.

It has already been pointed out (pp. 83-86) that when new growing tips arise in wound callus or from differentiated cells of plants, growth and differentiation proceed from these, not toward them. Plant stems, lateral branches, and leaves are subordinate parts or individuals of the plant and develop only under the dominance of growing tips. The root of the higher plant is likewise a subordinate individual. It possesses a growing tip and between this growing tip and other parts of the root individual the same relations of dominance and subordination exist as between the stem-tip and other levels of the stem, but the root as a whole develops only in subordination to some part of the plant, a stem-tip, a stem, a branch, a bud, a leaf, or some part of a root system already present. The same is true for the root-like structures, the rhizoids of the lower plants. The roots and rhizoids of the plant have apparently much the same relation to the organism as a whole as do the stolons of Tubularia and related forms. They are individuals, each with an axial gradient and a dominant region of their own, but they are specialized individuals, and arise from the basal region of the major axis of the individual which controls their formation, whether it is a single bud or branch, a leaf, or the whole stem of a composite plant individual. It is probable that these subordinate individuals really represent 
partially inhibited gradients (see pp. I78-8I). Certain external conditions, such as moisture and darkness, favor the development of roots, but do not determine their origin. It is commonly stated by botanists that roots may arise on any or almost any part of a plant where external conditions permit their development or where the need for them exists. This is true in a sense, because most plants are composite individuals, and when one of the constituent individuals of the plant, such as a bud, branch, or leaf, is sufficiently isolated from an existing root system, or under certain external conditions, that individual may develop a root or roots. Physiologically or physically isolated parts of a plant may undergo transformation into stem-tips without relation to other parts and the stem-tips determine the formation of other parts, but even though various parts of plants may give rise to roots in the absence of stem-tips, in no case does any other isolated part of a plant undergo transformation into roots alone. Moreover, in development in nature roots and rhizoids in general arise only after the primary apical region has been determined. They are, in short, subordinate to the individual as a whole, but, like leaves and various other plant "organs," possess a certain degree of individuation of their own. The question of the nature of the correlative influence of the root system upon other parts of the plant is one of considerable interest and is touched upon in chap. $\mathrm{v}$ (pp. $159-63$ ).

THE RECONSTITUTION OF AN INDIVIDUAL FROM AN ISOLATED PIECE

In the case of Planaria dorotocephala it has been possible to analyze the process of reconstitution to some 
extent and so to control it experimentally in various ways, and my experiments have led to certain conclusions concerning the nature of reconstitution. A part of the evidence on which these conclusions are based has already appeared in various papers, ${ }^{\mathrm{I}}$ but some of it is still unpublished. Here only some of the more important points and the conclusions are briefly presented. The results of the reconstitution of pieces in Planaria dorotocephala differ widely in different cases. I have found it convenient to distinguish five different forms: the normal (Fig. 50, p. I03), an individual in all respects like the type of the species; teratophthalmic (Fig. 54, $A, B)$, in which the eyes show various degrees of fusion, inequality, or other departures from the usual condition, but the head as a whole shows the usual form; teratomorphic (Fig. 55, $A, B$ ), usually with a single eye in the median line and the cephalic sensory lobes more or less approximated or completely fused at the front of the head instead of in a lateral position; anophthalmic (Fig. $56, A, B$ ), with an outgrowth more or less like a head and containing a small ganglionic mass, sometimes with cephalic lobes fused at the front, but without eyes; headless (Figs. 52, 53, p. I03), in which the cut end merely heals without outgrowth of new tissue. Different degrees of development of the cephalic ganglia

x Child, "Studies on the Dynamics of Morphogenesis, etc., I," Jour. of Exp. Zoöl., X, I9I I; II, ibid., XI, I9I I IV, ibid., XIII, I9I2; VII, ibid., XVI, I9I4; VIII, ibid., XVII, I9I4. See also Child, "Experimental Control of Morphogenesis in the Regulation of Planaria," Biol. Bull., XX, I9г1; "Certain Dynamic Factors in Experimental Reproduction and Their Significance for the Problems of Reproduction and Development," Archiv für Entwickelungsmechanik, XXXV, I9I3. 
correspond to these different types of head ${ }^{\mathrm{x}}$ and are undoubtedly the fundamental factors in determining general form and localization of the parts in the head.
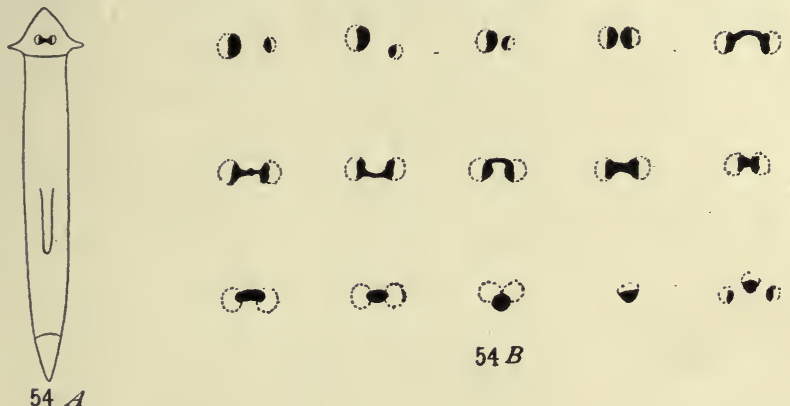

$54 B$

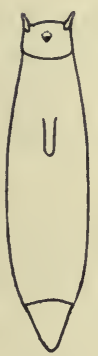

$55 A$
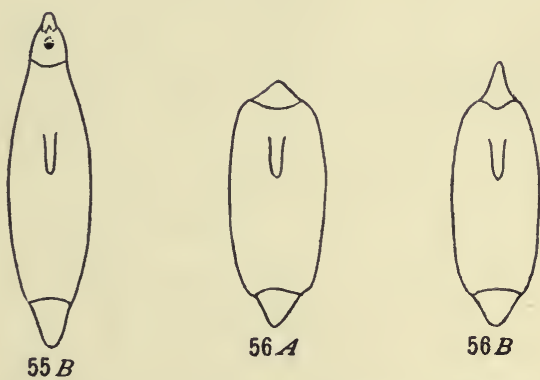

FIgS. 54-56.-Different results of reconstitution in Planaria dorotocephala: Fig. $54 A$, teratophthalmic animal; Fig. $54 B$, different forms of eyes in teratophthalmic animals; Fig. $55 A, B$, teratomorphic forms; Fig. 56A, $B$, anophthalmic forms.

As a matter of fact, these different forms are a more or less arbitrary grouping of what is actually a graded series of forms from the normal head at one extreme to the

${ }^{x}$ See Child and McKie, "The Central Nervous System in Teratophthalmic and Teratomorphic Forms of Planaria dorotocephala," Biol. Bull., XXII, I9II. 
headless form at the other. I have determined experi-

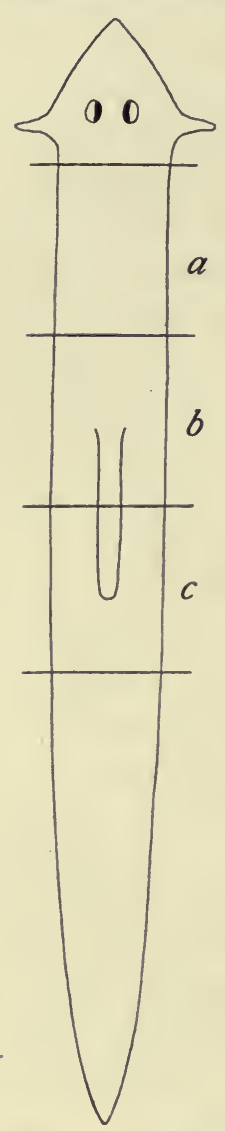

Fig. 57--Outline of Planaria dorotocephala, indicating regions, $a, b, c$, from which pieces are taken. mentally that these different forms represent different degrees of retardation or inhibition of the process of head formation. Their formation can be controlled experimentally in a great variety of ways. For example, the percentage of pieces producing heads, which we may call the headfrequency, is less in shorter than in longer pieces, in pieces from more basal than in those from more apical levels of the body; less in pieces from young than in pieces from old animals, in pieces from starved than in pieces from well-fed animals, in pieces which are kept quiet than in those forced to move about.

The effect on head-frequency of substances which decrease metabolic rate, such as dilute solutions of cyanides and narcotics, is of great interest, for it is definite and modifiable experimentally, but not uniform. In series of pieces of equal length, $a, b, c$, Fig. 57 , taken from animals of the same size and as nearly as possible the same physiological condition, the head-frequency under natural conditions is highest in the $a$-pieces which represent the most apical region below the head of the anterior zooid, in 
the $b$-pieces it is lower, and in the $c$-pieces lowest of all. If such a series of pieces is placed for a few hours after cutting in a low concentration of cyanide, alcohol, etc., the head-frequency in the $a$-pieces is considerably lower than in water, that in the $b$-pieces slightly lower or about the same as in water, while that of the $c$-pieces is higher than in water. This result is characteristic, but the actual percentages can be altered by differences in concentration of the reagents, temperature, and many other factors.

Although at first glance these results appear hopelessly confusing, they depend upon a very simple relation between that region of the piece which gives rise to the head and other parts. In an isolated piece of the planarian body (Fig. 58) the head arises from the cells of the region $x$, which are more directly affected by the wound and undergo rapid dedifferentiation and rejuvenescence

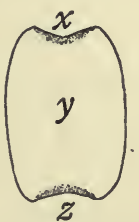

Fig. 58.-Diagrammatic outline of a piece of Planaria to illustrate relations of new apical region, $x$, new basal region, $z$, and old body region, $y$. and so attain a higher metabolic rate than cells farther away from the cut surface and begin soon after section to divide and grow rapidly. If these cells give rise to a head, the region $y$ undergoes more or less transformation to form the body of the new individual. I have found that the head-frequency varies directly with the metabolic rate in $x$, the head-forming region, and inversely with the metabolic rate in the region $y$. This relation may be stated in the formula, headfrequency $=\frac{\text { rate } x}{\text { rate } y}$. This means that the higher the metabolic rate in $x$, the more likely the piece is to give rise 
to a head, and vice versa, and it also means that the higher the metabolic rate in the region $y$, the less likely the piece is to give rise to a head. If this relation is altered by an increase of rate $x$ relatively to rate $y$, headfrequency is increased; if by an increase in rate $y$ relatively to rate $x$, head-frequency is decreased. On this basis all the experimental effects of different physiological and external conditions on head-formation can be readily accounted for, and it has even been possible in many cases to predict the results of various experiments.

Some of the facts on which this conclusion is based are as follows: By means of the susceptibility method I have demonstrated that the act of section always increases metabolic rate, particularly in the part basal to the cut. This condition of stimulation continues in the pieces for several hours after cutting and only gradually disappears. ${ }^{\mathrm{I}}$ The more basal the level of the piece in the original body, the more its metabolic rate is increased by section. In the cases of pieces $a, b, c$ in Fig. 57 the metabolic rate during the first few hours after section is higher in $b$ than in $a$ and higher in $c$ than in $b$, although before section the rate decreased from $a$ to $c$. This difference in stimulation of pieces from different levels results from the different degrees of subordination. The region $c$ is subordinate to all more apical regions and is much more dependent upon impulses coming from these regions than is the region $a$, which is subordinate only to the head. When the chief paths of conduction in the nervous system are cut they

"Child, "Studies on the Dynamics of Morphogenesis. VII," Jour. of Exp.Zoöl., XVI, I9I4. 
are stimulated; consequently the more basal the level of a piece the more its rate is increased by section. I have also found that the shorter a piece, the higher the metabolic rate after section. Long pieces are stimulated but little, except at the ends, chiefly the apical, but in short pieces the rate increases greatly.

Another simple experiment ${ }^{\mathrm{x}}$ shows that under ordinary conditions it is determined within three to six hours after section whether or not a head will develop on a piece. This is during the period of stimulation of the piece, and when we compare head-frequencies and metabolic rates during the period of stimulation following section, we see that the higher the metabolic rate in the piece as a whole, i.e., the region $y$, Fig. 58 , the less likely a head is to develop, and vice versa. The headfrequency is lower in more basal pieces such as $c$ than in more apical pieces like $a$, and in shorter than in longer pieces, because the metabolic rate in the region $y$ is higher at the time of determination of the course of development. Pieces from young or starved animals also have a higher metabolic rate $^{2}$ and a lower head-frequency than similar pieces from old or well-fed animals.

These facts may seem to involve a paradox, but their interpretation is actually simple. The two regions $x$ and $y$ (Fig. 58) of the piece behave differently after section. The cells of $x$ are so extremely affected by the presence of the wound and the altered conditions that they rapidly dedifferentiate and begin to divide and grow, and so approach or attain an embryonic

IChild, "Studies on the Dynamics of Morphogenesis. VIII," Jour. of Exp. Zoöl., XVII, I9I4.

${ }^{2}$ Child, Senescence and Rejuvenescence, I915, pp. I55-63. 
condition. The cells of $y$, however, merely undergo a temporary increase in metabolic rate. The region $x$ is a small group of cells undergoing dedifferentiation, while $y$ represents a considerable portion of a fully developed individual with established relations of parts and specialized nerves which are much more efficient than embryonic protoplasm as conducting paths. The region $x$ originally has a higher metabolic rate than $y$, because it represents a more apical level in the gradient, and its rate rises still farther as it begins to dedifferentiate. The facts of experiment indicate that in order to produce a new head rate $x$ must not merely be higher but much higher than rate $y$. The relation between $x$ and $y$ is evidently this: if rate $x$ is sufficiently above rate $y, x$ develops independently of $y$ into a head and dominates $y$, while otherwise $y$ dominates $x$ to a greater or less extent and so retards or inhibits head-formation, and the various forms between normal and headless condition are produced.

This relation $\frac{\text { rate } x}{\text { rate } y}$ can be altered in various ways: by means of dilute narcotics it is possible according to the method of use either to decrease the stimulation in $y$ resulting from section or to delay the reaction in $x$ until after the increased rate in $y$ has largely or wholly disappeared, or finally the relation may be altered by the more rapid and more complete acclimation of the young cells at $x$ as compared with the older cells of $y$ (see pp. $\left.5^{1}, 5^{2}\right)$. In pieces such as $c$, Fig. 57, where under ordinary conditions $x$ and $y$ are, so to speak, evenly matched in the struggle for dominance and the headfrequency is low, all these methods increase the headfrequency, because the relative increase in rate of $x$ as 
compared with $y$ overbalances the absolute decrease in rate produced by the narcotic. In pieces like $a$, where $y$ is only slightly stimulated by section and rate $x$ is so much higher than rate $y$ that the head-frequency is very high, the effect of narcotics is to decrease headfrequency, because in such cases dominance is not reversed and only the direct inhibiting effect of the narcotic on the region $x$ appears.

Head-frequency may be increased in all pieces by inducing them to move about. ${ }^{x}$ The apical end, of course, precedes in such movement, the cells of the region $x$ are subjected to more excitation than in a piece which is not moving, and the higher metabolic rate of $x$ results in increased head-frequency.

In Planaria maculata and certain other species the degree of subordination of basal regions of the body is not as great as in $P$. dorotocephala; consequently the increase in metabolic rate after section in pieces from this region is less than in $P$. dorotocephala, and in these species the head-frequency of such pieces is almost or quite as great as that in more apical pieces. Various other differences in the reconstitutional process in different species of planarians only serve to confirm the conclusions reached in the case of $P$. dorotocephala.

These and many other facts have forced me to the conclusion that the head which appears in the reconstitution of a piece is not physiologically a part of the piece and is not formed by the piece, but develops, so to speak, in spite of it. Only when the metabolic rate of the cells at $x$ is high enough to make them essentially

I Child, "Experimental Control of Morphogenesis in the Regulation of Planaria," Biol. Bull., XX, I9r1. 
independent of $y$ do they begin the development of a new individual by the formation of a head. The formation of a head at the end of a piece is then exactly the same process as the transformation of short pieces into heads when no other part of the body is present (pp. 96-Ior). The new head arises independently of other parts and dominates them. The influence of other parts on head-formation is merely inhibitory or negative, while the influence of head-formation on other parts is determinative or positive. The process of development of the cephalic ganglia in the head formed on a piece also indicates the independence of the head. The ganglia arise in the new tissue independently of the parts of the nervous system in the old tissue of the piece and become connected with these parts only secondarily. ${ }^{\mathrm{I}}$ This fact suggests that head-formation actually depends upon the establishment of a metabolic gradient in the region $x$ with its apical region near the free end and decreasing in rate toward $y$. If this occurs, a head forms, but if rate $y$ is high enough in relation to rate $x$, headformation is inhibited or retarded by the interference between two gradients in opposite directions. Inhibition or retardation of head-formation consists then in the interference of one metabolic gradient with another in the opposite direction or the obliteration of the one by the other.

The new basal end of the piece develops from a group of cells $z$, Fig. 58 , which react to the wound at the basal end by more or less dedifferentiation and growth. This

IS. Flexner, "The Regeneration of the Nervous System of Planaria torva," etc., Jour. of Morphol., XIV, I898; Child and McKie, "The Central Nervous System in Teratophthalmic and Teratomorphic Forms of Planaria dorotocephala," Biol. Bull., XXII, I9II. 
reaction is less rapid than that of $x$ (see Fig. 3I), because they represent a lower level in the gradient and their relation to the region $y$ is different from that of $x$. The rate of development and completeness of the new basal end varies directly with the metabolic rate in $y$; any conditions which decrease the metabolic rate in $y$ decrease the development of the basal end, and vice versa. We may say then that tail-frequency $=\frac{\text { rate } y}{\text { rate } z}$ but that under the usual conditions, when a gradient is already present in the piece, rate $z$ is so low that it becomes negligible, and the formula becomes tailfrequency $=$ rate $y$. This holds true as long as a new zooid does not arise in this basal region. If a new zooid does arise there in consequence of physiological isolation, as is often the case in headless pieces, then the lower the rate in $y$, the more rapid the development of this posterior zooid. In headless pieces the large size of the posterior outgrowth (cf. Figs. 52, 53, with Fig. 50, p. 103) is due to the fact that this region is not physiologically the basal end of the individual but a second individual. ${ }^{x}$

The development of the basal region is then dependent upon the presence and influence of more apical regions, while the development of the head occurs independently of other parts, so far as it is not inhibited by them. The relation between the major axial gradient and these differences of behavior in different regions is evident. The process of reconstitution of a new individual from a headless piece in Planaria is a process of development beginning at two different levels, first, at the apical end of the piece with the formation of a

I Child, "Studies on the Dynamics of Morphogenesis. III," Jour. of Exp. Zoöl., XI, I9II. 
new head, and, secondly, at the basal end with the formation of a new tail. The new apical region as the region of highest metabolic rate determines the establishment of a new major axial gradient, which has the same direction as the original gradient but possesses a higher rate, and in consequence of these changes the parts of the piece below the new apical region undergo more or less structural change into parts characteristic of more apical levels, until sooner or later a stable condition of the gradient is attained, and this determines the completion of reconstruction.

It can scarcely be doubted that the process of reconstitution of pieces into new individuals is fundamentally the same in all animals, though it may differ widely in details, with the kind and physiological condition of the individual or piece and the nature of the external conditions under which reconstitution occurs. Moreover, it is essentially the same process as reconstitution in plants, in that it consists in the development of a new individual beginning with the apical end. The chief difference is that in animals the development of the new individual is usually closely associated with the cut surface or surfaces, while in plants the reaction of the cells at the cut surface usually does not at once cover it with more or less embryonic rapidly growing cells, as it does in animals, and, since the plant is usually a composite individual, other apical regions already present become dominant, or new apical regions arise in other parts before a new apical region develops at the cut surface. In some cases, where only a small part of the apical region is removed, a new growing tip develops from the cut surface, and in such cases the formation of the new grow- 
ing tip is, I believe, essentially the same process as the formation of the new head in Planaria. In cases where wound callus develops, new growing tips may arise in that. In the formation of a new growing tip in callus tissue (pp. 85-86) and its later connection with other parts of the plant we have again a process very similar to the formation of a head in a piece of Planaria, and the development under its dominance of other parts, so far as they are not already present. In both cases the new apical region is not determined by other parts but develops independently of them, and its later relations to them are determined by its own dominance.

\section{SOME MODIFYING AND LIMITING FACTORS IN ANIMAL RECONSTITUTION}

The development of double or biaxial apical regions from short pieces has been discussed above (pp. 98, 99). In some cases biaxial basal regions instead of apical regions arise from pieces. Pieces of the stems of certain hydroids sometimes produce stolons at both ends, biaxial tails have been observed in short pieces of Planaria by Morgan, and I have been able to produce them experimentally in some cases (Fig. 59) by altering the relations

FIG. 59.-Experimentally determined reconstitution of biaxial basal ends in piece of Planaria. of metabolic rate between the regions $x$ and $y$ (Fig. 58) with the aid of narcotics. In the earthworm and related forms various investigators have observed the development of tails at both ends of pieces from the more basal regions of the body. My own experiments indicate that when the development of the new tissue at a cut end of 
a piece is completely dominated by the piece it gives rise to a basal structure. Such dominance means simply that the old tissue has a high enough metabolic rate to determine the direction of the gradient in the new tissue. In Planaria the development of tails at both ends of a short piece is apparently due simply to the fact that the metabolic rate in the piece is high enough so that the new tissue does not become dominant at either end but develops under the control of the old tissue. Dr. Hyman has found that the conditions determining the formation of double tails in Lumbriculus seem to be essentially the same as in Planaria, though the factors which produce them are somewhat different. She has been able to determine experimentally to some extent the production of heads instead of tails in such pieces by methods similar to those which I have employed for altering head-frequency in Planaria. She has also observed the development of structures intermediate between head and tail, or rather inhibited, rudimentary cephalic ends, in which certain caudal characteristics appear later. These are apparently cases in which the new tissue was at first to some extent independent but later became subordinated to the old. ${ }^{\mathrm{I}}$

The absence of any outgrowth at the apical end of a piece, as in the headless forms of Planaria (Figs. 52, 53), occurs when head-formation is completely inhibited, but the degree of dominance is not sufficient to determine development as a tail. In such cases local conditions at the cut apparently determine the result and the wound simply heals. In some other forms the wound

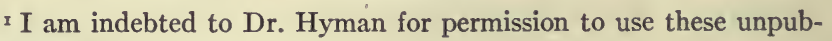
lished data. 
reaction involves more growth than in Planaria, and in such cases considerable outgrowths may sometimes arise which are neither heads nor tails, but cell masses of indeterminate character which gradually differentiate in relation to adjoining parts and may finally show both apical and basal characteristics.

In many of the flatworms and various other forms only an apical cut surface above a certain level of the body gives rise to a head, while tails may arise from cut surfaces at any level basal to the head of the parent body. In some of these cases the level where headformation ceases lies a considerable distance from the cephalic ganglia, while in other cases head-formation does not occur when the cephalic ganglia are removed; but when parts of the head are removed leaving a portion of the cephalic ganglia intact-sometimes half or more, sometimes only a small part, is necessary-such parts develop again. In the headless pieces there may be more or less outgrowth at the apical end of the piece, but it is indeterminate in character. Some authors have maintained that in such cases the cephalic ganglia or the more apical regions of the longitudinal nerve cords exercise a specific formative influence of some sort and so determine the development of a new head, but there is no real evidence in favor of this view. Probably the head fails to develop in such cases either because the cells reacting to the wound do not attain a high enough metabolic rate to become independent of other parts and their development into a head is therefore inhibited, as in the headless pieces of Planaria, or because these cells do not dedifferentiate to a sufficient extent to be capable of giving rise to a new cephalic 
ganglion and so to a head, while they may still be able under the dominance of other parts to produce basal regions of the body. The development of the apical region or of the apical part of the central nervous system, which in all except the lowest animals is the primary and dominant part of the apical region, is a self-determining process, independent of other parts, while the development of other parts is determined by their relations to dominant regions. It is highly probable therefore that a more complete loss of differentiation is necessary as a condition for head-formation than for the development of other parts. As a matter of fact, we find that as the capacity for reconstitution becomes limited by increasing differentiation the capacity for head-formation disappears first of all. Many animals in which reconstitution of new heads does not occur are still able to reproduce all subordinate parts, and with further limitation it is the more subordinate parts, such as legs and other appendages or caudal regions, which the body is capable of reproducing.

This limitation is more or less progressive from lower to higher forms, until in the higher vertebrates the capacity for reconstitution under any known conditions is limited practically to tissue regeneration. The primary limiting factor is unquestionably the increasing physiological stability of the protoplasmic substratum, in consequence of which the capacity for dedifferentiation and rejuvenescence, at least under ordinary conditions, is more and more narrowly limited. ${ }^{\mathbf{x}}$

I Child, Senescence and Rejwvenescence, I9I5, pp. 35, 39, 4I-43, 53, I94, 267, 304, 463-65. 
The embryonic stages of different animals differ widely as regards their capacity for reconstitution. In the sea-urchin and starfish isolated cells or groups of cells of the developing embryo down to a certain limit may give rise to complete larvae of small size, while in other forms, such as the annelids and mollusks, isolated parts of the embryo show little or no reconstitutional change, but remain alive for a time and continue to differentiate as they do when they remain as parts of an intact embryo. From the failure of the isolated parts to undergo reconstitution the conclusion has been drawn that they are independent of each other in the intact embryo, and that development in these organisms is a sort of mosaic made up of independent parts with some sort of pre-established harmony between them. If this view is correct, there is no relation of dominance and subordination in these stages of development. The failure of isolated parts to undergo reconstitution does not, however, demonstrate the absence of dominance but merely the ineffectiveness of isolation. The absence or limitation of embryonic reconstitution in certain forms is apparently due, like the increasing limitation of reconstitutional capacity in higher animals, to the higher specialization of the parts of the egg and embryo in these forms. There is good reason to believe that in such eggs the condition in embryonic stages is the result of differentiation dependent upon dominance and subordination of parts in the earlier life of the egg, and that specialization has gone beyond the stage where it can be greatly altered by isolation. Development proceeds in isolated parts as far as it has been determined by past relations with other parts or as 
far as nutritive or other conditions permit, and then ceases. There can be little doubt that relations of dominance and subordination exist during embryonic stages, and that these are factors in determining what occurs in later stages. According to this view, the difference between these eggs and those in which a high degree of embryonic reconstitution occurs is primarily a difference in the stability or fixity of the effects of previously established metabolic gradients. At the one extreme are eggs in which axial differences at the beginning of embryonic development are probably largely or wholly differences in metabolic rate, at the other, those in which specialization and differentiation of parts have gone far beyond this condition. The egg, in short, is an individual, and some eggs are more highly specialized individuals than others.

The proportional relations of parts in reconstitution, of which much has been made by Driesch, Morgan, and others, are obviously, so far as they exist, dependent upon metabolic relations between the parts. On a short piece of Planaria, for example, a smaller head usually develops than on a long piece. This fact has often been regarded as in some way associated with the fact that the shorter piece will produce a smaller animal than the longer and that the size of the new head foreshadows the size of the animal. As a matter of fact, the size of the head formed by pieces of the same size may differ widely in different cases and can be controlled experimentally to a very large extent by controlling metabolic conditions. The higher the metabolic rate in the region $x$, Fig. 58 , in relation to that of the region $y$, the larger the head, and vice versa. The size of the 
head in relation to other parts is determined primarily by its ability to grow at their expense. In a shorter piece there is less material available for such growth than in a longer piece, consequently a smaller head develops. Essentially the same relation exists as regards other parts. Where an excess of nutritive material is available the relation is not necessarily very different, for each part uses nutrition instead of the substance of other parts according to its metabolic activity, i.e., according to its position in the axial gradients, so that in this case also the chief factors in determining the proportions of parts characteristic of each form are the metabolic relations between them. In the early stages of development in nature the simple quantitative gradation in size from the apical toward the basal region appears, but as specialization occurs and the differences in metabolic rate at different levels bring about changes in metabolic character the size relations must of course become more complex.

The return or approach to the characteristic form of the species which very commonly takes place in the reconstitution of pieces has been regarded by Morgan and others as largely a matter of the physical rearrangement of the substance of the piece. That changes in shape may be brought about in soft-bodied forms like the flatworms by mechanical conditions connected with motor and other functional activities of the animals, I have shown. ${ }^{x}$ Wherever such factors play a

I Child, "Studies on Regulation. IV," Jour. of Exp. Zoöl., I, I904; VII, ibid., II, I905; "Studies on Regulation. IX, X," Arch. für Entwickelungsmechanik, XX, I905; "The Regulatory Change of Shape in Planaria dorotocephala," Biol. Bull., XVI, I909. 
part in determining the characteristic shape of the animal they undoubtedly play a part in determining the approach to this shape in pieces undergoing reconstitution, but in cases where they are not primarily concerned the metabolic relations are unquestionably the primary factors in determining shape and proportions of the whole and parts.

In most adult animals and embryonic stages which are capable of any considerable degree of reconstitutional reproduction, a limit of size of isolated pieces seems to exist below which reconstitution becomes incomplete or fails to occur. In Planaria, for example, with decrease in size of piece head-frequency falls to zero, but with still further decrease in size head-formation begins to occur again and head-frequency rises. These changes are simply due to changes in the relation $\frac{\text { rate } x}{\text { rate } y}$ (see pp. 109Io). With decreasing size of the piece, $y$ is more and more highly stimulated by section until in pieces below a certain size heads do not develop at all, but when the piece becomes very small $y$ practically disappears, for the whole piece becomes involved in the direct wound reaction and so corresponds to the region $x$ or such a region in relation to both cut ends. In such pieces there is nothing to inhibit or retard headformation except the simultaneous development of a head at the opposite end (see pp. 98-10r), and in such cases the effect is mutual and results merely in retardation.

Here then the completeness or incompleteness of reconstitution in relation to size of piece is wholly a matter of quantitative metabolic relations. There is no minimal size of piece which represents the "organi- 
zation" of the species reduced to its lowest terms. The minimal size can be altered widely even now by controlling conditions, and I have no doubt that if we are ever able to isolate single cells and to provide proper nutritive and other conditions for them we shall find that in many of the lower animals such cells are capable of giving rise to new individuals, as they undoubtedly are in many plants.

Most investigators have regarded the minimal size of pieces undergoing reconstitution as something absolute and have failed entirely to note that it differs with the physiological condition of the animal, the region of the body, and the various external conditions which affect metabolic rate. To determine the smallest piece of animal capable of reconstitution under given conditions is merely to determine one special case out of an indefinite number of possible cases.

\section{CONCLUSION}

The experimental evidence demonstrates, first, the essential independence of the apical region in both plants and animals, and, secondly, determination and control by this apical region of the developmental processes at other levels of the major axis of the individual. The reconstitution of pieces into new individuals is fundamentally the same process as embryonic development, and the same relation of dominance and subordination exists in both. The different results of reconstitution in pieces of different size, from different levels, in different physiological conditions, under different environmental conditions, etc., depend primarily upon relations of dominance and subordination, 
determined by the relations of metabolic rate in different parts. In the higher animals other factors, such as the stability of the differentiated cellular substratum, may contribute to limit reconstitutional capacity. 


\section{CHAPTER V}

THE RANGE OF DOMINANCE, PHYSIOLOGICAL ISOLATION, AND EXPERIMENTAL REPRODUCTION

If the conception of physiological dominance which is presented in chap. ii is correct, the existence of a transmission-decrement in the impulses, stimuli, or excitations which are the effective agents in dominance must determine a certain range of dominance and therefore a physiological size limit or limit of length for each axis, which cannot be exceeded without physiological isolation of the part that lies beyond the range of dominance. Moreover, the limit of dominance in a given case must vary with the metabolic rate in the dominant region and the conductivity along the path of transmission. Its effectiveness upon a subordinate part may also depend upon the receptivity of the part to the transmitted excitations, and this may be determined by local conditions to which the part is subjected. If the characteristic gradients are present or arise in a physiologically isolated part, such a part may become a new complete individual, if it is not so highly specialized or differentiated as to be incapable of reacting to the altered conditions by dedifferentiation and redevelopment. Some of the evidence bearing upon these aspects of the problem of dominance is considered in this chapter. 
EXPERIMENTAL CONTROL OF SPATIAL RELATIONS OF PARTS AND OF THE RANGE OF DOMINANCE

The dimensions and distance relations of parts along an axis can be altered by altering the metabolic rate in the dominant region or throughout the organism and so increasing or decreasing the length of the gradient.
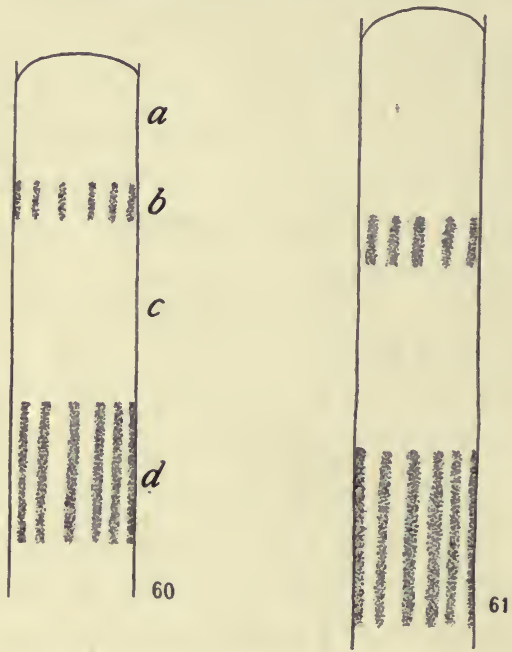

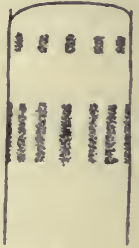

62

FIGS. 60-62.-Different lengths of hydranth primordium in reconstitution of pieces of Tubularia: Fig. 6o, length at medium metabolic rate; $a, b, c, d$, the four regions of the primordium; Fig. 6I, length at high metabolic rate; Fig. 62, length at low metabolic rate.

In Tubularia the reconstitutional development of a hydranth is a transformation inside the perisarc of the terminal region of the piece into a hydranth without outgrowth of new tissue from the cut surface. In the early stages of this process (Figs. 60-62) the two rows of tentacles arise as two series of longitudinal ridges (Fig. 6o, $b, d$ ), usually distinguishable from other parts 
by accumulations of red pigment. Various facts, some of which have been mentioned above (pp. 79, 96-99), show that the parts of the hydranth are determined from the apical end in the basal direction. The point of present interest in this process is the length of stem concerned in the formation of the new hydranth and the length of each of the four distinguishable regions, $a, b, c, d$, of the developing hydranth. In pieces of like physiological condition kept under the same external environment these lengths show a high degree of constancy, but they can readily be altered by altering the metabolic rate in the pieces. Fig. 60 shows the length and proportions of the early stage of a hydranth developing with a medium metabolic rate, Fig. 6r, with a high rate, and Fig. 62, with a very low rate. Evidently the higher the metabolic rate the greater the distance from the end of the stem and from each other at which the two rows of tentacles arise. The relative lengths of the different parts also change with metabolic rate, that of the region $a$ increasing and that of the region $d$ decreasing with increasing metabolic rate, and vice versa. ${ }^{\mathrm{I}}$

The position, size, and time of appearance of hydranths and the relation of hydranths to other parts in the reconstitution of isolated pieces of Tubularia and related forms have been repeatedly investigated, but, although the facts are very definite, the various authors

x Child, "An Analysis of Form Regulation in Tubularia. II, Differences in Proportion in the Primordia," Archiv für Entwickelungsmechanik, XXIII, I907. In this paper I showed that such differences in proportion appeared in hydranths from different levels and ends of the stem, but it is now known that these differences in level really represent differences in metabolic rate. 
have failed to reach any very satisfactory general interpretation of them. Driesch, who has used Tubularia to a large extent as experimental material, even maintains that they cannot be interpreted on a physico-chemical basis. As a matter of fact, however, not only do the facts fall readily into line with the dynamic conception of the individual which I have outlined, but many of them constitute valuable evidence for that conception.

I have found that previously existing metabolic gradients in the stem of Tubularia are rapidly obliterated and new gradients readily arise when metabolic conditions change. This is due to the fact that the protoplasmic substratum is not very stable, and, except in the hydranth, there is little structural differentiation in relation to the metabolic gradient. Wherever the stem of Tubularia is cut across, and even in many cases where section is not complete, a metabolic gradient arises in connection with the stimulation of the wound and the open end exposed to sea-water and the oxygen contained in it. The region of highest rate in this gradient is at the cut end, and the gradient extends a greater or less distance from the cut, according to the physiological condition of the stem and the direction and metabolic rate of the pre-existing gradient in the region concerned. If the metabolic gradient resulting from stimulation at the cut end is in the same direction as the pre-existing gradient, then of course there is merely an augmentation of the gradient, but if two gradients are in opposite directions, as they are at the basal end of a piece, they tend to neutralize, obliterate, or inhibit each other, and the one which has the higher metabolic rate sooner or later obliterates the other. The evi- 
dence indicates that when such a gradient is sufficiently marked, that is to say, when the metabolic rate in its apical region is sufficiently high, and when the inhibiting or obliterating influence of a gradient in the opposite direction is not too great, a hydranth develops. The formation of a stolon, on the other hand, apparently represents a gradient which is partially inhibited or obliterated, or, in other words, partially dominated by a gradient in the opposite direction, but in addition to this relation a relatively high metabolic rate in the piece or individual as a whole is also apparently necessary for stolon-formation. The stem represents the lower levels of a simple uninhibited gradient, and its formation always occurs under the dominance of a hydranth or other region of higher metabolic rate.

It is also important for an understanding of the facts to note that in general the metabolic rate of these animals decreases when they are transferred from natural to laboratory conditions, and the hydranths which develop in the laboratory possess a lower metabolic rate than those in nature; consequently the range of dominance is less and physiological isolation occurs at shorter distances from the dominant region than in animals in nature. Moreover, the development of a new hydranth at the cut end of a piece of stem is, I believe, a process essentially similar to the development of a head on a piece of Planaria (pp. 105-14). The new hydranth region is independent of other parts and becomes dominant over them, but during the early stages of its development this dominance is less complete, because the changes in the protoplasm of the stem in accordance with the new metabolic conditions require some time; 
therefore removal of the original hydranth favors physiological isolation of basal regions of the piece.

In Corymorpha the metabolic relations and the relations of the various parts of the body to the metabolic gradients are essentially the same as in Tubularia, and the demonstration of the metabolic gradients by means of the susceptibility method in Corymorpha, where most of the stem is naked, is not open to the objection which might be raised in the case of Tubularia, where all parts of the stem except the cut end are covered by the horny perisarc, viz., that the reagent penetrates the tissues only or chiefly from the cut end and so produces a death gradient which is merely a gradient of penetration and does not represent metabolic conditions.

Some of the facts and their interpretations in terms of metabolic gradients and physiological dominance are briefly as follows:I In pieces of Tubularia stem eight or ten millimeters or more in length and with a cut surface at each end reconstitution usually results first in the development of a hydranth at the apical end of the piece and later of a second smaller hydranth at the basal end (Fig. 63). Occasionally pieces from vigorous animals which evidently possess a high metabolic rate produce an apical hydranth and a stolon at the basal end (Fig. 64), but before it attains any great

${ }^{x}$ I have described and discussed these facts in the following papers: Child, "An Analysis of Form Regulation in Tubularia. I," Archiv für Entwickelungsmechanik, XXIII, I907; IV and V, ibid., XXIV, I907; "Die physiologische Isolation von Teilen des Organismus," Vorträge und Aufsätze über Entwickelungsmechanik, H, XI, I9II, 96-II9. The discovery since these papers were written of the existence of metabolic gradients and their relation to physiological dominance affords a definite basis for most of the earlier conclusions and interpretations. 
length this stolon gives rise to a hydranth at its tip. This is a process of reproduction like that occurring in nature (Fig. 43, p. 90), and differs from it only in that the distance of the second hydranth from the first is less in the pieces than in the animal under natural conditions. This difference indicates that, as might be expected, the range of dominance of the apical region is less in the experimental piece than in the whole animal in nature.

In most pieces, however, the dominance of the apical region is insufficient to inhibit the establishment of a well-marked new gradient in relation to the cut basal end of the piece, and so the formation of a hydranth usually occurs at this end also, as in Fig. 63. The development of this hydranth is usually delayed, as compared with that of the apical hydranth, because the establishment of the new gradient is more or less retarded by the gradient already existing in the original direction, and the
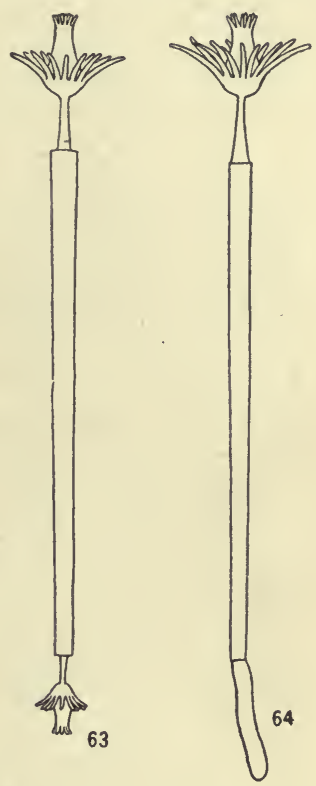

Figs. 63, 64.-Reconstitution of longer pieces of Tubularia: Fig. 63, usual result of reconstitution with hydranth at basal end; Fig. 64, reconstitution with stolon at basal end. shorter the piece the greater the delay, because in shorter pieces the dominance of the apical region is more complete, or, in other words, the gradient from the apical region is more marked at the basal end and therefore inhibits or retards to a greater 
extent than in longer pieces the establishment of a new gradient in the opposite direction. In pieces more than eight or ten millimeters long, however, the local conditions at the basal end usually determine the result sooner or later, and the new gradient is established and a hydranth develops here.

In pieces between eight or ten and two or three millimeters in length neither hydranth nor any other outgrowth arises at the basal end in most cases. In these shorter pieces the dominance of the apical region is sufficient to inhibit the new gradient at the basal end to a sufficient degree to prevent hydranth formation, and the general metabolic rate in these as in most other experimental pieces is not high enough for stolonformation to occur.

In the very short pieces described in chap. iv (pp. 96-99) the difference in metabolic rate between the two ends of the piece dependent upon the original gradient is so slight that in many cases the local conditions at the two ends become the determining factors, and hydranths begin to form simultaneously or nearly so at both ends, the portion of each hydranth formed depending on the length of the piece. If the original gradient in the piece is sufficient to determine the more rapid reaction at the apical end this becomes dominant and a single, instead of a double, structure arises.

These are the chief facts of reconstitution in Tubularia under ordinary conditions and their interpretation in terms of metabolic gradients and dominance. It is possible, however, to obtain more positive evidence in support of these interpretations by controlling and altering the experimental conditions. By diluting the 
sea-water to a certain extent the metabolic rate in pieces is increased, and under these conditions pieces which in normal sea-water produce only hydranths at their basal as well as apical ends produce in a large percentage of the cases stolons which later develop hydranths at their tips. ${ }^{\text {I }}$ The hydranths in such piećes are longer and larger than in normal sea-water.

When a piece is cut with a fully developed active hydranth at its apical end, no hydranth appears at the basal end until the metabolic rate of the apical hydranth decreases or its death occurs, which in Tubularia is usually within a few days at most. In Corymorpha relations are similar. Evidently, then, a full-grown, active, apical hydranth inhibits the development of a basal hydranth in a piece, but a hydranth beginning to develop at the apical end is usually only able to retard to some extent the development of the basal hydranth. The dominance of the full-grown hydranth is more effective than that of the early stages of hydranth development.

Various investigators have observed that when the development of the hydranth at the apical end of a piece is inhibited by inclosing this end in paraffin or sticking it in the sand the development of the hydranth at the basal end is accelerated, and it has been found that in such cases the basal hydranth is longer and larger than when the apical hydranth is not inhibited. Evidently the inhibition of development at the apical end decreases dominance, and the establishment of the new gradient and so the development of a hydranth at the basal end

"Child, "An Analysis of Form Regulation in Tubularia. I," Archiv für Entwickelungsmechanik, XXIII, I907. 
is accelerated. The same result may be attained by compressing, sharply bending, or partially crushing the stem at some point between the two ends. In such cases the influence of the dominant apical region is prevented from reaching the basal end, which is therefore physiologically isolated and the establishment of the new gradient but little retarded. Often also the development of the basal hydranth can be accelerated by cutting partly through the stem, so that only a slender organic connection between the two ends remains. In these and various other ways the controlling influence of the apical region can be demonstrated.

Neither the inhibition of development of the basal hydranth by paraffining the basal end or sticking it in sand nor the partial crushing or bending of the stem at a certain level influences the development at the apical end except in very short pieces. In these, inhibition of either end may accelerate the development of the other, and a single instead of a double structure may result. These experiments show that in the longer pieces dominance extends chiefly in the direction of the original gradient, and we find correspondingly that the new gradient which arises at the basal end does not extend very far from that end. If, however, inhibition of the apical end be continued for a longer time, the gradient at the basal end extends farther from that end.

The length of the hydranths formed in very short pieces is often, though not always, less than in longer pieces, particularly in pieces from the more basal regions of the stem. Driesch has made much of this point as an indication that an adaptation of the length of the hydranth to the length of the piece takes place in order 
that a stem as well as a hydranth may be formed. According to Driesch this adaptation is not determined physico-chemically, but by the principle which he calls entelechy and which as he believes controls development. Unfortunately for Driesch's view this "adaptation" does not occur in all cases, and is very incomplete, for, as I have pointed out (pp. 96-99), ${ }^{\mathbf{1}}$ these short pieces often give rise to hydranths or apical parts of hydranths without stems or basal parts. The experimental evidence indicates that the shorter hydranths in short pieces are merely hydranths which are partially inhibited by other regions of the piece, just as the head of Planaria may be partially inhibited by other regions of the piece. As in Planaria, short pieces, particularly those from the more basal regions of the body, are more stimulated by section, and their metabolic rate is therefore higher throughout than that of longer or more apical pieces. Under these conditions the gradient arising at the cut end is much less effective in determining the development of a new structure, the hydranth, than it is when the general metabolic rate is lower. Figuratively speaking the new gradient is partially obliterated by the general high metabolic rate in the piece. Consequently its length is less and the length of the hydranth determined by it is correspondingly less than in longer pieces, and development is also retarded. A piece of given length may produce a single short hydranth and stem, or a longer hydranth without stem, or biaxial hydranths, or apical portions, and all these differences in behavior are determined by simple differences in the gradient relations.

'See also Child, "An Analysis of Form Regulation in Tubularia, Regulation in Short Pieces," Archiv für Entrickelungsmechanik, XXIV, I907. 
In Planaria also the positions and space relations of parts along an axis and the range of dominance can be altered and controlled by means of conditions which alter metabolic rate. ${ }^{I}$ At ordinary room temperatures in well-aerated water the isolated postpharyngeal region of Planaria (Fig. 65) forms a new individual like that in Fig. 66. The new mouth and pharynx form near the middle of the piece at a certain distance from the new head, and the region in front of the pharynx undergoes the internal changes which make it over into the prepharyngeal region of the new individual. If, however, the rate of metabolism in such a piece is decreased by means of dilute narcotics, by the presence of carbon dioxide and metabolic products in the water, or by other means, the head develops slowly, is small and usually abnormal, and the lower the metabolic rate during development the nearer to the head the mouth and pharynx arise and the less the length of the new pharyngeal region. Fig. 67 shows the effect of a slight decrease, Fig. 68 of a greater, and Fig. 69 of a still greater decrease in metabolic rate during reconstitution. The length of the region undergoing reconstitutional change is less in Fig. 67 than in Fig. 66, still less in Fig. 68, and in Fig. 69 practically no changes occur below the level of the very rudimentary head.

Reconstitution of similar pieces with a very high metabolic rate (at high temperature) results in forms like Fig. 70, in which the pharynx and mouth arise at a

I Child, "Physiological Isolation of Parts and Fission in Planaria," Archiv für Entwickelungsmechanik, XXX (Festband für Roux), II. Teil, I9Iо; "Studies on the Dynamics of Morphogenesis, etc. III," Jour. of Exp. Zoöl., XI, I9I1. 
greater distance from the head and the prepharyngeal region is longer than in Fig. 66.
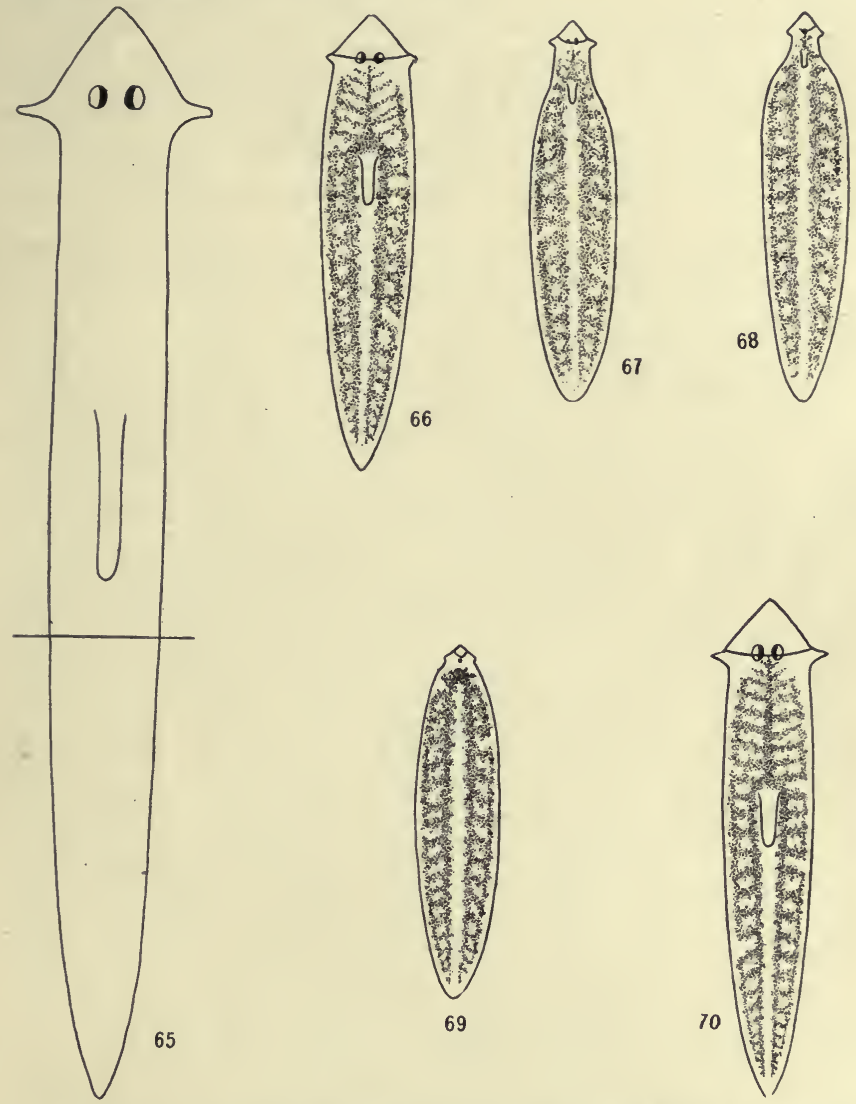

66
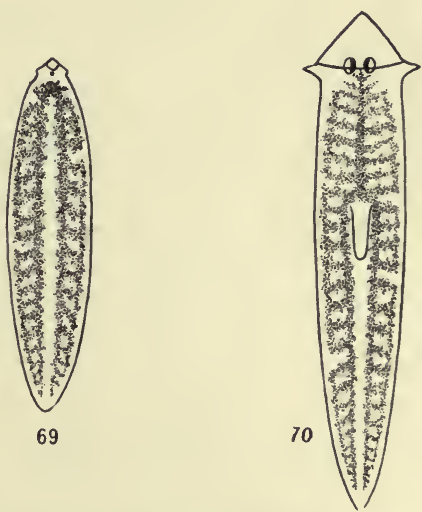

Figs. 65-70.-Space relations of parts in reconstitution of Planaria dorotocephala under different metabolic conditions: Fig. 65, outline indicating level of section; Fig. 66, reconstitution under standard laboratory conditions; Figs. 67-69, different ranges of dominance and space relations of new parts in reconstitution with low metabolic rate in different concentrations of narcotics; Fig. 70, reconstitution with high metabolic rate at high temperature. 
The metabolic gradient associated with the new head shows a corresponding decrease and increase in length in such pieces. The influence of the new headregion extends to a greater or less distance according as its metabolic rate is high or low, and the position of the various organs is altered correspondingly, or, as in the extreme case of Fig. 69, no new organs are formed except the head.

When the metabolic rate is high, as in Figs. 66 and 70 , dominance extends nearly or quite to the basal end of the piece, though short zooids may be present as more or less distinct gradients (see pp. 92-94) at the basal end. Before section most of this region of the body consisted of one or more zooids, but the development of a head nearer to these zooids than the original head has brought about the obliteration of the gradients which represented them, except perhaps in the extreme basal region, and after reconstitution a single gradient extends over at least most of the length of the piece. When the metabolic rate is lower, as in Figs. 67 and 68, a short individual develops from the apical region of the piece, but most of the broader portion is not physiologically a part of this individual. This is very evident in the behavior of these forms, for, when creeping about, they are unable to control and co-ordinate this region to any great extent, and simply drag it about like a dead mass. As long as they remain in the narcotic they are not active enough to undergo fission, but if they are returned to water, fission may occur after a few days, although the range of dominance gradually extends, and more and more of the length of the piece comes under the control of the head. 
The different types of head in Planaria (see pp. Io6I4) represent, as I have pointed out, different degrees of inhibition of head-formation, and, even after development is completed, possess different metabolic rates, as susceptibility determinations show. The metabolic rate is highest in the normal head, slightly lower in the teratophthalmic, and still lower in the teratomorphic and anophthalmic forms. In connection with these differences in the heads it is of interest to note that when the different forms are fed and grow, the length which they attain before fission varies in general with the form and metabolic rate of the head. Under ordinary conditions normal animals usually become twelve or fifteen millimeters long before undergoing fission, teratophthalmic forms usually slightly less, teratomorphic forms from eight to ten millimeters, anophthalmic, from six to eight or less, according to the degree of development of the head-region, while headless forms rarely become more than five or six millimeters long before dividing and often divide at a length of only three or four millimeters. These differences indicate very clearly the difference in range of dominance associated with the differences in metabolic rate in the dominant region.

There are many ways of inducing advance in development of the basal zooids and the occurrence of fission in Planaria, of which the simplest is the removal of the head of the animal. This decreases the degree and range of dominance to such an extent that fission almost invariably occurs within a few days. By removal of new heads as fast as they develop fission may be induced even in animals much shorter than those which usually 
undergo fission. ${ }^{\mathrm{I}}$ These and various other methods all serve merely to increase the degree of physiological isolation of the basal region by decreasing the degree and range of dominance.

EXPERIMENTAL OBLITERATION AND DETERMINATION OF AXIAL GRADIENTS AND DOMINANCE

In the case of the hydroid Corymorpha (see pp. 92, I32) the original gradient can readily be obliterated and the establishment of new gradients determined by experimental conditions. Reconstitution in pieces four or five millimeters or more in length from the naked region of the stem in sea-water under the usual laboratory conditions is like that in most of the longer pieces of $T u b u$ laria stem (see Fig. 63, p. 133). A hydranth develops at the apical end of the piece, and later a second smaller hydranth appears at the basal end. The metabolic conditions are also similar to those in Tubularia, and reconstitution can be altered and controlled in much the same way in both forms. If, however, such pieces of Corymorpha are placed after cutting in $2-2 \frac{1}{2}$ per cent alcohol in sea-water the cut ends heal, but hydranths do not develop. In the course of a few days the pieces become shorter and more rounded, decrease in size, and lose the characteristic structure of the Corymorpha stem. The changes in shape are indicated in Figs. $7 \mathrm{I}$ and 72. On removal to water after several days in alcohol a new hydranth begins to develop on the upper side of the piece (Fig. 73), then a stem arises below it, and

I Child, "Physiological Isolation of Parts and Fission in Planaria," Archiv fïr Entwickelungsmechanik, XXX (Festband für Roux), II. Teil, I9ro. 
basal structures develop on the lower side of the piece in contact with the underlying surface, and gradually the piece is transformed into a new small individual (Fig. 74). In most cases the old outline of the piece is still preserved by a thin layer of hardened slime secreted by the piece while in alcohol. This is indicated by the dotted line in Fig. 74. Susceptibility determinations show

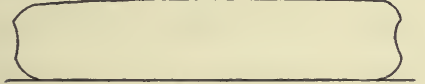

71

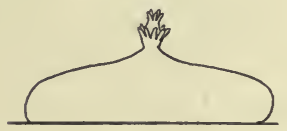

73

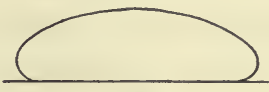

72

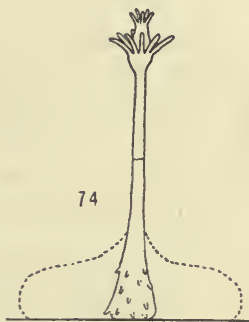

FIGs. 7I-74.-Experimental establishment of a new major axis in a piece of Corymorpha: Fig. 71, the piece after section; Fig. 72, after reduction in alcohol; Fig. 73, appearance of new hydranth on upper side after return to water; Fig. 74, fully developed new individual; dotted lines indicate old outline of piece preserved by slime.

that in alcohol the original axial gradient disappears, and that when the pieces are returned to water a new gradient arises in the direction in which the new axis develops. Since the pieces adhere to the surface soon after being placed in alcohol, it is possible to keep them in the same position throughout the experiment and so to be certain of the original direction of the major axis and gradient, even though they become hemispherical 
or nearly spherical in form. In most cases, however, there is no difficulty as regards this point, because the longest diameter of the pieces coincides in direction with the original axis. A comparison of the direction of the new axis which arises after return to water with that of the original axis shows that the former is at right angles with the latter. The new hydranth develops without relation to either of the cut ends from the uppermost region of the piece as it lies in the aquarium, and this region was originally its lateral surface. In these cases the alcohol not only inhibits the increase in metabolic rate in relation to the terminal cut surfaces, which determines the development of hydranths at the two ends, but decreases the rate throughout the piece. In this way it obliterates the original gradient and dominance to such a degree that when the metabolic rate rises again on return to water the original axial relations do not reappear, but a new gradient and a new dominance arise in relation to the external conditions to which the piece is subjected, and the axis of the new individual coincides in direction with the new gradient. In all cases, so far as my experiments go, the new hydranth arises from the uppermost part of the piece, no matter what region of the piece in its original condition this part represents.

When short pieces, which have already produced biaxial hydranths (Fig. 75), are used for this experiment, the changes are very similar to those described for longer pieces. In alcohol the tentacles and the apical regions of the two hydranths die and disintegrate, but the more basal portions gradually lose their hydranth structure and the pieces become small rounded masses 
in which no structure is externally visible (Fig. 76). After return to water a new hydranth arises, as in the longer pieces, on the uppermost part (Fig. 77), which represents one side of the basal region of the previously existing hydranths, and the piece undergoes transformation into a new small individual (Fig. 78). In this case the two opposed metabolic gradients which were present at the beginning of the experiment were completely obliterated and a new single gradient arises at right angles, or, if the pieces are not kept
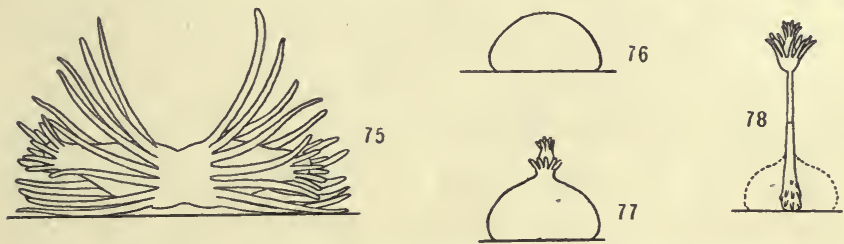

FIGS. 75-78.-Experimental establishment of a new major axis in a piece of Corymorpha which has already formed a biaxial structure: Fig. 75, the biaxial hydranths developed from the piece; Fig. 76, the same piece after reduction in alcohol; Fig. 77, appearance of new hydranth after return to water; Fig. 78 , fully developed new individual.

in the same position throughout, in any relation to the original gradients as determined by the external conditions.

My experiments along this line were interrupted and no opportunity to continue them has as yet arisen. I believe, however, that the new metabolic gradient in these pieces is primarily determined by the difference in oxygen supply between the free upper surface and the surface in contact, the region of highest rate representing the region of greatest oxygen supply; but further experiment is necessary to determine positively whether 
this or some other factor in the environmental conditions is the essential one. The important point is that a new metabolic gradient, major axis, or polarity is in these cases determined by external conditions, and that morphogenesis occurs with reference to this gradient.

In the case of a sea-anemone, Harenactis (Fig. 79), obliteration of the original gradient is accomplished in a somewhat different way. ${ }^{x}$ 'The bodies of these animals are tubular, with partial longitudinal partitions, the mesenteries. When the rather bulky mesenteries are not removed, pieces cut from the body close by gradual contraction at each end, the wounds heal, and a new disc and tentacles develop at the apical, and a new "foot" at the basal end. If, however, rather short pieces are taken ( $a, b$, Fig. 79) and the mesenteries are largely cut away from the interior of the body, the pieces close up and heal as indicated in the longitudinal section (Fig. 80), because there is no mass of internal tissue to prevent the two ends meeting when the piece contracts. In such pieces the apical cut surface of the body wall unites with the basal about the whole circumference, and the result is a ring or doughnut-shaped structure which makes an attempt to orient its body as it does in nature by revolving about a circular axis like a vortex ring until the region of union of the two ends lies on its upper or outer surface.

At this region of union more or less new tissue arises, particularly if the cut surfaces are irregular and do not

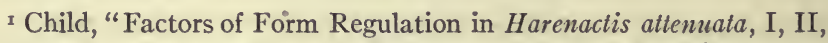
III," Jour. of Exp. Zoöl., VI, VII, I909; "Further Experiments on Adventitious Reproduction and Polarity in Harenactis," Biol. Bull., XX, I9IO. 


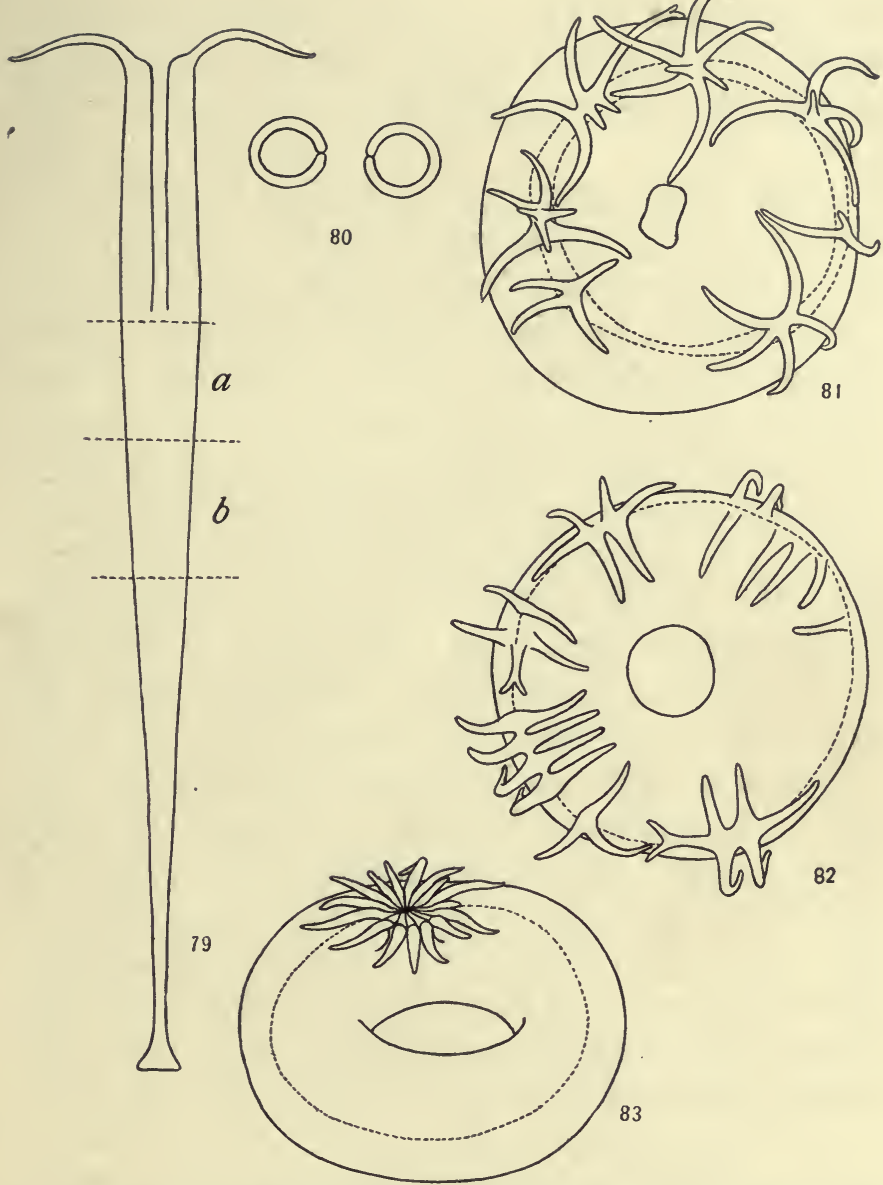

FIGS. 79-83.-Reconstitution in "rings" from sea-anemone, Harenactis attenuata: Fig. 79, longitudinal sectional outline of animal, indicating regions, $a, b$, from which pieces are taken; Fig. 80, diagrammatic longitudinal section through a "ring," showing method of closure by union of apical and basal cut surfaces of body wall; Figs. 8I, 82, tentacle groups arising from the region of union of cut surfaces; Fig. 83 , a perfect animal developed on a ring. 
unite smoothly, and from this new tissue all gradations from single tentacles, through groups of tentacles of various sorts up to complete small anemones (Figs. $8 \mathrm{I}-83$ ) arise.

The various tentacle groups in Figs. $8 \mathrm{I}$ and 82 and the individual in Fig. 83 are made up of cells which are descended from both apical and basal ends of the piece and a more or less definite new individuation occurs in these cells. There can be little doubt that in these cases the origin of these various degrees of individuation is associated with the growth of new tissue at the line of union between the cut surfaces. The metabolic rate in this tissue is higher than in the other regions of the piece, and if it is enough higher the new tissue becomes independent and produces a new apical region, or some part of it, according to conditions. Wherever, about the circumference, growth of new tissue is most rapid and extensive, there the new individual is most likely to arise. Often it is possible to determine beforehand the region of the circumference where such tentacle groups or individuals shall arise, by making the outline of one or both cut surfaces irregular at some point or making a number of small cuts near together in them. In such regions there is more growth of new tissue and a new gradient and new individual are more likely to arise.

As regards the minor axes, it is of great interest to note the wide range of variations which occurs. Many bilaterally as well as radially symmetrical and asymmetrical forms appear among the tentacle-groups, and it is evident that the symmetry of the groups is in many cases related to the line of union and not to any preexisting symmetry of the parent animal. In these rings 
we see new individuals being localized and developing where it is impossible to conceive of any internal localizing and determining factors other than quantitative metabolic conditions.

In the case of Planaria I have been able to increase the frequency of biaxial heads (see Fig. 48, p. 99) in very short pieces by partially narcotizing the animals before cutting and keeping the pieces in a dilute solution of a narcotic, e.g., chloretone, for a day or two before allowing them to develop. Under such conditions the metabolic rate in the pieces is of course decreased, and so dominance in the direction of the original gradient is still further decreased. Consequently, when the pieces are returned to water and allowed to develop, the conditions are even more favorable for the establishment of the reversed gradient at the basal end, and biaxial structures develop in a larger percentage of cases than when the pieces are not narcotized. The effect of the narcotic is simply to aid in decreasing the dominance of the original apical region of the piece and so to increase the probability of the establishment of an effective reversed gradient and dominance at the basal end. This experiment has not as yet been attempted with Tubularia, but will no doubt be successful with proper technique.

THE EXTENSION OF DOMINANCE DURING DEVELOPMENT

That the range of dominance undergoes extension during development is evident from many facts. In the young Planaria, for example, a second zooid arises at the posterior end of the body when the animal is less than five millimeters in length, i.e., the range of dominance 
at this stage of development is only three or four millimeters. ${ }^{I}$ In the adult animal, however, the range of dominance as indicated by the length of the first zooid may be ten or twelve millimeters or even more under certain conditions. Evidently with advancing differentiation of the nervous system the conductivity has increased, and so the transmission-decrement has become less and the range of transmission greater.

In Stenostomum also the more advanced the development of a zooid, the greater the distance from its head-region at which the head-region of a new zooid is determined, as will appear by reference to Fig. 29 (p. 8r). Other animal forms which undergo agamic reproduction show similar relations, and it is also probable that the increasing capacity for co-ordination and control of parts with advancing development, so far as it depends on the nervous system, results to some extent from the increase in efficiency of transmission, though various other factors may also be concerned.

In plants also similar relations appear. In the differentiated part of the plant stem the range of dominance of a bud or a growing tip over others is very much greater than in the embryonic region of the growing tip, but their later development is inhibited by the growing tip as a whole, even though further growth has greatly increased the distance between them. The dominance of the growing tip as a whole has a much greater range in the differentiated parts of the plant than the dominance of its apical region over much nearer parts in the

"Child, "Studies on the Dynamics of Morphogenesis. III," Jour. of Exp. Zoöl., XI, I9Ir. 
embryonic or slightly differentiated tissue of the growing tip itself.

In the higher animals the extension of dominance is evidently very much greater than in the lower forms. In the medullated nerve fibers of the higher vertebrates the transmission-decrement is so slight that some authors have denied its existence. Various lines of experiment have indicated, however, that a transmission-decrement does exist even in vertebrate nerves (see pp. I73-75). Tashiro has shown that a gradient in carbon-dioxide production exists in nerve fibers, and I have observed a distinct susceptibility gradient in certain nerves. The nerve is essentially a specialized protoplasm which conducts with less decrement and therefore to greater distances than other kinds of protoplasm, and the central nervous system arises in those regions of the body where the transmitted changes primarily originate.

The extension of dominance during the development of the higher animals is so great that the range of dominance is undoubtedly very much greater than the size of the individual. In these forms individual size is limited, not by the range of dominance, but by the decrease in metabolic rate which accompanies the progressive differentiation, and so limits growth. Only in early stages of development, or in the lower organisms, where nerves are either absent or not very good conductors, does the size of the individual equal the range of dominance.

EXPERIMENTAL PHYSIOLOGICAL ISOLATION AND REPRODUCTION IN PLANTS

The course of development in the single plant individual suggests the dominance of the growing tip 
of the stem, but physiological isolation of parts and reproduction of new individuals afford the only means of demonstrating experimentally the existence of dominance and its varying range. From among the accumulated data concerning what the botanists commonly call correlation, a few simple, well-known experiments
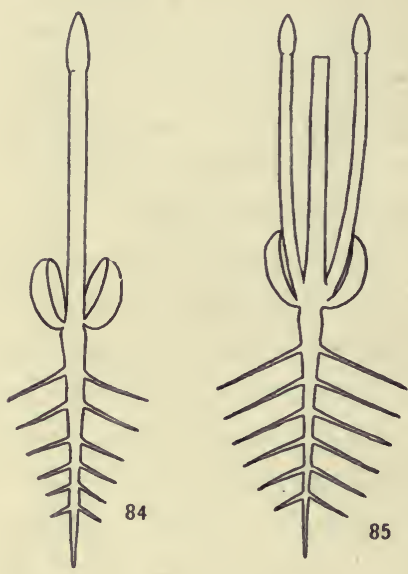

Figs. 84, 85.-Diagrammatic outlines of leguminous seedlings, illustrating effect of removal of growing tip: Fig. 84, uninjured seedling; Fig. 85, development of shoots from axils of cotyledons after removal of stem-tip. are briefly described to show how readily physiological isolation and reproduction may be brought about in plants.

The young seedling of a leguminous plant (pea, bean) possesses the general form indicated diagrammatically in Fig. 84. The further normal development of the stem consists primarily in its elongation and the development of leaves by the activity of the growing tip at its apical end, but if this growing tip is removed a new growing tip, or in some cases more than one, arises from the axillary region of each cotyledon, as indicated in Fig. 85. These axillary shoots very rarely appear when the original growing tip is present and active, but their development results regularly from its removal. If both of the shoots grow at about the same rate they may both continue to develop and so give rise to two 
stems, each of the same character as the single stem in normal plants, but if one grows more rapidly the growth of the other is usually soon inhibited and only the one continues to develop. If, instead of removing the primary growing tip, we inhibit its metabolic activity in any way without killing it or injuring it otherwise, the result is the same as if it were removed. Inclosure of the primary growing tip in plaster of paris or in an atmosphere of hydrogen accomplishes this result without injury, for it is capable of resuming growth after removal of the plaster or return to air. If the primary tip is inhibited in this way until the axillary shoots have appeared and is then allowed to resume its activity, the growth of the axillary shoots is in turn inhibited and the primary stem continues its development, unless the axillary shoots have attained a length two or three times as great as that of the main stem before the inhibition of the primary tip is removed. In that case the further growth of the primary tip may be almost entirely inhibited by the axillary shoots, and it may even die, while they, or one of them, as the case may be, continue development. Many modifications of the experiment are possible at different stages of development and in different plants. In stems with lateral buds, such as the willow, if the apical growing tip is removed the uppermost lateral bud or buds will develop and their development inhibits the development of those lower down; if we remove them or prevent their development by inclosing them in plaster, the buds next below will develop, and so on.

In many plants removal or inhibition of all the growing stem-tips present results in the formation of 
so-called "adventitious" buds, which may arise from differentiated cells, as in the case of the begonia (Figs. 38,39 ), and may be scattered irregularly over various parts of the plant according to the conditions of the experiment. Often the presence of a single one of the original buds is sufficient to inhibit the formation of these adventitious buds. The appearance of adventitious buds on plants in nature is usually due to the weakening of existing growing tips through advancing age or injury of some sort.

Such adventitious buds very often arise in large numbers simultaneously without any regular arrangement with reference to each other. The absence of definite space relations in such cases is undoubtedly due to the fact that they arise simultaneously, or nearly so. Various cells here and there which happen to have a slightly higher metabolic rate than others begin to develop into new buds at about the same time; consequently none of the buds is dominant over the others. If, however, one of the adventitious buds gets a start beyond the others in any way, it inhibits the further development and may even bring about the death of others within a certain distance of it. Moreover, where a gradient is present in the part on which the buds appear, so that one or more buds appear first in a certain region - the region of highest metabolic rate in the partthey inhibit the growth of others within a certain distance or throughout the part.

In various conifers the dominance of the growing tip of the main stem appears in a somewhat different form. In these trees, as long as the growing tip of the main stem is present and active, lateral branches arise radially 
around the main stem and grow outward from the trunk, and the branches of the second order arise in most cases more or less bilaterally on them. Removal of the main growing tip is followed by the bending upward of one or more of the uppermost lateral branches, further growth in the vertical direction, and radial instead of bilateral outgrowth of new branches. Here one or more of the lateral branches nearest the upper end of the stem react to the absence of the main growing tip by changing direction and form of growth to that characteristic of the original tip. If this branch is removed, branches farther down the trunk react in the same way.

According to most authorities, dominance of one part over another is effective only or chiefly in one direction along the stem, namely, from the apical end downward. Buds or growing tips at or nearer the apical end are capable of inhibiting buds farther down the stem, but the latter are not capable or are less capable of inhibiting the former. In recent experimentation, ${ }^{I}$ however, it has been demonstrated that these relations may be reversed, and that if shoots lower down are allowed to grow for a long enough time and to a large enough size, while buds higher up are inhibited by artificial means, the lower shoots sooner or later acquire the ability to inhibit the higher ones after the removal of the artificial inhibition. This is what might be expected if inhibition depends on the relations of metabolic gradients. Under ordinary conditions the upper levels of the stem represent higher levels in the gradient and therefore inhibit or obliterate gradients

${ }^{x}$ W. Mogk, "Untersuchungen über Korrelationen von Knospen und Sprossen," Archiv für Entwickelungsmechanik, XXXVIII, IgI4. 
lower down more readily than these with their lower rate are able to reverse the whole established protoplasmic gradient higher up. If, however, a new gradient at a lower level becomes established while the dominant region above is inhibited, it is conceivable that it may in time, by its gradual extension in the stem, obliterate more or less completely, or perhaps reverse, the original gradient and so dominate regions higher up, at least to some extent. This is apparently the case in the seedling mentioned above (p. 153) when the axillary shoots are allowed to grow long enough while the main growing shoot is inhibited. Under such conditions they are apparently able to inhibit what was originally the dominant region of the whole plant.

It is often possible to isolate a part of the plant from the dominance of the growing tip merely by cutting the vascular bundles connecting the two parts. The development of buds on the leaves of certain plants may be induced by severing the chief vein or veins of the leaf, other tissues remaining intact. In such cases buds appear peripheral to the cut, usually near the veins, but in some plants on the leaf margins.

The inhibiting influence is not confined to the growing tips of stems, for it has been shown that a leaf plays a part in inhibiting the growth of the bud in its axil. Removal of the leaf or inhibition of its activity may bring about outgrowth of the bud, if the inhibition from other souces is not too complete. In certain cases it has been shown that one part of a leaf may inhibit other parts. In Cyclamen persicum, for example, the young seedling (Fig. 86) possesses at first only a single leaf, one of the cotyledons. Removal or inhibition 
by inclosure in plaster of the distal part of the blade of this leaf before its growth is completed is followed by the development of a new leaf surface from each side of the basal portion, as in Fig. 87. When the whole blade of the leaf is cut off or inhibited, the margins of the petiole just below the level of the cut give rise to a separate new leaf on each side (Fig. 88). Here the basal portion of the leaf and the distal region of the petiole margin
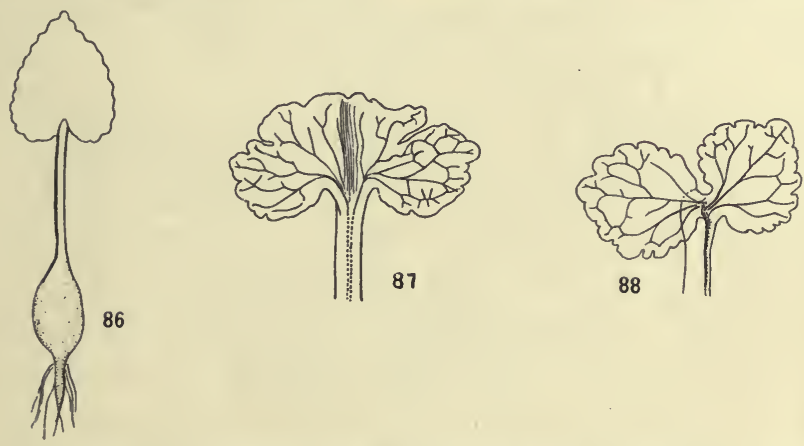

FIGs. 86-88.-Dominance and physiological isolation in leaf of Cyclamen persicum: Fig. 86, intact seedling (from Hildebrand); Fig. 87, development of new leaf blade from each side of leaf base after removal of more apical portion; Fig. 88, development of new leaf from each side of petiole margin after removal of whole leaf (from Goebel).

evidently possess the capacity to develop as a leaf, but are prevented from doing so as long as the original leaf or its distal portion is present or active.

Attention has been called to the fact that roots, wherever they appear on the plant, are apparently subordinate, specialized individuals and originate in definite relations to parts which represent regions or levels physiologically less remote than the root-tip from a stem-tip or bud (see pp. I04, I05). Most plants 
with roots possess, however, not a single root, but a root system which is a composite individual, each root representing a single constituent individual. In such a root system relations of dominance and subordination similar to those in stem systems exist. The formation of each new root represents a reproduction and the establishment of a new root individual. In plants possessing a single main root with lateral roots arising from it (Fig. 84) this relation appears very clearly. As the main root grows in length directly downward, lateral roots arise

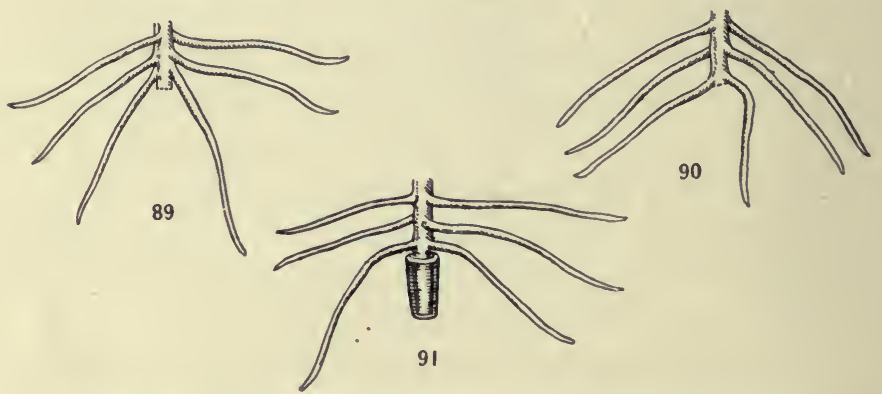

Figs. 89-91.-Effects of removal or inhibition of main root-tip on direction of growth of lateral roots (from Bruck).

successively at a certain distance from its growing tip and grow obliquely downward or almost horizontally. Experiments with seedlings show that if the growing tip of the main root is cut off, new lateral roots arise in larger numbers or nearer the end of the main root, and one or more of these nearest the cut end grows more nearly in the vertical direction downward than when the main growing tip is present (Figs. 89, 90), the behavior differing somewhat according to the level of the cut. Apparently in these seedlings the lateral roots which 
have already developed do not change their direction of growth when the chief growing tip is cut off; only those which develop after the operation react, but they or some of them develop as main instead of lateral roots and later themselves give rise to lateral roots. If the outgrowth of new roots near the cut surface is inhibited after the removal of the main growing tip by inclosing this region of the main root in plaster, roots which arise above the inhibited region may react by growing more directly downward, provided they are not too far away from the cut surface (Fig. 9I). The lateral roots which react in this way to the absence of the main growing tip resemble more or less closely the main root in their later development. When the growing tips of all roots are cut off, adventitious roots arise, usually in large numbers and without any definite order, on the parts remaining. Evidently the relation between the constituent parts of the root system is a relation of dominance and subordination like that in the stem system.

The root system as a whole seems to exert an inhibiting influence on the development of roots in other parts of the plant. When the whole root system is removed or its metabolic activity inhibited, new roots usually develop from the basal region of the stem if external conditions permit their growth there; if not, they may appear higher up on the stem. The propagation of plants by cuttings depends on this ability to produce roots on the stem in the absence of the root system. In an experiment described by Goebel and represented diagrammatically in Fig. 92, a bean seedling was placed in nutritive solution, $b$, which was kept at low temperature, whereby the activity of the root system was largely 
inhibited. A part of the stem was then surrounded with water, $a$, at ordinary temperature to provide the moisture necessary for the growth of roots, and roots arose
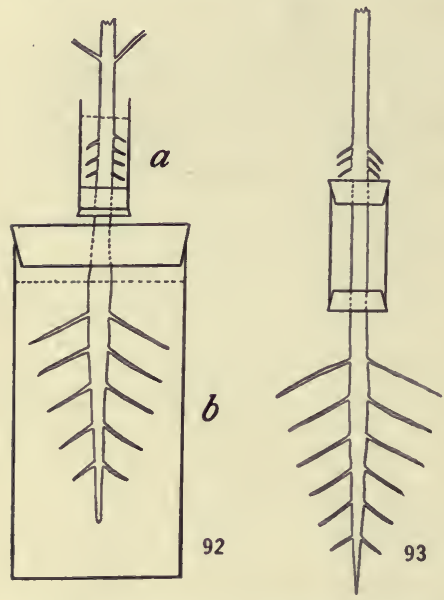

FIGS. 92, 93.-Diagrammatic figures illustrating experiments on root production on the stems of seedlings; only lower parts of plants shown: Fig. 92, formation of roots on stem at $a$ when this region is kept moist after inhibition of original root system, $b$, by low temperature (after Goebel); Fig. 93, formation of roots above a region of stem inclosed in narcotic atmosphere (after McCallum's description).

These experiments with roots seem to indicate that not only does a relation of dominance and subordination exist between the different parts of a root system, but that the root system as a whole dominates the stem to a certain extent, so far as the production of roots is con- 
cerned. If this dominance and the dominance of the stem-tip both result from metabolic gradients, then there must be in plants possessing roots two metabolic gradients in opposite directions, the apical region of one being in the stem-tip or tips, that of the other in the root-tip or tips.

Two gradients in opposite directions along the same axis cannot exist at the same time without interfering with and partially obliterating each other unless they have different paths of transmission or are of different metabolic character. Concerning the possibility of the simultaneous transmission of different metabolic changes in different directions in the same protoplasm we know nothing, and our knowledge of conducting paths in the plant does not go far beyond the fact that some part of the vascular bundles seems to transmit some kind of change better than other tissues.

It is possible, however, that the influence of the root system on the stem as a whole may be different in character from the dominance of the main root-tip on lateral roots. This possibility is suggested by the fact that the range of dominance within the root system is rather short, even where the tissues are differentiated, while the apparent dominance of the root system as a whole over the stem and other parts of the plant is apparently unlimited in range or without relation to distance. The root system takes up water and nutritive salts and these are transported to other parts of the plant. It is conceivable that the inhibiting influence of the root system on the formation of roots in other parts of the plant may be rather a transportative than a transmissive correlation, and that the other parts give 
rise to roots when this transportation falls below a certain minimum or when they are isolated from it in any way. This alternative is more nearly in accord with the views of most botanists, and it seems at present more satisfactory than the assumption of two opposed and overlapping gradients. If, however, this relation between root system and other parts is transportative rather than transmissive, McCallum's experiment described above of bringing about physiological isolation of the upper levels of the stem from the root system by local anesthesia seems to indicate that the transportation is not a simple physical process but is dependent in some way and to some extent upon the metabolic activity of living cells.

If we accept this alternative and admit at the same time the primary dominance of the stem-tip or tips and the secondary dominance within the root system of the root-tip or tips we must regard the root system as a subordinate specialized constituent individual of the composite plant individual. The root, like the leaf, is primarily determined by relations to other parts of the plant, but requires certain external conditions for its development and differentiation. Like the leaf also, the root or root system shows a certain degree of secondary individuation among its parts.

The formation of roots is the reaction of a plant individual to a certain relation between internal and external conditions, and this relation may apparently be brought about either by the inhibition of activity in, or absence of, the original root system, or in many cases by changes in the external conditions, such as decrease in light and increase in. moisture, even though the 
original root system is present. The root of the plant, like the basal end of the animal body, is the morphological expression of the performance of a certain functional activity primarily subordinate to and dependent upon the activities of other parts. Without the activities of parts representing higher levels in the primary gradient, root formation does not occur, but when it has occurred the products of the special metabolic activity of roots transported to other parts affect the metabolic processes there and so inhibit more or less effectively the formation of roots there.

From this point of view the apparent dominance of the root system over other parts of the plant with respect to root formation is not a feature of the primary and fundamental relation of dominance and subordination in the individual, but rather a secondary relation - transportative rather than transmissive - unlike the primary relation, and resulting from local differentiation which is itself associated with and dependent upon the primary relation.

THE LOCALIZATION OF EXPERIMENTAL REPRODUCTION IN RELATION TO DIFFERENT AXES

It is often possible to alter the localization of the new dominant region in the reconstitution of an isolated piece by altering the gradient relations of the piece. A few examples from the flatworm, Planaria, among the animals and the liverwort, Marchantia, among the plants will illustrate the point.

It has been pointed out (pp. 80, 8I) that the outgrowth of new tissue on a piece of Planaria isolated by transverse planes of section is most rapid in the median 
ventral region of the apical end, this region representing the region of highest metabolic rate or irritability resultant from the three main axial gradients. By altering the shape of the piece in relation to the axial gradients it is possible to alter the position of this outgrowth and so the position of the new head. In a piece cut very obliquely ( $a b c d$, Fig. 94), the head develops as in Fig. 95, and the side of the head which arises from the more

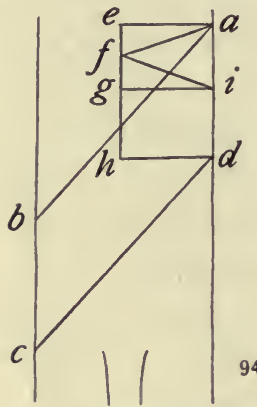

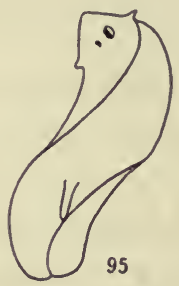

94

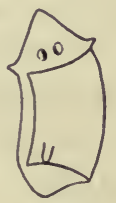

96
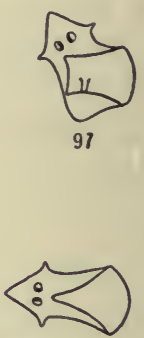

98

Figs. 94-98.-Localization of head-formation in the reconstitution of pieces of Planaria as resultant of apico-basal and transverse axial gradients: Fig. 94, diagrammatic outline of part of body of Planaria, indicating shapes of pieces; Fig. 95, asymmetrical position of head in reconstitution of piece, abcd; Fig. 96, reconstitution of piece, achd; Fig. 97, reconstitution of piece, aegi; Fig. 98, reconstitution of piece, afi.

apical level of the piece is likely to develop somewhat more rapidly than the other side. This asymmetry of position and development is due largely to the fact that one side of the cut surface represents a higher level in the major axial gradient than the other and so reacts more rapidly. When the cut surface is oblique, the major gradient becomes a factor in determining the position of most rapid dedifferentiation, division, and new development of cells, and this determines the 
position of the new head. In a piece aehd, Fig. 94, the head develops, as shown in Fig. 96, on the apical cut surface, but in a shorter piece aegi, Fig. 94, the head is likely to appear at an angle to the apical and median cut surfaces, as in Fig. 97. This condition results when the metabolic rate of the cells on the median cut surface is as high as that of the cells on the apical cut surface, so that both take an equal part in giving rise to the new head. In pieces like $a f i$, Fig. 94, the head often develops nearly or quite in the direction of the transverse axis (Fig. 98). In such pieces there is little difference in metabolic rate between apical and basal cut surfaces, and the cuts are not sufficiently oblique so that the higher level in the major gradient of the lateral as compared with the median region of the cut surface overbalances its lower level in the transverse gradient. Consequently the median regions of both cut surfaces represent the region of highest rate or irritability in such a piece and therefore become the head-forming region. For these and many other experimental modifications of the position of the head in reconstitution no satisfactory general basis of interpretation has heretofore been discovered, but I know of no case which cannot be very simply accounted for in terms of axial metabolic gradients.

In the bilaterally symmetrical liverwort Marchantia (Fig. 23, p. 78), the gradient-relations are apparently very similar to those in Planaria. In these plants practically every cell of the body is capable of giving rise to a new plant, but in pieces without the growing tip new growing tips originate in definite relations to the axes, and their presence inhibits the formation of others. In general, on transverse cut surfaces new individuals arise, like 
the head in Planaria, in or near the median ventral region of the apical end of the piece just basal to the cut surface (Fig. 99). When the piece is taken from the lateral margin of the plant body and does not contain the median region, individuals usually arise near the apical end and ventrally on the most nearly median region of the piece (Fig. 100). In pieces with oblique instead of transverse apical cut surfaces the position of the new individual varies according as the piece contains part of the midrib or not, according to the obliquity of the plane of the cut, and probably also according to the region of the body. Where the piece does not include the midrib the new individual usually arises ventrally near the most apical region of the piece, the major gradient being the chief factor in determining its position. Thus in Fig. Iог the new plant appears near the lateral margin, undoubtedly because the metabolic level is higher here than elsewhere. The conditions here are apparently much like those which determine the asymmetrical position of the new head in Planaria in Fig. 95. In pieces which contain a part of the midrib this is usually the chief factor in determining the position of the new head. The piece in Fig. IO2, for example, is cut from one side of the body and includes part of the midrib at the basal end of the oblique cut, and the new bud arises here. The influence of the midrib in localization in this form depends on the fact that the cells in this region retain their capacity for growth and division much longer than the cells of the lateral regions, and so they represent a relatively high metabolic level and bear much the same relation to the transverse gradient that the apical growing tip does to the major 
gradient. Because of the relatively high metabolic level of these cells along the midrib this region plays a more important part in the localization of reproduction than the median region in Planaria. In fact, the experimental evidence seems to indicate that the chief difference in axial relations between Marchantia and Planaria is the higher metabolic level of the apical region of the transverse gradient, the median region of the body.
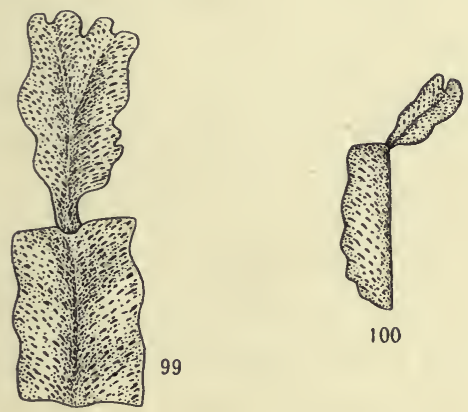

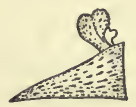

101

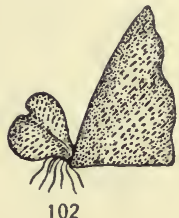

FIGS. 99-I02.- - Localization of new individual as resultant of different axial gradients in pieces of liverwort, Marchantia: Fig. 99, usual position in median ventral region near apical end of piece; Figs. IooI02, different positions of new individual apparently determined by the different relations of the axial gradients according to shape of piece and region represented (from Vöchting).

With advancing age the region of the midrib undergoes gradual differentiation and so loses to a greater or less extent its high metabolic rate.

These experiments and many others which cannot be discussed here are highly significant in that they indicate the essential identity in character of the different axes of the physiological individual. In fact, I believe they constitute evidence of the greatest importance 
for the fundamentally quantitative character of at least the main axes of the body, for if the different axes are qualitatively different, I cannot conceive how the position of a new head or growing tip on an isolated piece can be determined in one case chiefly by the major axis, in another as a resultant of two or more axes, and in a third by one of the minor axes. If, however, all axes are fundamentally gradients in metabolic rate, the facts are very simply accounted for, as I have tried to show. The major axis is the major axis, not because its nature is fundamentally different from that of other axes, but because it arises first or because its apical region has the highest metabolic rate of any part of the body, and the minor axes are minor axes because they arise later or their apical regions have a lower rate. When the major gradient is in any way obliterated to a sufficient degree one of the minor gradients may act in exactly the same way as, though often more slowly than, the major gradient where it is present. This is true, of course, only for forms and stages in which the fundamental quantitative character of the axes has not been too greatly altered by progressive differentiation.

The fact that a plant bud may be inhibited by the main growing tip, by another bud, by a growing leaf, or by a lateral branch also indicates that there is nothing specifically different in these different inhibitions and so suggests that these different plant axes act in essentially a quantitative way in dominating other parts. One may be substituted for the other without altering the character of the effect. 


\section{CONCLUSION}

It is possible to control and alter experimentally the spatial relations of parts in the individual by altering the length of the metabolic gradient and so the range of dominance. Parts of the individual may come to lie beyond the range of dominance in consequence of increase in size of the whole, of decrease in range and degree of dominance by decrease in the metabolic rate in the dominant region, of decrease in conductivity of the paths of correlation, and of the direct local action of external factors which increase the independence of subordinate parts. Parts thus physiologically isolated may reproduce new individuals if the essential axial gradients exist, or arise in them. In many of the lower organisms the original axis or axes may be experimentally obliterated and a new axis and dominance established in relation to external conditions which determine differences in metabolic rate in different parts of the mass. In general, the range of dominance increases during the development of the individual because the conductivity of the protoplasm increases, and special conducting paths develop as the morphological expression of the fundamental correlative conditions in the individual. The essentially quantitative character of different axes of the individual is indicated by the fact that one axis may be experimentally substi- tuted for another in determining the localization of a new individuation. 


\section{CHAPTER VI}

\section{DISCUSSION, CONCLUSIONS, AND SUGGESTIONS}

\section{THE NATURE OF DOMINANCE}

It has been assumed thus far that dominance depends on a transmitted change, or excitation, rather than on the transportation of substance, and it now becomes necessary to consider what basis there is for this conclusion. As already pointed out (pp. 26, 27), some sort of organization must be present in order that transportative or chemical correlation may occur in a definite and constant manner. If different regions of the body produce specifically different substances they must be specifically different, and if these substances act on certain other parts in a definite specific way those parts must possess a certain constitution. The data of experimental reproduction discussed in earlier chapters show that new individuals arise from parts of old individuals which either cannot possibly possess the "organization" of a complete individual or must possess an indefinite number of such organizations. The latter alternative leads to a conception of the Weismannian sort, and I have tried to indicate how unsatisfactory such conceptions are (pp. 22, 23).

If, on the other hand, the individual is primarily a metabolic gradient in a specific protoplasm, the only primary difference between the dominant and other levels of the gradient is a difference of metabolic rate. At this time the products of metabolism at different 
levels of the gradient are not specifically different, but differ in quantity. If the transportation of chemical substances is the only means of correlation between the different levels of the gradient, it is impossible to understand either how the gradient can persist or how a relation of dominance and subordination can arise between levels of higher and those of lower metabolic rate. Specific chemical correlation between parts is possible only when specifically different parts are present, and the definite space relations which we find associated with physiological dominance do not usually appear in such correlation. In short, I believe it is impossible to conceive of the process of organic individuation with the definite, constant, and orderly character which it actually possesses as having its origin in transportative or chemical correlation alone.

If, however, the metabolic gradient arises and is maintained by the transmission of excitation from the region of highest metabolic rate, this region becomes dominant simply because its metabolic rate is so high that it determines and maintains the gradient in rate, and the differences in rate at different levels bring about sooner or later differences in constitution and character of the protoplasmic substratum. In regions of high rate only certain relatively stable substances remain as constituents of the substratum, and others are broken down and eliminated. In regions of lower rate, on the other hand, other substances accumulate as parts of the substratum because under these conditions they are less readily or less rapidly broken down than where the rate is higher, and it is also probable that the character of synthesis differs with the rate of metabolism. In 
this way each level of the gradient develops a characteristic protoplasm and the character of the protoplasm in turn modifies and alters the character of the reactions, and so specific, or what we call qualitative, differences arise, and different specific substances may be produced at different levels of the gradient. At the moment when these specific differences first appear chemical correlation in the commonly accepted sense becomes possible, and from this time on it may play a part in determining the character of further changes at the various levels. After chemical correlation appears it is unquestionably a factor of great importance in determining the character of the various parts and so of the individual as a whole. The point which I wish to emphasize is that chemical or transportative correlation does not and cannot account for the origin of the individual, because the individual must exist as some sort of orderly and definite relation or organization before orderly and definite chemical correlation between its parts is possible. The dynamic conception of the individual is primarily concerned, not with the orderly specificities of chemical correlation, but with the conditions in protoplasm which make those orderly specificities possible.

The occurrence of transmission in living protoplasm is a familiar fact. The existence of a transmissiondecrement and therefore of a limited range of effectiveness has been demonstrated for the transmission of stimuli in plant tissues and in various animal nerves. In many of the lower animals the range of effectiveness in transmission can readily be observed by means of the range of reaction to stimuli of different intensity. In transportative correlation a definite range of effective- 
ness cannot exist unless transportation is uniform and constant in rate in all parts at each level and the substance is gradually destroyed or transformed during the transportation. The dynamic theory affords an adequate basis for the very definite range of dominance which we find in organisms, and a chemical theory does not.

Tashiro's recent investigations on carbon-dioxide production and my observations on susceptibility gradients in the nerve indicate that physiological dominance in the neuron, i.e., the direction of transmission, is associated with the existence of a metabolic gradient. Individuation in what is probably the most highly specialized cell individual in the organism apparently starts from the same condition, the metabolic gradient, as in the simplest axiate animal or plant. It is certain that dominance in the neuron depends primarily on transmission and not on transportation. This argument from the highly specialized to the simple is perhaps not of great value; still I cannot but believe that the existence of an axial gradient in metabolic rate in the neuron and in the simple axiate individuals among the lower organisms is a fact of real significance.

It has been very generally believed by physiologists that the nerve, at least the medullated nerve of vertebrates, transmits excitations under normal conditions without a decrement in energy or intensity. It is, however, a well-known fact that even in these nerves a decrement appears when transmission takes place at low temperature or in partially narcotized or compressed nerves; in fact, under various conditions which decrease metabolic rate or irritability in the nerve. 
Those who hold that the nerve in normal condition transmits without a decrement have usually maintained that under depressing conditions the nerve behaves in a different way from the normal nerve and that the decrement exists only under these conditions. In view of the fact that in the nerves of the lower animals a transmission-decrement undoubtedly occurs normally, and that in protoplasmic transmission in the absence of nerves the decrement is even more marked, the grounds for the belief that transmission without a decrement occurs in the vertebrate nerve do not appear to be adequate. It seems scarcely probable that the higher degree of specialization of the vertebrate nerve has brought about a fundamental change in the character of transmission of such a nature that the decrement is reduced to zero and transmission to an indefinite or infinite distance is possible. The experiments along this line prove only that with the very limited lengths of nerve available the decrement under normal conditions is very slight or inappreciable. Evidently the nerve of the vertebrate, and particularly of the higher vertebrate, is a much better conductor than undifferentiated protoplasm or even than the nerves of lower animals, and within the limits of the individual vertebrate body the decrement is undoubtedly slight or practically absent when the nerve is in good metabolic condition, but the conclusion that there is no decrement in such cases seems unwarranted. It is also highly improbable that the nature of transmission in the cooled, partially narcotized, or compressed nerve is essentially different from that in the same nerve under normal conditions, and since a decrement appears under depressing condi- 
tions, the only conclusion justified by the facts seems to be that a decrement must exist in normal transmission, but is much less marked, and the range of transmission is therefore much greater, than under depressing conditions. Undoubtedly in the higher animals the range of transmission is very much greater than the limits of the individual body, for the size of the individual in these forms is limited by other factors than the range of dominance (see pp. 46, 47, I5I), but that transmission without decrement occurs is far from being demonstrated and, as I have endeavored to show, there is much evidence against such a view.

It is also a highly significant fact that the nervous system, which is the chief conducting organ of the body in those forms which possess it, develops in a definite relation to the axial gradients. The dominant region of the nervous system appears in the apical region of the major axial gradient, and at other levels of the body which contain the central nervous system it represents the region of highest metabolic rate in the minor gradients. If the unity of the organism depends primarily upon transportation, there is no apparent reason why it should change to a unity depending on transmission or why the dominant region of the central nervous system should arise in the dominant region of the primitive individual. If, however, organic unity is fundamentally and from the beginning dependent upon transmission, the general plan and arrangement of the nervous system are very evidently the expression in specialized structure and function of the primary unity and relation which was the starting-point of individuation, and dominance or control by nervous transmission is merely 
a specialized and more effective modification of the dominance which is the foundation of organic unity and order.

Moreover, the nervous system dominates or controls the chemical activities of the organism to a very considerable degree. If the primary dominance is purely a matter of chemical correlation, it is difficult to conceive how the functional dominance of the nervous system has come about, but if the primary dominance depends upon transmission of the same general character as nervous transmission, the functional dominance of the nervous system is the natural and necessary consequence of the primary relations.

As regards the rôle of the nervous system in development and reconstitution, there has been much difference of opinion. Many biologists have maintained that the nervous system exerts a specific formative influence on various parts and so determines their course of development and differentiation, while others deny the existence of any such influence. In the case of certain organs and parts, e.g., striated muscle, it has been definitely demonstrated that embryonic development may occur without nervous connection, but in the mature condition frequent nervous stimulation is necessary for maintenance of structure and function. And as regards reconstitution, some investigators have found that certain parts, such as the amphibian leg, regenerate incompletely or not at all in the absence of nerves, while others have maintained that connection with nerves is unnecessary for complete regeneration of these parts. These apparently contradictory and confusing results can, I believe, be very simply inter- 
preted and harmonized. If the metabolic rate in the organ or part in question is sufficiently high, it is capable of undergoing its characteristic development and differentiation without nervous stimulation, assuming of course that its other relations as a part of the individual are not fundamentally altered; but when its intrinsic metabolic rate falls below a certain level its development does not occur, or is incomplete, or it undergoes atrophy unless its rate is further increased by nervous stimulation. In the case of striated muscle during the earlier stages of development the intrinsic metabolic rate is high enough to permit without nervous stimulation the accumulation of structural material and the characteristic course of differentiation determined by other correlative conditions, but as differentiation and senescence progress the metabolic rate falls, and finally the muscle is not even able to maintain itself in the absence of the accelerating influence of nervous stimulation upon its metabolic rate, because when its rate falls below a certain level it does not replace its losses by new muscle substance. In the regeneration of the amphibian leg and other cases where the influence of the nervous system is in dispute, the relations are without doubt essentially the same.

There is no reason to believe that the nerve impulse is anything more than an acceleration of metabolism. The appearance of the nervous system does not constitute the addition of something new to the organism; it is merely the visible expression of relations already existing and, as the facts indicate, of the relations which constitute the foundation and starting-point of individuation. 
The question whether metabolic gradients involving different metabolic processes may exist at the same time in the same protoplasm must at least be raised. So far as gradients depending on transmission are concerned, this question is really the question whether different sorts of changes or excitations may be transmitted through the same protoplasm and whether different metabolic effects result. Any answer to this question at present is little more than a guess. It is perhaps conceivable that at least in undifferentiated or slightly differentiated protoplasm some degree of difference in the character of the transmitted change may exist under different conditions of excitation, etc. If such differences do exist, they must of course be important factors in development and differentiation, but they merely complicate and do not alter fundamentally the character of unity and order in the individual. At present there seems to be no real evidence that they exist.

\section{THE NATURE OF INHIBITION}

In chaps. iv and $\dot{v}$, I have pointed out that the inhibition or retardation of new individuation by the dominant region of an individual occurs when the original gradient is sufficiently fixed in the protoplasm, or the metabolic rate at the levels concerned is sufficiently high to prevent the establishment of a gradient in another direction or to obliterate more or less completely or prevent the further development of a gradient in another direction. In Tubularia the inhibiting influence of the apical region on the development of a hydranth at the basal end of a piece is apparently simply the obliterating effect of the original gradient on the gradient in the 
opposite direction. If the latter attains a sufficiently high rate it interferes with or obliterates the other and the hydranth develops, though partial inhibition may be evident in its shortness and slow development.

In the case of a lateral bud of a plant, the development of which is inhibited by the main growing tip, the relation is probably the same. As long as the bud is within the range of dominance of the growing tip its own gradient from apex to base is more or less completely obliterated by a gradient from base to apex determined by the main growing tip. This may in time alter the protoplasmic gradient in the bud determined in the earlier stages of its individuation so that it becomes incapable of development or develops only into a short branch, a spine, or some other rudimentary structure. It is interesting to note that Mogk in his studies of plant correlation finds that when the axillary shoots of a seedling are allowed to grow until they attain dominance over the main shoot (see pp. I52, I 53), the latter often dies and the death gradient is in the reverse direction from that of death from lack of water or other conditions in an uninhibited shoot. Leaves and roots probably represent partially inhibited gradients under certain conditions, and some of the specialized outgrowths on the animal body, such as appendages, may perhaps in some cases represent somewhat similar relations, though I know of no definite evidence bearing on this point.

So far as the evidence goes, it indicates that all inhibition of this sort is a matter of interference between gradients in opposite or nearly opposite directions, the one gradient reducing, obliterating, or even reversing 
the other. This interference is in certain respects analogous to physical interference in the transmission of water waves, sound waves, light waves, etc., but the protoplasmic substratum in the organism represents a factor not concerned in physical interference in nonsolid media. Undoubtedly a gradient which is originally dynamic becomes more or less stably fixed or established in the protoplasm as a gradient in irritability, structure, or differentiation, because the effects of the transmitted excitations modify the protoplasmic condition and this modification may become more or less persistent. Temporary inhibition may result from temporary interference between metabolic gradients, but for permanent or long-enduring inhibition the protoplasmic condition determined by one gradient must be reduced or obliterated or its direction reversed by the action on the protoplasm of another gradient. In the cases of obliteration or reversal of the axial gradients by other gradients this factor undoubtedly plays a more or less important part, and the increasing stability of the protoplasmic substratum with the progress of individual development ${ }^{\circ}$ and evolution ${ }^{\mathrm{I}}$ determines that such obliteration and reversal occur much more readily in the lower than in the higher organisms.

Since conduction in the nerve is apparently associated with an axial gradient, it is at least an interesting question whether nervous inhibition may not be fundamentally a similar relation of gradients, either in different neurons or in the innervated organ. The mechanism of nervous inhibition is still obscure, but if the nervous

${ }^{I}$ Child, Senescence and Rejuvenescence, 1915, pp. 50, 53, 194, 267, $463-65$. 
system is really the final expression of the primitive dominance in the individual, it is conceivable that the highly specialized nervous inhibition may have something in common with the primitive form of inhibition in the lower animals and plants.

ORIGIN OF METABOLIC GRADIENTS AND OF DOMINANCE

The data of reconstitution discussed in chaps. iv and $\mathrm{v}$ show very clearly that new metabolic gradients arise in relation to various external factors: in Tubularia the cut end (pp. I32-37); in Corymorpha the difference between a free surface and one in contact (pp. I42-46); in Harenactis difference in the character of a wound determining more or less growth of new tissue and so the localization of a new apical region. As regards the plants, the evidence from adventitious buds (pp. 83-86) also indicates that the axes of such buds arise anew, slight differences in metabolic rate between different cells apparently often determining whether a new individual shall arise in one place or another. As regards various plants, we know that certain of the minor axes, and in some cases the major axis, are determined by the differential action of light. I believe we are justified in saying that whenever a new metabolic gradient of sufficiently high rate is established by an external factor a new individuation occurs.

It is of course easy to assume, as is often done, that polarity and symmetry are self-determined in the individual, and that these self-determined relations are simply altered and modified by external factors. But the evidence for self-determination is lacking, and the evidence for external determination is abundant and 
highly conclusive. The assumption of self-determined polarity and symmetry in protoplasm is simply superfluous, and the burden of proof is upon its supporters.

Of course the metabolic gradients present in one individual may persist in the parts when that individual divides, so that in such cases the axial relations of the new individual are predetermined. This is the case in fission in Planaria (pp. 92-96) and in many other forms. Apparently also the gradient in a reproductive body, e.g., many eggs, is often determined by its relations of attachment, nutrition, etc., to the parent body.

In pieces of Tubularia, Corymorpha, Planaria, and many other forms, the original polarity gradually disappears as the length of the isolated piece decreases until it becomes practically apolar, and new polarities arise in relation to conditions at the cut ends (pp.97-10 I). This fact indicates that polarity is rather a matter of relation of parts than a fundamental property of protoplasm, for in fractions of the axis below a certain length it disappears.

In nature a particular kind of individual shows certain characteristic axial relations; it is radially or bilaterally symmetrical, or a combination in a characteristic way of radial and bilateral arrangements. But the characteristic axial relations are not invariable; they appear regularly merely because events follow the same course in successive generations. In plants the axial relations can be altered in many ways and by many external factors. Bilateral symmetry may be transformed into radial or radial into bilateral, the position of branches may be altered from alternate to opposite or to whorled, and so on. The bilateral tentacle groups on the rings 
in Harenactis (Fig. 82, p, 147) show that the radial arrangement characteristic of the animals in nature is not invariably determined in the protoplasm, but is only one of various possibilities, which may or may not be realized according to conditions.

If my conception of the relation between the metabolic gradient and dominance is correct, then of course the origin of a new gradient is the origin of a new dominance, and if such a gradient is uninhibited by gradients in other directions, and if its metabolic rate is high enough, it becomes the major axis of an individual and its region of highest rate the dominant apical region.

\section{MORPHOLOGICAL DIFFERENTIATION IN RELATION TO METABOLIC RATE}

The belief that qualitative differences of some sort in the fundamental constitution of the organism must underlie the morphological and physiological differences which arise during development in different parts of the individual has been so widespread among biologists that any attempt at even a statement of the problem of differentiation in anything like quantitative terms is sure to meet with serious objection and criticism in some quarters. Nevertheless, the simplest and most satisfactory, and, I believe, the only adequate, interpretation of the data of reconstitution which have been discussed in preceding chapters is that the starting-point of differentiation is in differences in metabolic rate. The attempt to interpret these facts on any other basis very soon becomes involved, either in the barren assumptions of the hypotheses which simply postulate an invisible organization to account for a visible, or else 
in the equally barren neo-vitalistic assumptions of some non-mechanistic controlling or determining principle, entelechy, or whatever we please to call it.

The head of Planaria will serve to illustrate the point. I have shown that a series of different forms of head occur in reconstitution, ranging from the normal to the headless condition (pp. Io6-8). These different forms represent various degrees of inhibition and they result, not only from the inhibitory influence of other parts (pp. I08-i4), but can be produced experimentally by a great variety of conditions. In a lot of similar pieces from animals in similar physiological condition a decrease in head-frequency or a shift toward the headless condition can be induced by low temperature, narcotics, carbon dioxide, etc., although in certain cases, as we have seen (pp. I12-I3), the results are complicated by the metabolic relations between the headforming region and other parts of the piece. On the other hand, conditions which accelerate metabolism, such as high temperature or increased motor activity, increase the head-frequency or shift it toward the normal end of the series. We cannot believe that differences in temperature or motor activity alter the fundamental "organization" in the head-forming region, but it is a fact that such conditions according to their degree may determine any or all of the various kinds of head between the normal and headless extremes.

Again, how does either an "organization" or an entelechy aid us in interpreting the structures formed on rings in Harenactis (pp. I46-49)? Here results range from various bilateral arrangements of parts to the characteristic radial symmetry, and from single 
tentacles to normal animals. Either the plan of organization or the purpose of entelechy must be very different in different tentacle groups on such rings. We know, however, that the pieces will not form rings except under certain experimental conditions, and that when they do not they undergo reconstitution in the usual way to animals of the usual form. Evidently the development of these structures on the rings results from certain experimental conditions, but if simple experimental conditions can alter the fundamental axial relations in the individual, what is the necessity of the postulated organization, or entelechy, or other similar principle? And does not the obliteration in Corymorpha of the original axial relations and the establishment of new relations in their place, by means of experimental conditions whose action upon metabolism is primarily quantitative (pp. I42-46), indicate that the axes themselves are primarily quantitative relations? Similarly the fact that the localization of experimental reproduction may be determined as a resultant of different axes or by a minor axis in the absence of the major axis (pp. I63-68) forces us to the conclusion that the different axes are fundamentally identical and therefore represent quantitative relations.

Moreover, the conception of the organic axis as a metabolic gradient enables us not only to interpret, but to control and to predict. In recent work on the oligochete annelids, by Dr. Hyman, it has been possible on the basis of the metabolic axial gradient to predict and control experimental results, and this is possible among the flatworms to an even greater degree. As regards the manner in which physiological and morphological 
specialization results from difference in metabolic rate there are various possibilities. In a physico-chemical complex like living protoplasm a change in temperature of a certain amount alters the rate of chemical reaction to a certain degree, but it also alters many other conditions in protoplasm, e.g., osmotic conditions, surface-tension, aggregate condition of colloids, etc., and it alters some in a greater, others in a less, degree. In such a case the change in each particular process or condition in the living protoplasm may be quantitative, but since different factors are altered in different degree the total change may determine qualitative differences in the reactions or their products. Changes of this sort may result, not merely from differences in temperature, but from other primarily quantitative changes. In fact, it is very doubtful whether we can alter metabolic rate to any great extent without bringing such changes in quality somewhere in the complex.

Elsewhere I have called attention to various facts which have as yet received but little attention, but which indicate that a relation exists between morphological structure and metabolic rate. ${ }^{\mathrm{x}}$ Structural features which are stable with a certain metabolic rate are eliminated when the rate increases, while decrease in rate may determine the addition of new structural substances, and so on. Metabolic rate is apparently a factor, though of course by no means the only one, in determining what substance or substances accumulate in the living cell as structural substratum, and the structural substratum is an important factor in determining the character of the reactions which occur in it.

${ }^{1}$ Child, Senescence and Rejuvenescence, I9I5, pp. 47-54, 226-27. 
The lack of specificity in the action of a great variety of experimental conditions upon development and morphology has often been noted. For example, the aberrations or abnormalities in development, or more properly the partial inhibitions of development produced by low temperature, various narcotics and poisons, and many other conditions are essentially the same. The reason for the lack of specificity undoubtedly lies in the fact that the action of these various substances and conditions is primarily quantitative, yet a greater or less degree of differentiation, various differences in form and arrangement, and even the presence or absence of specific organs may be determined by their action.

The results of the quantitative changes in living protoplasm in a particular case must of course depend upon its specific constitution. The kind of specialization or differentiation which arises at a particular level of a metabolic gradient must depend upon this constitution, and the developmental and morphological resemblances between different forms must of course depend in general upon similarities of constitution. The development of the region of highest metabolic rate in the major gradient as a growing tip in plants and as a central nervous system or brain in animals must result from differences in constitution and dynamic processes in the plant and animal protoplasm, but growing tips in general and central nervous systems in general have certain common characteristics.

We must, I believe, conclude that the conception of the metabolic gradient, a gradient primarily quantitative, originating in and primarily determined by the dominant region, as the basis of physiological and morphological 
order, of "organization," specialization, and differentiation in the organic individual, not only presents no fundamental difficulties, but is supported by a great body of experimental and observational evidence from various biological fields.

\section{THE FUNDAMENTAL REACTION SYSTEM}

If the dynamic conception of the organic individual is correct, the starting-point lies, not in a certain organization, but in a certain reaction system. This is a protoplasm of specific constitution with a corresponding metabolic specificity, or one may say that this specificity is the expression of a specific constellation of conditions and that this in turn has been determined by the specific constellation of factors external to itself to which each organism, individual, or part has been subjected in the past. It is this reaction system, not an organization, which constitutes the basis of inheritance, and it is in this system that differences in metabolic rate initiate the process of organization. We may for convenience regard the embryonic or undifferentiated cell of the species as representing this fundamental reaction system, although even there the system is doubtless not reduced to its lowest terms. The developmental changes in this system fall into two groups, the self-determined ${ }^{\mathrm{T}}$ changes

${ }^{\mathrm{I}}$ It is perhaps desirable to indicate just what is meant by selfdetermination in this connection. All that the word is intended to imply here is that the region of highest metabolic rate may undergo certain progressive changes, which are determined by its own constitution and by continued metabolism in it. These changes may in time make this region different structurally and physiologically from what it was originally, even though it is independent of other parts. 
characteristic of the dominant region and the correlatively determined changes characteristic of subordinate regions. It is a very significant fact that the self-determined changes in animals always result, where they proceed far enough, in the development of a nervous system. Of course as a matter of fact the changes which occur in the development of a central nervous system are not all absolutely self-determined, for if they were all cells of the nervous system would be alike. We may say, however, that in the animal the nervous system or its apical portion represents more nearly than any other part of the body the result of self-determined progressive changes in the fundamental reaction system of the species, while other parts represent the result of changes determined by correlation and dependence. From this point of view the animal organism is fundamentally nervous system; all other parts represent lower levels of metabolism and independence. The central nervous system represents more nearly than any other part of the individual the product of the fundamental reaction system at its highest level. The cephalic nervous system is, so to speak, the organism at its best.

In the plant, however, the self-determining dominant region remains, at least during growth, in an undifferentiated or relatively undifferentiated condition as the growing tip, and growth and cell division are its chief activities. In consequence of this condition its dominance over other regions is slight, the degree of individuation in the plant remains low, and the life of the plant remains simple and narrowly limited in character.

This difference between animals and plants, in the one the development of the dominant region into the 
central nervous syștem, the most stable structure physiologically of the body, and in the other its persistence indefinitely as an embryonic cell or a group of cells, must be an expression of the fundamental difference between the two groups of organisms. Evidently this difference is primarily a difference in relation between the protoplasmic substratum and the metabolic reactions. Stable morphological structure and differentiation in the plant consist largely in the deposition of carbohydrates and other non-proteid substances within or about the cells, while in the animal morphological differentiation very generally has its origin and foundation in the accumulation and specialization of protoplasm itself. Apparently the protoplasmic substratum of the plant is much less stable physiologically than that of the animal. The plant seems to be incapable or almost incapable of synthesizing proteid molecules which are physiologically stable where the metabolic rate is high. The protoplasm of the plant cell is certainly much more directly and intimately involved in the chemical reactions of metabolism than that of most animal cells; consequently in regions of high metabolic rate no persistent protoplasmic structure like that of the animal cell can arise, because there is no accumulation of relatively stable substances in the cell. In regions where the metabolic rate is lower, substances may accumulate in the cell as structure which with a higher metabolic rate would be decomposed. In the plant, therefore, morphological differentiation increases with increasing distance from the growing tip and decreasing metabolic rate, while in the animal differentiation begins and is most stable in the apical region - the region of highest reaction rate- 
and progresses from this to other parts. Animal metabolism evidently synthesizes highly stable molecules, even where metabolic activity is most intense.

In the plant the whole substratum may apparently be mobilized to some extent when the metabolic rate is high, and only as the rate becomes lower do substances accumulate as structure. In nearly all if not all animals, on the other hand, certain protoplasmic substances are relatively more stable under the existing metabolic conditions than in the plant and therefore accumulate, and a progressive structural development and differentiation occur even when the metabolic rate is highest. In the animals the morphological structure which develops in the region of highest metabolic rate is physiologically the most stable structure of the body, because the less stable substances are decomposed in the intense metabolic activity and so do not form permanent constituents of the substratum. In regions of lower metabolic rate substances accumulate which are readily removed by an increase in metabolic rate. These parts may therefore undergo dedifferentiation and redifferentiation. The head-region, however, or, more specifically, the central nervous system, is almost or quite incapable of dedifferentiation under ordinary conditions, because its structure has developed under conditions of more intense metabolic activity than any other part of the body and is therefore more stable. If the metabolic rate could be increased sufficiently above the rate in the developing nervous system without bringing about death, doubtless dedifferentiation of the nervous system would occur to some extent. To refer briefly to the analogy between the organism and the flowing 
stream which I have used elsewhere, ${ }^{x}$ the plant is somewhat like a stream flowing in an alluvial channel, capable of shifting and removing previous structural deposits, and, when its rate is highest, of holding all its sediment in suspension. The animal, on the other hand, represents a condition like that in the stream when deposition of sediment is going on and giving rise to stable structure, even where the rate of flow is highest. In such a stream the most stable structure develops where the rate of flow is highest, while the structure developed with a low rate of flow is readily altered or eliminated by an increase in rate.

The fundamental differences in behavior between plant and animal are of course associated with this difference. Since the plant is to a large extent incapable of developing morphological colloid structures, such as nerve and muscle, its reactions to external factors are limited very largely to growth reactions, instead of being motor reactions like those in most animals. The low degree of individuation and physiological efficiency in the plant as compared with the animal must also depend on this low degree of physiological stability in the protoplasmic substratum.

AGAMIC REPRODUCTION IN RELATION TO PHYSIOLOGICAL ISOLATION

The occurrence of reproduction in consequence of physiological isolation of parts under experimental conditions makes it highly probable that at least many of the processes of agamic reproduction in nature are like-

${ }^{x}$ Child, "The Regulatory Processes in Organisms," Jour. of Morphol., XXII, I9II. 
wise the result of physiological isolation. Elsewhere I have endeavored to show that physiological isolation is a fundamental factor in asexual reproduction in both plants and animals, and that reproduction results from physiological isolation because the isolated part loses to a greater or less extent its differentiation as a part, becomes physiologically younger, and undergoes a new individuation. ${ }^{x}$ In chap. iv above it was also pointed out that agamic reproduction in Tubularia and Planaria is readily interpreted as the result of physiological isolation. Moreover, in the discussion of the data of experimental reproduction we have seen that physiological isolation and reproduction may result, not only from increase in size beyond the range of dominance, but also from decrease in the range of dominance in consequence of decrease in metabolic rate in the dominant region, from decrease in conductivity in the path of transmission, and finally from a decrease in receptivity of a subordinate part, brought about by the action of local factors, which determine the establishment of new gradients in it or make it otherwise more independent. Undoubtedly all these different forms of physiological isolation occur in nature, and in many reproductive processes more than one of them are probably concerned.

Reproduction in consequence of increase in size is one of the commonest forms of reproduction in organic individuals from the single cell to complex organisms among both animals and plants. Reproduction also occurs very commonly under conditions unfavorable to

"Child, "Die physiologische Isolation von Teilen des Organismus," Vorträge und Aufsätze über Entwickelungsmechanik, H, XI, I9II; Senescence and Rejuvenescence, I915, pp. 228. 
growth or active life; that is, under conditions which undoubtedly decrease metabolic rate and so decrease the range of dominance. Under such conditions unicellular forms often fragment into a number of small individuals, and some of the simple plants break up into their constituent cells, which then grow and divide to form small individuals, even under the same conditions which made impossible the persistence of the original larger individual. Other plants give rise to adventitious buds, sometimes in great numbers, under such conditions, while still others break up into quiescent forms, and so on. In my study of senescence and rejuvenescence $I$ have pointed out that the decrease in metabolic rate with advancing senescence in the lower animals and plants often leads automatically by decreasing dominance to physiological isolation of parts and so to rejuvenescence and reproduction of new individuals.

Reproduction under depressing conditions has often been interpreted in a teleological way as an attempt of the organism to avoid extinction by producing new individuals, some of which might succeed in finding favorable conditions for continued existence. As a matter of fact, however, such reproduction is merely the expression of physiological weakness; the individual can no longer maintain itself as a unity in its original size, and as the original unity disappears, new unities arise as local metabolic conditions determine.

Regarding the part played by changes in the conductivity of the path of transmission in bringing about physiological isolation and reproduction in nature, we know little. It is undoubtedly a fact that the increase in conductivity during development of the individual 
brings about an extension of dominance and so inhibits or retards physiological isolation (see pp. I49-5I), and it is probable that sooner or later with advancing senescence a decrease in conductivity occurs in at least some cases. It is also probable that decrease in conductivity occurs in the lower organisms under external conditions which decrease metabolic rate in the organism in general. Such changes, where they occur, may play a part in determining physiological isolation and reproduction.

Local external conditions undoubtedly assist in the physiological isolation of subordinate parts in many cases. In various plants local conditions very favorable to metabolic activity and growth may determine the development of buds in spite of the inhibiting influence of the dominant region. We have seen how in pieces of Tubularia stem the presence of the wound at the basal end assists in establishing the new gradient, even in spite of the presence of the old (see pp. 132-37). This is a good case of physiological isolation by the action of local factors.

Further analytic investigation along these lines is greatly needed to enable us to determine the part played by the various factors in different cases of reproduction, but the mere observation of various reproductive processes - such, for example, as the production of a new plant by a strawberry runner, after it has attained a certain length - will enable us to learn much concerning the range of dominance and its changes under different conditions.

The reduplication of parts in an organism, such as leaves and roots in the plant and segments and various 
other parts in the animal, belongs in the same category with the reproductive processes which give rise to new whole organisms. In such cases physiological isolation may be partial or with reference to a specialized constituent individual of the organism.

The localization of reproduction in the individual may be determined by various other factors besides distance from the dominant region. Some parts less distant than others may be physiologically isolated earlier because of lower conductivity of paths, or because of other correlative conditions within the organism, or because of certain external conditions. In isolated parts the least differentiated cells or regions, or those with the highest metabolic rate, are likely to react earlier than others and so determine the localization of the reproductive process. Sometimes, particularly among plants, in reproductions which occur with advancing age or under depressing conditions, it is the original dominant region which separates from other parts as a smaller individual and so becomes the reproductive body, spore, or whatever it may be called.

Special unrecognized factors may play a part in certain cases, but it seems impossible to doubt that, in general, agamic reproduction in organisms results from physiological isolation of parts of the individual. Individuation is a physiological integration depending primarily on the dominance and subordination of parts in relation to an axial gradient or gradients, and agamic reproduction is a physiological disintegration of this unity which makes possible new integrations.

The fundamental similarity in individuation and reproduction in the lower animals and plants is well 
illustrated by a comparison of certain corals with the plants. Wood-Jones ${ }^{\mathrm{I}}$ has recently found from a study of living animals under natural conditions that in the staghorn corals there is a radially symmetrical, apical zooid at the tip of the stem which gives rise by budding to the bilaterally symmetrical, lateral zooids, while these do not reproduce as long as the apical zooid is present and active. At a certain distance from the apical zooid one of the bilaterally symmetrical zooids may become radially symmetrical and begin to reproduce new zooids and so become the apical zooid of a branch. If the apical stem-region with the apical zooid is removed, several branches may arise by the transformation of bilateral into radial, reproducing zooids. Moreover, the apical zooid of stem and branches remains young indefinitely, while the lateral zooids which do not reproduce undergo senescence and die. In other corals various degrees of composite individuation are found to exist. The relation of the dominant apical zooid to other parts in the staghorn corals is very evidently essentially the same as that between the growing tip and other parts in plants, and it is impossible to doubt that the same fundamental principle underlies and determines the relation, not only in these two cases, but in organisms in general.

\section{GAMETIC REPRODUCTION}

Sexual or gametic reproduction, with rare exceptions the only reproductive process giving rise to whole new organisms among the higher animals, is commonly

${ }^{x}$ F. Wood-Jones, Coral and Atolls, London, I912, chaps. viii, ix. 
regarded as very different from the agamic reproductive processes. Actually, however, there are certain fundamental similarities between the two processes. I have discussed this matter at some length elsewhere, ${ }^{\mathbf{x}}$ and need only review certain important points here. The evidence indicates that the gametes, the two cells which unite in sexual reproduction and which in their more highly specialized forms we call egg and spermatozoon, are physiologically subordinate parts of the body and undergo differentiation with other parts, instead of being composed of a mysterious, independent substance, the germ plasm, as Weismann and many others have believed. Gametic maturity occurs at a relatively advanced physiological age in the organism, and the gametes, like other parts of the body, are physiologically old cells with a low metabolic rate and are evidently approaching death. Their isolation from other parts of the body in those multicellular forms in which complete isolation occurs has apparently no relation to the range of dominance, but seems rather to be associated with the completion of their period of growth and differentiation. So far as the parent organism is physiologically concerned, the isolation of the sex cells may be compared with the casting off of other old cells which have played their part and are approaching death. In many cases, however, the egg remains in the parent body until an earlier or later stage of embryonic development is reached, but even in such cases the egg, after completing its developmental period, seems to have little physiological relation to other parts of the parent body.

${ }^{x}$ Child, Senescence and Rejuvenescence, I915, Part IV. 
Except in the case of parthenogenic eggs, which develop without fertilization, neither of the gametes undergoes dedifferentiation and a new development by itself, but in some way their union, or conditions associated with it, or in various cases certain experimental conditions ("artificial parthenogenesis"), initiates the process of dedifferentiation and rejuvenescence which makes possible the development of a new individual and a new period of differentiation and senescence. The increasing metabolic rate and the loss of differentiation in the early stages of embryonic development indicate clearly that rejuvenescence is occurring, but sooner or later the intake of nutrition results in renewed accumulation of substratal substance and senescence begins again. The period of dedifferentiation and rejuvenescence is short, and during most of its development the sexually produced organism is growing old.

As I have endeavored to show, the development of the individual in gametic reproduction is fundamentally the same process as in agamic and experimental reproduction. In most cases the polarity, i.e., the major axial gradient, and in some cases the minor gradients, are determined in the eggs before embryonic development begins, usually, so far as observation permits definite conclusions, by their relations to the parent body, but in some of the lower plants the major axis is apparently determined after the egg leaves the plantbody by the direction or differential action of light or other external factors. The point of entrance of the sperm seems in many cases among animals to be a factor in determining the symmetry gradients, where they are not already determined. In at least many 
plants, however, and doubtless in some animals, the symmetry gradients are determined in later stages.

From this point of view the chief difference between agamic and gametic reproduction is that in the latter the mere isolation of the reproductive body from the parent individual is not sufficient to start the process of dedifferentiation and new development. The gametes do not react except under special conditions, because they have become so highly specialized and differentiated as parts of the parent individual that they are incapable of such reaction. But when the special conditions are present, dedifferentiation begins and development proceeds. Certain eggs develop parthenogenically, and these in many cases are very evidently less highly differentiated than eggs which require fertilization. It is probable that they or some of them represent a stage in gametic development in which the egg is still capable of reacting to isolation like the physiologically or physically isolated part of the body of Tubularia or Planaria by undergoing dedifferentiation and a new course of development. If this conclusion is correct, these parthenogenic eggs represent a condition intermediate between the parts of the body of lower forms which undergo agamic reproduction when isolated and the more highly specialized gametes for which fertilization is a necessary condition of further activity. At least many of the eggs in which development can be initiated experimentally by other means than fertilization are apparently almost capable of natural parthenogenesis, and so are probably less highly specialized than eggs which are not susceptible to experimental treatment. 
If we accept this view, we must regard gametic reproduction merely as a more highly specialized form of reproduction which occurs in more advanced life or in more highly differentiated individuals than agamic reproduction, but which involves essentially the same cycle of differentiation and senescence, followed by dedifferentiation and rejuvenescence, the production of a new individual, and another period of differentiation and senescence.

From this standpoint the egg and the embryo are in general the most unfavorable material that could be found for the investigation and analysis of the processes of reproduction and individuation, for in most cases the gametes are formed in the parent organism under conditions which do not permit of extensive and exact experimental control. Moreover, they consist of single cells, and so cannot be divided experimentally before development begins, and the egg has usually attained a certain, often a very high, degree of individuation before it is isolated. The agamic and experimental reproductions afford a much wider range of control, and we can analyze the beginnings of individuation there as we cannot in the egg. The only logical procedure is, in my opinion, to interpret gametic reproduction, as I have attempted to do, on the basis of our knowledge of the experimental and agamic processes, and not vice versa. Our slow progress toward an adequate conception of organic individuality has undoubtedly been due in considerable part to the fact that we have confined our attention so largely to gametic reproduction, and have neglected the simpler processes in which, if anywhere, the key to the problem is to be found. 
HEREDITY, EVOLUTION, AND OTHER PROBLEMS FROM THE DYNAMIC STANDPOINT

If the organism is fundamentally a specific reaction system in which quantitative differences initiate physiological individuation, development, and differentiation, nothing can be more certain than that it acts essentially as a unit in inheritance. It is the fundamental reaction system which is inherited; not a multitude of distinct, qualitatively different substances or other entities with a definite spatial localization. Development is not a distribution of the different qualities to different regions, but simply the realization of possibilities, of capacities of the reaction system. The process of realization differs in different regions because the conditions are different. Neither characters nor factors as distinct entities are inherited, but rather possibilities, which are given in the physico-chemical constitution of the fundamental reaction system, but not necessarily localized in this or that part of it.

The fact that in the past investigation of inheritance has been almost entirely limited to the special aspects of heredity and development connected with gametic reproduction has contributed very largely to delay our progress and limit and distort our conceptions of the processes of inheritance. This, the most highly specialized form of reproduction, is the most unfavorable point of attack upon the problems involved, for the possibilities of control of the earlier stages of individuation are narrowly limited, and many factors which are not really essential to reproduction and development are characteristically present in this reproductive process. 
The process of inheritance is involved to exactly the same extent in the reconstitutional development of a new individual from a piece of Tubularia stem or of the planarian body, or in the formation of a new growing tip from the differentiated cells of a leaf (Figs. 38, 39), from callus tissue (Fig. 40), or from any other part of the plant, as it is in the reproduction of a new individual from the egg, with or without fertilization, in any of these forms. The simple agamic and experimental reproductions, moreover, afford very much greater possibilities for the analysis and control of the processes and mechanism of inheritance and development than gametic reproduction. Any adequate conception of inheritance and development must be based upon analytic investigation of these simple reproductions and synthesis of the results, and it must interpret inheritance in gametic reproduction in terms of the simpler processes. Continued sexual breeding and hybridization under controlled conditions and with pedigreed individuals has contributed much and undoubtedly will contribute further toward the solution of certain special problems of inheritance, and also affords results which possess a statistical value, but this method of procedure alone can never carry us very far toward the solution of the fundamental problem of inheritance. The key to this problem also will be found in the simpler reproductive processes.

If the organism is a unit in inheritance and development we must expect to find that so-called "acquired characters" may be impressed on the organism to such a degree that sooner or later the reaction system may give rise to these characters without the action of the 
particular external factor which originally produced them. The reaction of the organism to a sufficient local excitation is not simply a local reaction, but a reaction more or less of the whole organism, and we know that in the case of many physiological reactions the repetition of the reaction in response to repeated external excitation alters the reaction system so that response occurs more readily or more rapidly or with a lower intensity of stimulus. We say that the irritability of the protoplasm is increased, its "threshold" for stimulation is lowered, etc. If this change goes far enough the reaction may occur in the absence of the external factor which first produced it, simply because the condition or constitution of the protoplasm has been so altered by the repetition of the reaction that it occurs automatically when any condition determines a sufficiently high metabolic rate in the reaction system. The "inheritance of acquired characters" then belongs in the same general category as the increase in irritability resulting from repeated excitation, but it may in many cases require thousands or hundreds of thousands of generations before a condition approaching automaticity in its production is attained. In the face of the physiological facts it is difficult to understand how biologist $\dot{s}$ can continue to maintain the distinction between soma and germ plasm, and to content themselves with the assertion that natural selection is adequate to account for adaptation in the organic world. If the organism is in any sense a dynamic entity, then its evolution must be a reaction determined, on the one hand, by its physico-chemical constitution, and on the other, by its relation with the external world, 
and its adaptations are simply special features of this relation.

Evolution is not directly concerned with morphological characters, but with the physico-chemical constitution of the reaction system, and so with the rate and character of its reactions and the conditions under which they occur. I have called attention elsewhere ${ }^{x}$ to the resemblance between the progress of evolution and the progress of senescence and development in the individual, and have suggested that evolution, like senescence and other processes in nature, may be essentially a change from a less stable to a more stable condition in the dynamic reaction system which constitutes the organism.

The significance of this dynamic conception of the organism for various other biological problems will be apparent without further discussion, and I believe it may possess a certain significance for certain problems of comparative psychology and sociology. It is at least a matter of some interest to be able to trace the fundamental identity in individuation from the simple unicellular organism to the highest plants in the one direction and to conscious man in the other, and to show that the growing tip of the plant and the brain of man have something in common. Moreover, to find the same principle of individuation in the egg and in the adult organism and again in the single nerve cell and its fiber is at least highly suggestive. The recognition of the fact that individuation in the organism is a relation of dominance and subordination of parts removes much of the difficulty in accounting for the high degree

${ }^{\Upsilon}$ Child, Senescence and Rejuvenescence, I9I5, pp. I44, I93, 463-65. 
of definiteness and the constancy of character of the developmental processes and other activities of living things. It also has a certain bearing upon the problem of the origin of individuations whose component parts are human beings or groups of human beings. Between the organic individual and the state there is, from this point of view, a real analogy, for control or government is the essential feature in the individuation in both, and the relations are in certain respects similar in both cases. It is not a mere fanciful analogy to conceive the organism as a state or the state as an organism, since both are dynamic individuals and some degree of dominance or government exists in both. These suggestions are an indication of some of the broader bearings of the dynamic conception of the organic individual, but discussion along these lines must be postponed.

In conclusion it is perhaps permissible to call attention to the simplification and unification of viewpoint which this conception accomplishes. The separation of morphological from physiological investigation and thought, particularly in zoölogy, which followed the acceptance of the theory of evolution, and the fact that the morphologists, rather than the physiologists or biochemists, have chiefly concerned themselves with the great problems of heredity, development, and evolution, have brought it about that biological theory in these fields has been to some extent a world apart. While proclaiming their acceptance of the mechanistic or physico-chemical conception of life, the theorists of this group and their followers have not only made but few attempts to apply physico-chemical conceptions to 
the organism, but have often decried the value of such attempts. It is still true, therefore, to a large extent that to grasp these theories we must enter a new world of symbols, which only too often appear to have no resemblance or relation to any other symbols commonly in use in scientific thought. When we have become familiar with our new world, we can perform marvelous feats with its symbols and fill our pages with formulae of gametic constitution or what not, but so far as any real connection between this world and the other world of science is concerned, such theories and their symbols leave us, at least in most cases, exactly where we were at the beginning. We can discuss the topographic location of hereditary factors in the chromosome, and we can arrange them in any way necessary to account for the observed facts. In fact, we can invent symbols to describe development or any other process in the organism. But some of the discussions which have to do with these static, morphological symbols remind us irresistibly of that old problem of the angels and the needle point.

Being entirely unable to find any degree of intellectual satisfaction in those static conceptions of the organism which seem to have no relation to anything else in the world and which raise many questions but answer none, and being forced by my own experimental investigations to conclusions very different from these, I have attempted to apply dynamic conceptions to certain biological problems, with the results which have been considered in the preceding pages. Whatever other value the dynamic viewpoint may possess, it serves as a basis for the synthesis and ordering of many 
facts in various fields which heretofore have seemed to have little or nothing in common, and I think we may say that it aids in bringing certain aspects of biology at least within hailing-distance of physico-chemical conceptions. 


\section{INDEX}

NoтE.-References give the number of the page on which the matter referred to begins.

Anophthalmic form in Planaria, I06, I4I.

Axis, organic: occurrence of, 8; apical and basal ends of, Io; terminology of, I9; simplest form of, 35 ; susceptibility gradients in relation to, 53,60 ; independence of apical region of, 96 , I 13 ; dominance of apical region of, I02; control of space relations in, I28; experimental obliteration and determination of, I42; as resultant of two pre-existent axes, 164 ; quantitative character of, 167,185 ; time of determination of in egg and embryo, 199. See also Dominance; Gradients; Individual; Polarity; Symmetry.

Begonia, adventitious buds in, 83 . Biaxial forms: in Tubularia, 97, I33; in Planaria, 99, II7; experimental transformation of, in Corymorpha, I44; experimental determination of, in Planaria, I49. See also Axis; Gradients; Individual.

Conductivity: in relation to transmission, 40; increase in, during development, ${ }_{5} \mathrm{O}$; in relation to physiological isolation, I94. See also Transmission.

Corals, individuation in, 197.

Correlation, physiological: different kinds of, 4, 27; occurrence of transportative, $26,44,170$; conditions determining transportative, 26, I70, 172 . See also Axis; Dominance; Gradients; Individual; Transmission; Transportation.
Corymorpha: description of, 92; metabolic gradients in, 132 ; obliteration and determination of gradients in, $\mathbf{1} 42$.

Crystal, compared with organic individual, 24.

Cyclamen persicum, dominance and subordination in leaf of, 156 .

Dedifferentiation: in agamic reproduction, 7, 9, 91; in formation of adventitious individuals in plants, 83; in reconstitution of Planaria, rog; capacity for, in lower and higher animals, I 20; in embryonic development, I99. See also Differentiation.

Differentiation: occurrence of, 6; orderly character of, 7 ; different degrees of, in eggs and embryos, I2I; in relation to metabolic gradient, I7I; in relation to metabolic rate, I83, I9o. See also Dedifferentiation.

Dominance, physiological: origin of, $36,18 \mathrm{r}$; in relation to metabolic gradients, 37,88 , I7I; range of, $45,127, I_{33}, I_{3} 8,1_{49}$, $\mathrm{I} 62$, I72; in experimental reproduction of Tubularia, 102, I33; in experimental reproduction of Planaria, I02, II4; of apical region in plants, $104, \mathrm{I}_{52}$; experimental control of, in Tubularia, I34; experimental obliteration and determination of, I42; extension of, during development, 149; in relation to size of individual, I5 $^{1}$, I93; in relation to adventitious buds in plants, I54; of growing tip in conifers, 154; direction of, in plants, I55; in leaf of Cyclamen, 
156; in root system, 157 ; nature of, I70; in the neuron, I73; decrease of, in relation to physiological isolation, I93; in corals, 197. See also Gradients; Individual; Isolation.

Entelechy, 23, 137, I84.

Evolution: increasing stability of order in, 6; in relation to environment, 204; as an equilibration process, 205.

Fertilization, 199.

Fission; in Stenostomum, 79; in Planaria, 92, 140, 141.

Frog, developmental gradient in early development of, 66 .

Ginkgo: developmental gradient in embryo of, 73; formation of growing tip of, 77 .

Gradients, developmental: in relation to metabolic gradients, 65 ; in early embryo of frog, 66; in flatworm, 67 ; in chick embryo, 69 ; in relation to rate of growth, 72; in embryo of moss, 73; in embryo of Ginkgo, 73; in plant axes, 73; in bilaterally symmetrical plants, 77 ; in agamic reproduction of Pennaria 79; in reconstitution of Planaria, $8 \mathrm{r}$; in Metzgeria, 83 ; in adventitious buds of Begonia, 83; in buds on callus, 86 . See also Gradients, metabolic.

Gradients, metabolic: origin of, 29, I8I; as simplest expression of order, 35,187 ; in relation to physiological dominance and subordination, 36, I70; interference between, 39 , 178 ; effect of, on protoplasm, 40; inheritance of, $4 \mathrm{I}, 182$; as basis of qualitative differences, 42 ; demonstration of, as susceptibility gradients, 52; in animals, 53, 59; in Stentor, 55; in starfish egg, 56; in parts and organs, 57; demonstration of, by differential inhibition, 58; in relation to axes, 6o; in plants, 6r; as gradients in carbon-dioxide production, 62 ; in neuron, 62, 151 , I73; in relation to differences in electrical potential, 63 ; demonstration of, by differential staining, 64; in relation to developmental gradients, 65 , 79; in experimental reproduction in Marchantia, 86, I65; in Tubularia, 9I; in agamic reproduction of Planaria, 93; independence of apical regions of, 96 ; in reconstitution of Tubularia, 130; control of length of, in Planaria, 140; experimental obliteration and determination of, 142 ; localization as resultant of different, I64; problem of different kinds of, I 78 ; relation of, to inhibition, 178. See also Axis; Dominance; Individual.

Growing tip: as feature of plant individual, 73 ; in relation to developmental gradients, 74 ; in adventitious individuals, 83 ; in relation to range of dominance, I50; dominance of, in plants, I 52; localization of, as resultant of different axes, 165 ; selfdetermination in, 189 ; conditions determining character of, I 90 .

Harenactis, control of reconstitution in, 146.

Head-determination, in Planaria, III.

Headless form; in Planaria, 106; conditions determining, II8, $14 \mathrm{I}$.

Head frequency: in pieces of $P l a$ naria, I08; experimental alteration of, 108; interpretation of, I 9; relation of, to metabolic rate, $\mathbf{1 8 4}$. 
Individual, organic: fundamental characteristics of, 2 ; nature of unity in, 3,48 , 175; various theories of, 3,22 ; character of order in, $8, \mathrm{I} 7,35$; reproduction in relation to, I 2 ; terminology of, I8; comparison of, with social individual, 21, 26, 206; formulation of the problem of the, 29; dynamic conception of the, $29,88,172$; as one or more metabolic gradients, 40, I70; limitation of size of, 45, 47, I5 $\mathrm{I}$; as result of relation between protoplasm and environment, 49; origin of adventitious, in plants, $83,1_{54}, 194$; size of, in relation to range of dominance, I5I; fundamental reaction system of, I88; difference between plant and animal, 189 ; in relation to inheritance, 202; significance of dynamic conception of, 205. See also Axis; Dominance; Individuality; Individuation.

Individuality: different kinds of, 48; superficial origin of organic, 49. See also Axis; Dominance; Individual; Individuation.

Individuation: in Amoeba protoplasm, 6; in experimental reproduction, 14 ; nature of, $4 \mathrm{r}$, 48; in "rings" in Harenactis, 146; conditions determining low degree of, in plants, I89; in corals, 197; degree of, in egg, 20I; fundamental identity of, in organisms, 205. See also Axis; Dominance; Individual; Individuality.

Inheritance: of metabolic gradients, $4 \mathrm{I}, \mathrm{I} 82$; in relation to organic individual, 202 ; in relation to different reproductive processes, 202; of "acquired characters," 204.

Inhibition: of head-formation in Planaria, II 2, I4I; in reconstitution of Tubularia, 135; of growing shoots in plants, I53; in apical direction in plants,
I55; by leaves in plants, ${ }_{55}^{6}$; of root-formation by roots, 159 ; non-specific character of, in plants, I68; nature of, I78.

Irritability: increase of, by repeated excitation, 33, 204; gradient of, 34, I80.

Isolation, physiological: conditions determining, 45; effect of, 46; infrequency of, in higher forms, 47 ; in agamic reproduction in Tubularia, 92; in agamic reproduction in Planaria, 94; experimental, in Tubularia, I35; experimental, in Planaria, $\mathrm{I} 4 \mathrm{I}$; experimental, in plants, $\mathrm{I}_{52}$; as the basis of agamic reproduction, r92; different conditions determining, 193; in relation to reduplication of parts, 195 . See also Dominance.

Lumbriculus, experimental control of reconstitution in, I 18.

Marchantia: experimental reproduction in, 86; localization in, as resultant of different axes, I65.

Metabolism: characteristics of, I5; relation of, to protoplasm, r6; susceptibility in relation to, $5 \mathrm{I}$; increase in rate of, after section in Planaria, I10; rate of, in relation to differentiation, 183 , I90; rate of, in relation to stability of structure, I9I. See also Gradients; Individual; Irritability.

Metzgeria, agamic reproduction in, 83.

Moss, developmental gradient in embryo of, 73 .

Nervous system: in relation to metabolic gradients, 40, 6I, I 75; superficial origin of, 49; metabolic gradient in cells of, 62 , I 5 I, I73; independent formation of, in reconstitution, 114 ; supposed 
formative influence of, 119,176 ; self-determination of, in development, I20, I88; extension of dominance in, 151 ; dominant region of, I75; functional dominance of, 176 ; possible nature of inhibition in, 180 ; in relation to fundamental reaction system, I88; animal organism in relation to, r89; possibility of dedifferentiation in, I9r. See also Conductivity; Transmission.

Organization: theories of, 22; as a condition of chemical correlation, 26; not the basis of organic individuality, $4 \mathrm{I}$; in relation to minimal size in reconstitution, I 24; in relation to experimental conditions, 184 .

Parthenogenesis, 199, 200.

Pennaria, developmental gradients in agamic reproduction of, 79 .

Planaria dorotocephala: susceptibility gradients in, 52; developmental gradients in experimental reproduction of, $8 \mathrm{I}$; agamic reproduction of, 92 ; experimental reproduction in short pieces of, 99; dominance and subordination in, 102; reconstitution in, 105; different forms of head in, 106; head-frequency in experimental reproduction of, ro8; experimental control of headfrequency in, ro8; control of range of dominance in, 138 ; determination of biaxial forms in, 149; extension of dominance in, r49; localization as resultant of different axes in, I64.

Planaria maculata, head-frequency in reconstitution of, II 3 .

Polarity: occurrence of, 8; theories of, 28; obliteration of, in experimental reproduction, IOO; origin of, $\mathrm{I} 8 \mathrm{I}$; nature of, $\mathrm{I} 82$. See also Axis; Dominance; Gradients; Individual.
Poplar, development of buds on callus in, 86 .

Protoplasm: in relation to metabolism, I6; as a metabolic product, I 7; metabolic gradients in, 34 ; differentiation of, in relation to metabolic gradients, I 7 I; effect of quantitative external factors on, 186 .

Reconstitution: in relation to metabolic gradients in Planaria, $8 \mathrm{I}$; independence of apical region in, 97; dominance and subordination in, 102; the process of, in Planaria, 105; limiting factors in, II 7; progressive limitation of, in animals, 120; in embryonic stages, I2I; proportional relations of parts in, 122 ; limit of size in, I 24; of hydranth in Tubularia, 128; in long pieces of Tubularia, 132; of "rings" in Harenactis, 146. See also Individual.

Rejuvenescence: nature of, 46,90 ; in reconstitution of Planaria, 89 ; in posterior zooids of Planaria, 94; capacity for, in lower and higher animals, I 20; in relation to physiological isolation, I93; in early embryonic development, r99. See also Senescence.

Reproduction, agamic: occurrence of, 12,89 ; of parts, 13 , 195; in relation to physiological isolation, 45, I92; in Pennaria, 79; in Stenostomum, 79; in Metzgeria, 83 ; of adventitious buds in Begonia, 83; in Tubularia, 92; in Planaria, 92; different conditions determining, I93; localization of, 196 ; difference between and gametic, I98. See also Isolation; Reproduction, gametic.

Reproduction, experimental: significance of, I4, 88; in Planaria, 81, 105; in poplar, 86; in Marchantia, 86, I65; in short pieces 
of Tubularia, 97; in short pieces of Planaria, 99; in long pieces of Tubularia, I32; in plants, $152 ;$ in relation to shape of piece in Planaria, rr4. See also Reconstitution; Reproduction, agamic, gametic.

Reproduction, gametic: occurrence of, $\mathrm{I}_{3}$; nature of, $47, \mathrm{r} 98$; difference between, and agamic, 200. See also Reproduction, agamic, experimental.

Roots of plants: as subordinate individuals, I04, 162; dominance and physiological isolation in, I 57; relation of, to other parts of plant, I59; conditions determining formation of, 162 .

Sea-urchin, control of proportions in larva of, 58 .

Senescence: nature of, 46,90 ; in relation to self-maintenance of parts, I77; in relation to gametic reproduction, I98; in relation to evolution, 205. See also Rejuvenescence.

Starfish: axial relations in, 8; susceptibility gradient in egg of, 56 .

Stenostomum: agamic reproduction in, 79; extension of dominance in, 150.

Stentor, susceptibility gradient in, 55 .

Subordination, physiological: origin of, 36; of basal to apical levels in Planaria, I02, II5; of basal to apical levels in plants, 104. See also Dominance.

Susceptibility: in relation to metabolism, 5I; gradients of, 52; gradient of, in Stentor, 55; gra- dient of, in starfish egg, 56; gradient of, in plants, 61 .

Symmetry: occurrence of, 8; of starfish, 8; susceptibility gradients in axes of, 57 ; bilateral, in certain plants, 77, 86; in "rings" in Harenactis, r48; in conifers, I55; origin of, I8I ; significance of experimental alterations of, 182; conditions determining, 199. See also Axis; Gradients; Polarity.

Teratomorphic form, in Planaria, I06, I4I.

Teratophthalmic form, in Planaria, I06, I4I.

Transmission: decrement in, 29, $32,45,47, \mathrm{I} 50, \mathrm{I} 72$, I 73; nature of, $3 \mathrm{I}, 44, \mathrm{I} 77$; in relation to conductivity, 40; possibility of different kinds of, $43, \mathrm{I} 78$; range of, 45 ; increase in range of, during development, I49; in relation to dominance, r7o. See also Conductivity.

Transportation: occurrence of, in organisms, 4,27 ; conditions determining, 26, 170, I72; from roots of plants, I6r. See also Correlation.

Tubularia: description of, 9I; agamic reproduction in, 92; experimental reproduction in short pieces of, 97, 133; dominance in experimental reproduction of, 102; control of distance relations in reconstitution of, I 28; reconstitution of hydranth of, $\mathrm{x} 28$; reconstitution in long pieces of, 132; range of dominance in, 133 ; inhibition in reconstitution of, I 35 . 


UNIVERSITY OP TORONTO

LIBRARY

मे

Do not

remove

the card

from this

Pocket.

Acme Library Card Pocket

Under Pat. "Ref. Index File."

Made by LIBRARY BUREAU 
